\title{
OFFENDER COMPETENCIES AND THEIR RELATIONSHIP TO CORRECTIONAL PROGRAM PERFORMANCE
}

\author{
A thesis submitted to \\ the Faculty of Graduate Studies and Research \\ in partial fulfillment of the requirements for the degree \\ Master of Arts
}

by

Laura Jennifer Hanby

Department of Psychology

Carleton University

July 2009

C2009 Laura Hanby 


$\begin{array}{ll}\begin{array}{l}\text { Library and Archives } \\ \text { Canada }\end{array} & \begin{array}{l}\text { Bibliothèque et } \\ \text { Archives Canada }\end{array} \\ \begin{array}{l}\text { Published Heritage } \\ \text { Branch }\end{array} & \begin{array}{l}\text { Direction du } \\ \text { Patrimoine de l'édition }\end{array} \\ \begin{array}{l}395 \text { Wellington Street } \\ \text { Ottawa ON K1A ON4 } \\ \text { Canada }\end{array} & \begin{array}{l}395, \text { rue Wellington } \\ \text { Ottawa ON K1A ON4 } \\ \text { Canada }\end{array}\end{array}$

Your file Votre reférence

ISBN: 978-0-494-60309-3

Our file Notre référence

ISBN: $978-0-494-60309-3$

NOTICE:

The author has granted a nonexclusive license allowing Library and Archives Canada to reproduce, publish, archive, preserve, conserve, communicate to the public by telecommunication or on the Internet, loan, distribute and sell theses worldwide, for commercial or noncommercial purposes, in microform, paper, electronic and/or any other formats.

The author retains copyright ownership and moral rights in this thesis. Neither the thesis nor substantial extracts from it may be printed or otherwise reproduced without the author's permission.
AVIS:

L'auteur a accordé une licence non exclusive permettant à la Bibliothèque et Archives Canada de reproduire, publier, archiver, sauvegarder, conserver, transmettre au public par télécommunication ou par l'Internet, prêter, distribuer et vendre des thèses partout dans le monde, à des fins commerciales ou autres, sur support microforme, papier, électronique etlou autres formats.

L'auteur conserve la propriété du droit d'auteur et des droits moraux qui protège cette thèse. $\mathrm{Ni}$ la thèse ni des extraits substantiels de celle-ci ne doivent être imprimés ou autrement reproduits sans son autorisation.
In compliance with the Canadian Privacy Act some supporting forms may have been removed from this thesis.

While these forms may be included in the document page count, their removal does not represent any loss of content from the thesis.
Conformément à la loi canadienne sur la protection de la vie privée, quelques formulaires secondaires ont été enlevés de cette thèse.

Bien que ces formulaires aient inclus dans la pagination, il n'y aura aucun contenu manquant.

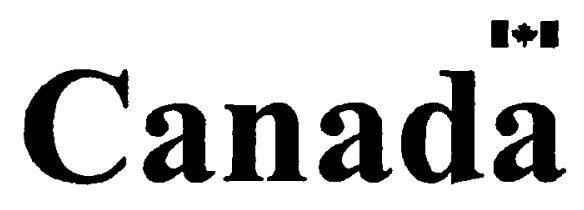




\begin{abstract}
Current understanding of the principles of offender rehabilitation has evolved considerably over the past two decades and much of this knowledge is based on Canadian research. However, there are gaps in our understanding of why some offenders succeed in attaining behavioural and cognitive changes and ultimately desist from crime while others appear to gain little from participation in correctional treatment programs. The purpose of this study was to determine if treatment program performance can be predicted from a model of offender competencies consisting of the following: need for change, personal accountability, cognitive flexibility, inhibitory control, and knowledge acquisition and application. Results suggest that competent offenders are more likely to succeed in programs. This research has important implications for correctional practice and, more generally, advances our understanding of the processes underlying offender change.
\end{abstract}




\section{Acknowledgements}

This project could not have been accomplished without the support and assistance from a number of individuals. First and foremost, I must express my gratitude to my thesis supervisor, Dr. Ralph Serin, for his guidance, enthusiasm and confidence in me. I feel privileged to benefit from his continued mentorship. I would like to thank both Dr. Larry Motiuk and Dr. Kevin Nunes for their interest in my study and their beneficial feedback. I would also like to express my appreciation to Dr. Diana Majury for taking the time to act as my internal-external examiner and Dr. Alfonso Abizaid for acting as the chair of my thesis committee. Thank you to Ben Vuong who assembled the data in such a timely manner to allow me to complete my thesis.

I appreciate the support from my friends, colleagues and family. A special thanks to Caleb Lloyd for his constant encouragement and advice. Thanks to Etelle Bourassa for her kind nature and for providing assistance in administrative matters from beginning to end. Dad, Mam and Dean provided support in countless ways throughout my M.A. Thank you for listening willingly about the obstacles along the way, providing encouragement and reassurance, and perhaps most importantly for reminding me of your pride in me.

Finally, my graduate studies have been generously funded by the Social Sciences and Humanities Research Council and the Ontario Graduate Scholarship Program during the past two years, for which I am grateful. 


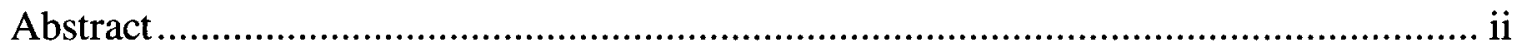

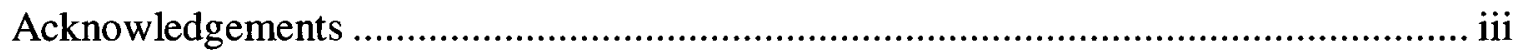

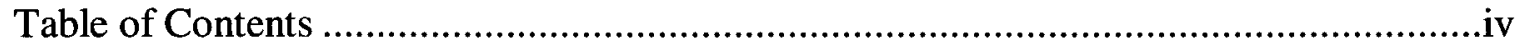

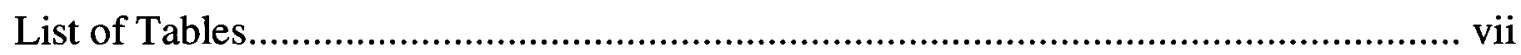

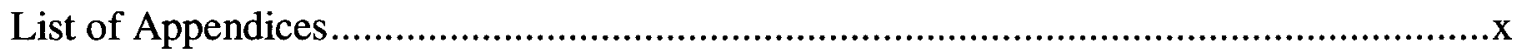

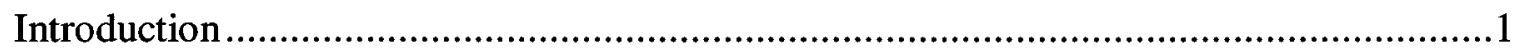

Individual Differences and Program Outcome

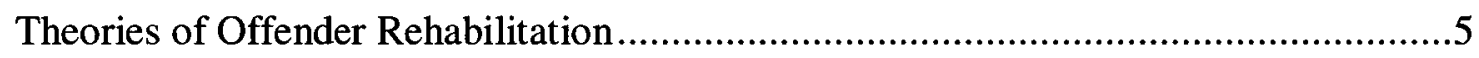

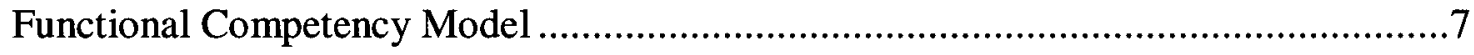

Need for Change

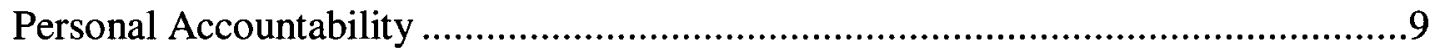

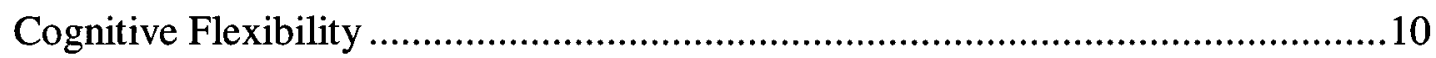

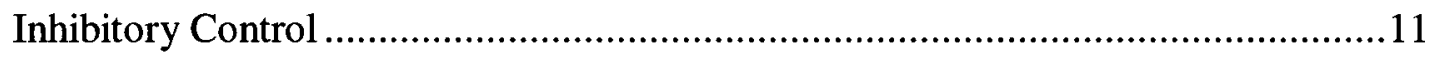

Knowledge Acquisition and Application .........................................................12

Importance of Core Competencies ...................................................................13

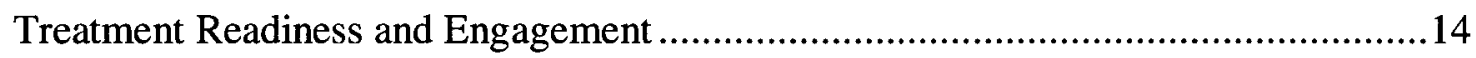

Theories of Motivation and Treatment Readiness..............................................15

Predictors and Correlates of Readiness and Engagement .....................................18

Outcomes of Treatment Resistant and Engaged Offenders ...................................23

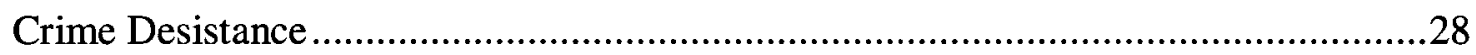

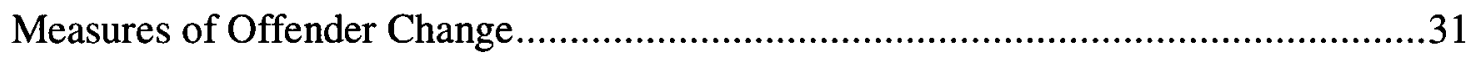

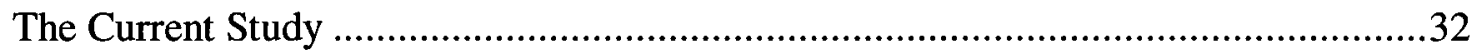


Study Rationale. .32

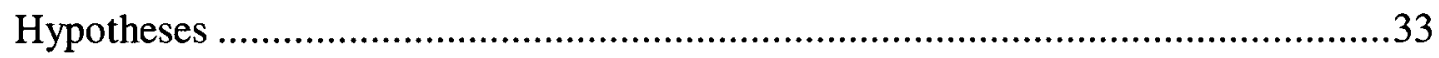

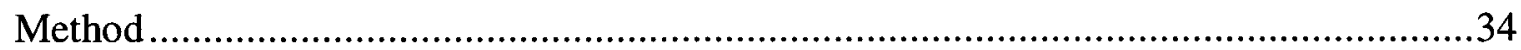

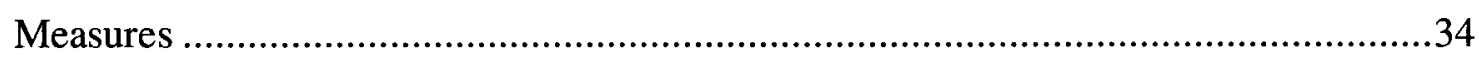

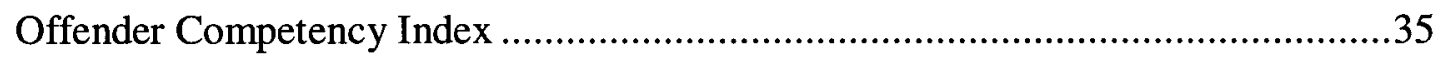

Generic Program Performance Measure ..........................................................36

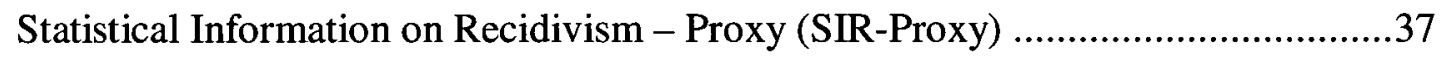

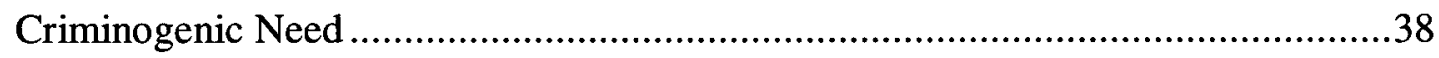

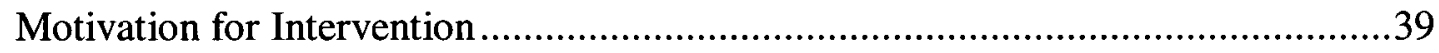

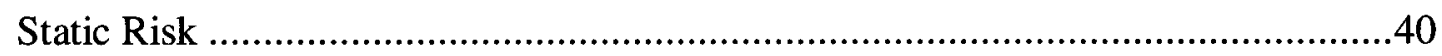

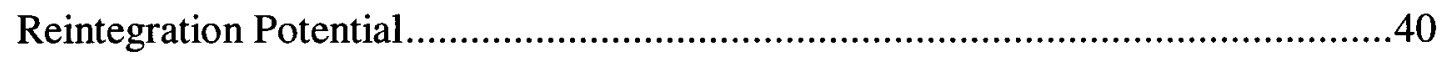

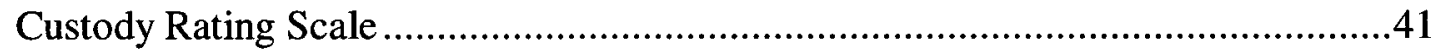

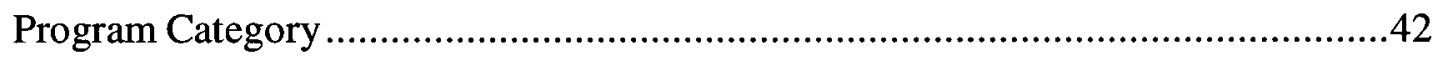

Participants ..................................................................................42

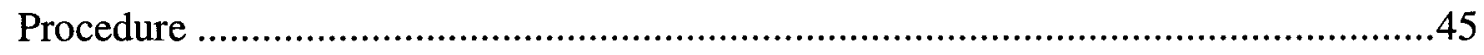

Results................................................................................................. 46

Scale Construction and Psychometrics .......................................................46

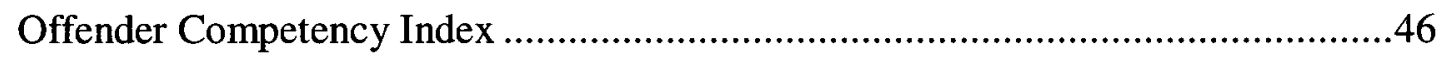

Generic Program Performance Measure ................................................59

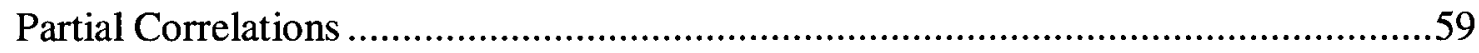

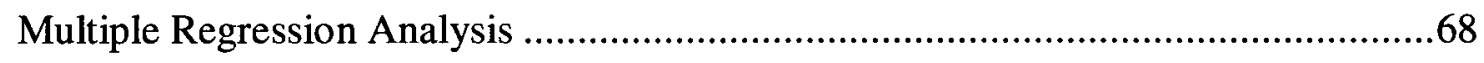

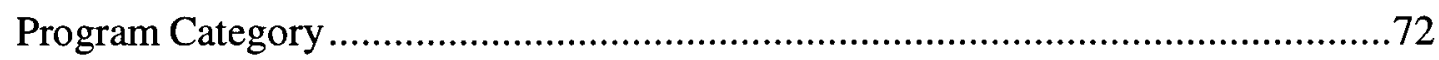

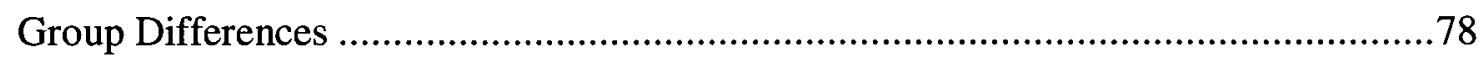


Comparing Low and High Competency Scores ..................................................78

A Comparison of Treatment Completers and Non-completers ...............................80

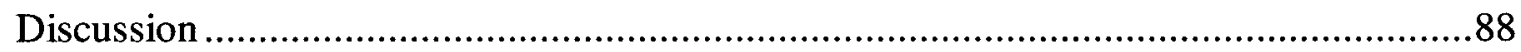

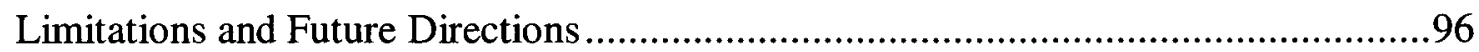

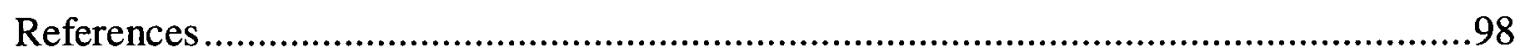

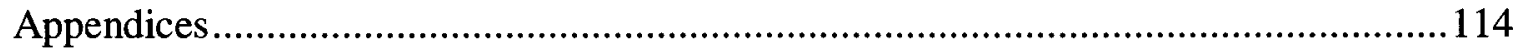




\section{List of Tables}

Table 1. Summary of Intake Assessment Information .................................................44

Table 2. Summary of Criminogenic Need Domains ....................................................44

Table 3. Variables proposed to comprise the Offender Competency Index .....................48

Table 4. Internal Consistency and Descriptive Statistics for Competency Scales ............51

Table 5. Inter-correlations among Identified Factors .....................................................55

Table 6. Internal Consistency and Descriptive Statistics for Identified Factors in

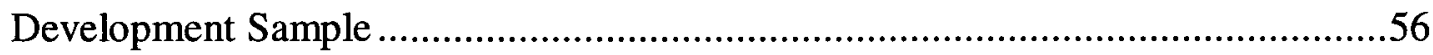

Table 7. Internal Consistency and Descriptive Statistics for Identified Factors in Cross-

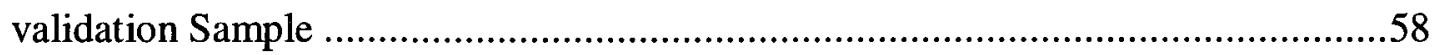

Table 8. Inter-correlations among Competency Factor Scores and Intake Assessment Measures $(\mathrm{p}<.001)$ .661

Table 9. Correlations between Competency Scores, Intake Assessment Variables, Behavioural Change and Program Performance …..............................................63

Table 10. Correlations between Competency Scores, Behavioural Change, and Program Performance while controlling for Risk to Re-offend ..........................................65

Table 11. Correlations between Competency Scores, Behavioural Change, and Program

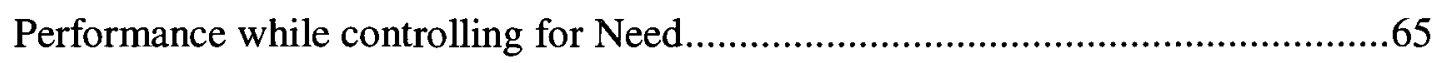

Table 12. Correlations between Competency Scores, Behavioural Change, and Program Performance while controlling for Reintegration Potential ....................................66

Table 13. Correlations between Competency Scores, Behavioural Change, and Program Performance while controlling for Institutional Adjustment Score. .66 
Table 14. Correlations between Competency Scores, Behavioural Change, and Program

Performance while controlling for Static Risk .67

Table 15. Correlations between Competency Scores, Behavioural Change, and Program

Performance while controlling for Security Risk Score .67

Table 16. Summary of Regression Analysis for Variables Predicting Program

Performance $(\mathrm{N}=2034)$

Table 17. Summary of Hierarchal Regression Analysis for Variables Predicting Program

Performance $(\mathrm{N}=2035)$

Table 18. Summary of Hierarchal Regression Analysis for Variables Predicting

Behavioural Change $(\mathrm{N}=2037)$.

Table 19. Summary of Regression Analysis for Variables Predicting Program

Performance in Violent Offender Programs $(\mathrm{N}=163)$ .73

Table 20. Summary of Regression Analysis for Variables Predicting Program

Performance in Sex Offender Programs $(\mathrm{N}=111)$

Table 21. Summary of Regression Analysis for Variables Predicting Program

Performance in Substance Abuse Programs $(\mathrm{N}=1174)$ .75

Table 22. Summary of Regression Analysis for Variables Predicting Program

Performance in Family Violence Programs $(\mathrm{N}=139)$ .76

Table 23. Summary of Regression Analysis for Variables Predicting Program

Performance in Living Skills Programs $(\mathrm{N}=198)$

Table 24. Summary of Regression Analysis for Variables Predicting Program

Performance in Counterpoint Programs $(\mathrm{N}=250)$ 
Table 25. Differences in Program Performance Scores for High versus Low Scores on Competencies

Table 26. Differences in Behavioural Change Scores for High versus Low Scores on

Competencies

Table 27. Significant Univariate Effects for Treatment Program Status for Competency

Factor Scores $($ at $\mathrm{p}<.001$ level $)$

Table 28. Means and Standard Deviations for Competency Scores for Program Status .84

Table 29. Significant Univariate Effects for Treatment Program Status for Intake Variables (at $\mathrm{p}<.001$ level) .85

Table 30. Means and Standard Deviations for Competency Scores for Intake Variables 87 


\section{List of Appendices}

Appendix A: Generic Program Performance Measure..............................................114

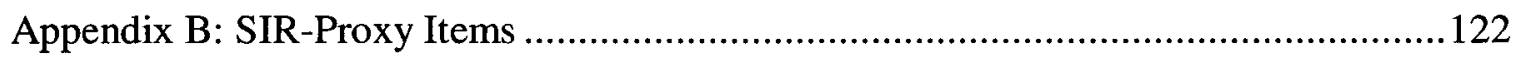

Appendix C: Reliability Analyses of the Composite Offender Competency Index .......124

Appendix D: Factor Analysis in Development Sample............................................127

Appendix E: Reliability Analyses of the Factor- Analysis Derived Offender Competency

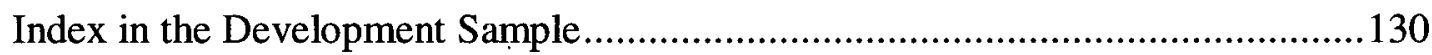

Appendix F: Factor Analysis in Cross-Validation Sample .........................................134

Appendix G: Reliability Analyses of the Factor-Analysis Derived Offender Competency

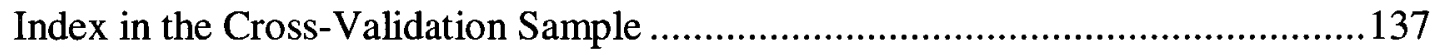

Appendix H: Reliability Analyses of the Generic Program Performance Measure.........141 
Offender Competencies and their Relationship to Correctional Program Performance Offender rehabilitation has been the focus of considerable research in the past few decades. A number of theories have been proposed that provide a framework for effective correctional programming. The Risk-Need-Responsivity (RNR) model, for instance, provides a set of principles to which treatment programs should be tailored in order to reduce the likelihood of future criminal conduct (Andrews \& Bonta, 2006). Although existing theoretical frameworks, namely the RNR, provide insight into methods of effective correctional treatment, there is insufficient insight into which offenders will likely succeed upon release if participating in such programming. It appears there is a gap in our understanding of the specific skills, knowledge and abilities associated with a greater likelihood of behavioural change and desistance from crime, although the RNR model has been associated with improved outcomes. A model of core offender competencies has thus been developed and is hypothesized to relate to success in treatment and later on release. Coupled with this limitation of the existing correctional literature, a range of measures of offender change have been developed purported to assess whether an offender has made progress during treatment. Typically these change measures are in the form of self-report questionnaires and for the most part, they lack the ability to accurately predict correctional outcomes (Serin, Derkzen, Helmus, Lloyd, \& Luong, 2009). It is unclear if the inadequate predictive validity associated with these measures can by explained by methodological or conceptual weaknesses. If these measures are based on constructs which are actually relatively unimportant in understanding offender change, it is then unsurprising that they are not predictive of behavioural change and treatment outcome. 
The current study involves re-conceptualizing the constructs that may be related to offender change and ultimately desistance from crime. The Functional Competency Model (FCM) proposed by Serin (2006) consists of five core competencies that are based on theory and are hypothesized to predict treatment program performance and offender change. A core competency is defined as a fundamental ability, knowledge or expertise associated with a greater probability of succeeding in treatment and remaining crime-free on release. This model has the potential to advance the offender rehabilitation literature by determining the offender competencies that may predict intra-individual success in treatment. It may also inform measures of offender change by offering specific measurable criteria related to treatment gains.

First, the context for the current research endeavour will be discussed, focusing on individual differences in treatment program performance and measurement methods that aim to capture these differences. The RNR model, the leading theory of offender rehabilitation and effective programming, will be briefly reviewed to provide a theoretical context for the current study. The FCM will be introduced by presenting the theoretical and empirical support for each of the five offender competencies. Also, the link between treatment readiness and engagement will be examined, as well as their relationship to offender change and desistance. The link between the FCM and crime desistance will then be discussed. Lastly, the state of existing measures of offender change will be reviewed, with a focus on the limitations associated with these measures.

\section{Individual Differences and Program Outcome}

Treatment program performance can be considered as a continuum, with noncompleters at the extreme negative end of the continuum. At this extremity, non- 
completion results from dropout or expulsion from a program, as opposed to administrative reasons or personal circumstances that are beyond the control of the offender. Moving along the continuum, offenders attend programs but are not engaged in treatment (e.g., avoid participation) or purposefully disrupt programming activities if they are especially resistant. Moving into the positive end of the continuum, offenders are engaged in treatment but do not make significant treatment gains or long-term changes. At the extreme positive end of the continuum, offenders attend programs and are engaged in the treatment process, succeed in treatment and ultimately achieve change. The hypothesized difference between the latter two groups is that the group of offenders that are successful possess a set of core competencies which results in higher levels of program performance. Program performance may be conceptualized as knowledge of program content, application of skills and knowledge, insight, motivation, understanding of criminality, depth of emotional understanding and confidence. Further, treatment program performance may be measured by attendance, appropriateness, disruptiveness and participation. Krause (1967) identifies four aspects of client-role performance relevant to the treatment setting: attending and making use of treatment sessions; openness concerning one's behaviour, feelings and history; making use of the therapist's contribution; and adequate between-session behaviour (e.g., reflection, doing homework).

There are gaps in our understanding of why some offenders succeed in attaining behavioural and cognitive changes and ultimately desist from crime, while others apparently gain little from treatment programs. Baxter, Marion, and Goguen (1995) argue that the interaction between individual offender traits and program characteristics has received little attention and thus it is unclear how this interaction affects treatment 
outcome. Encouragingly, advances have been made in identifying dynamic indicators which are related to outcome. The purpose of this study is to identify additional indices of intra-individual change in treatment in order to improve program delivery and outcome. Serin (2006) has proposed five core competencies that are hypothesized to be related to program performance and offender change. The FCM is believed to potentially account for some of the variation attributed to individual differences in program outcome. The five core competencies are the following: a need for change, personal accountability, cognitive flexibility, inhibitory control, and knowledge acquisition and application. These constructs are offender-based, apply to all types of offenders (i.e., rather than narrowly focusing solely on specific offender types such as violent offenders or sex offenders) and have yet to be comprehensively considered in other theories or empirically investigated.

In an attempt to accurately assess individual differences in program outcome, an index of the core competencies has been developed to measure offender change. Existing measures of offender change are typically derived from self-reported progress during the course of a treatment program. Relying solely on self-reports as a measure of offender change results in questions about the veracity of participant responses and therefore the reliability of measurement. There is limited evidence that self-report measures can accurately predict change, possibly due to methodological and conceptual weaknesses. Accordingly, the FCM expands and reconceptualizes how we think about offender change. 


\section{Theories of Offender Rehabilitation}

This study is informed by the RNR ("What Works") model, which outlines a set of four principles for effective correctional treatment based on empirical research (Andrews \& Bonta, 2006). First, the risk principle states that the intensity of treatment should match the risk level of the offender. Specifically, rehabilitation programs of greatest intensity should be provided to higher risk offenders in order to achieve the greatest reductions in recidivism. Research suggests that higher risk offenders respond best to intensive intervention, while lower risk offenders respond better to little or no intervention. In fact, treatment can be detrimental to low risk offenders if they are placed in the same program as high risk offenders (Andrews \& Kiessling, 1980). Second, the need principle dictates that criminogenic needs should be addressed in treatment in order to reduce the likelihood of future criminal conduct. Criminogenic needs are dynamic risk factors that reduce risk when changed, such as antisocial attitudes, antisocial associates and substance abuse (Andrews \& Bonta, 2006). Non-criminogenic needs, such as anxiety and self-esteem, do not have a significant impact on recidivism when changed (Andrews \& Bonta, 2006). Third, the responsivity principle states that the mode and style of treatment must be matched to the learning style and abilities of the offender. Offenders differ significantly in their motivation and response to various types of intervention. These factors directly influence the effectiveness of treatment and, consequently, recidivism. Further, cognitive-behavioural treatment programs are the most effective in reducing risk. Lastly, the professional discretion principle states that professional judgment must be exercised following a review of risk, need and responsivity considerations for each offender. 
Correctional programming adhering to these principles has been demonstrated to be successful in reducing recidivism (Andrews \& Dowden, 2005; Dowden \& Andrews, 2000; Latessa, 2004). For instance, treatment which adheres to the principles of risk, need and responsivity has a mean effect size $(r)$ of .30 , while inappropriate treatment (treatment not adhering to the principles) has a mean effect size of -.06 (Andrews, Zinger et al., 1990). Smith, Gendreau, and Swartz (2008) also found that recidivism was reduced by 28 percent (i.e., mean effect size $(r)$ of .28 ) when the principles of effective treatment are followed. The RNR model is useful in providing a framework for effective treatment but there are gaps in our understanding of which offenders will encompass the $30 \%$ for which evidence-based programming is effective. Much empirical research in this area has focused on the risk and need principles while responsivity factors have received relatively less attention. The model has been criticized for paying insufficient attention to the role of personal identity and agency in the change process (Ward, Melser, \& Yates, 2007). Further, Ward, Mann, and Gannon (2007) argue that the RNR model is often translated into a "one-size-fits-all" manner in practice which does not take into account individual needs and values, although this is not how it is described in the Personal, Interpersonal, and Community-Reinforcement (PIC-R) perspective (Andrews \& Bonta, 2006).

Current research indicates that offenders who complete programs rooted in evidence-based practice have improved outcomes relative to offenders who do not (i.e., either by not participating in treatment or by failing to complete treatment). Also, offenders who complete programs rooted in evidence-based practice have better outcomes than those who fail to meet such standards (Andrews, Zinger et al., 1990; 
Smith et al., 2008). The RNR model identifies dynamic indicators (e.g., antisocial attitudes and associates) that are related to outcome. Reductions in these indicators are associated with improved correctional outcomes. However, the goal of this study is to identify additional indices of intra-individual change (i.e., offender competencies) in treatment progress.

\section{Functional Competency Model}

The FCM is a conceptual perspective to offender programming which outlines a set of competencies that are proposed to be related to offender change and crime desistance. Offenders typically progress through three stages before behavioural change can be realized: engagement, skills acquisition and skills application. The engagement stage requires treatment readiness and motivation, as well as active participation in the treatment process. The skills acquisition stage consists of learning the knowledge and skills taught in programming which is necessary for offenders to change their criminal attitudes and behaviour. Lastly, it is not sufficient to simply acquire these skills; but the offender must learn how to apply the recently learned skills and knowledge within the institution and in the community in the third and final stage. The five core competencies are proposed in the FCM within the context of these stages of change but further identify the specific abilities, knowledge and expertise which are presumed to be present in order for an offender to successfully progress through the stages. The FCM highlights the importance of offenders acquiring the skills and knowledge necessary to desist from crime with a focus on accountability and self-regulation. The five competencies are the following: need for change, personal accountability, cognitive flexibility, inhibitory control, and knowledge acquisition and application. It is hypothesized that offenders who 
are proficient in these competencies will perform better in programs, will achieve greater treatment gain and behavioural change, and are ultimately more likely to desist from crime. Each competency will be discussed in turn.

\section{Need for Change}

The first step in the desistance process is the offender's appreciation they must change. The offender's reasons for and timing of the need for change may derive from cognitive, affective and behavioural change. This competency incorporates both motivation and the readiness to change, as a need for change cannot be present without the former. A need for change reflects the movement of the offender from being egocentric to demonstrating a concern for others. This shift involves a more relativistic style of thought which allows for new levels of social cooperation and competence (Chandler, 1973). This competency corresponds to a shift from an external locus of control and having a tendency to blame others to being internally responsible and accountable. An external locus of control can hinder engagement in treatment and is detrimental in that it supports criminal behaviour (Chambers, Eccleston, Day, Ward, \& Howells, 2008).

Various theories of offender change and rehabilitation identify the necessity of the recognition for the need for change before it can occur. For example, the multifactor offender readiness model (MORM; Ward, Day, Howells, \& Birgden, 2004) and the treatment readiness, responsivity and gain model (TRRG; Serin, Mailloux \& Kennedy, 2007) each emphasize the importance of the need for change. Stein and Markus (1996) also conceptualize behavioural change as a complex process which begins with an appreciation of the need to change. Notably, both parole officers and parolees rated an 
increased motivation to change as the highest marker for crime desistance, followed by increased emotional control and increased positive work ethic (Parhar \& Wong, 2007). Identification of the need to change and the commitment to do so is dependent on the individual's ability to recognize consistencies or trends in one's behaviour over time (Stein \& Markus, 1996). Often the offender desires to lead a more normal life and escape their relatively unorthodox style of living (Meisenhelder, 1977). In a study of offenders on probation, maintaining a decision to abandon crime was often met with difficulties (Rex, 1999). Thus an offender must not only acknowledge a need for change, but also be equipped with the skills, knowledge and abilities necessary to achieve and sustain change. The remaining four competencies reflect this.

\section{Personal Accountability}

Personal accountability is a multi-dimensional competency, involving the offender losing his or her sense of entitlement, a common attribute among offenders (Yochelson \& Samenow, 1976). It also encompasses a modicum of humility in the offender. Personal accountability is related to the need for change as it represents an interpersonal focus by the offender on the needs of others. This competency relates to the suggestion by Maruna and LeBel (2003) that change is preceded by the offender recognizing the need for redemption or to make amends for their criminal behaviour. In a study of the social development of adolescent offenders, male desistors (participants who did not reoffend within a 2-year follow-up) were compared to de-escalators, stable moderate offenders and stable high offenders (Ayers et al., 1999). De-escalators were participants who continued to offend but committed less serious acts, while the offending patterns of stable participants remained the same with moderate (i.e., stable moderates) or 
high (i.e., stable highs) levels of delinquency. Desistors were more bonded to conventional society on measures of attachment and commitment to school, attachment to conventional peers and belief in the moral order than de-escalators, stable moderate offenders and stable high offenders. This study demonstrates that personal accountability is an important competency in desisting from crime. An offender that has desisted from crime lives thoughtfully and with an awareness of the rights of others (Maruna, 2001), as opposed to disregarding the rights and feelings of others in accordance with their own self-interests.

\section{Cognitive Flexibility}

Cognitive flexibility refers to the ability to do more than simply problem solve but also generate and evaluate alternative solutions to issues specific to crime desistance. This competency represents an information processing component to offender change, as many offenders have cognitive distortions. Offenders commonly minimize the effects of their behaviour on others, deny responsibility and rationalize their law violations (Serin \& Kennedy, 1997). Even if an offender accepts responsibility for their behaviour, they typically employ external explanations for their behaviour in terms of blaming the victim or the situation and denying the wrongfulness of their acts (Henderson \& Hewstone, 1984). Individuals with an egocentric orientation typically misread social expectations, misinterpret the actions and intentions of others, and act in a callous and disrespectful manner (Chandler, 1973). Processing deficits such as these lead to poor and often violent responses to ambiguous stimuli (Bettman, 1998; Serin \& Brown, 2004). Ward and colleagues (2004) argue that the existence of hostile attitudes and beliefs can reduce an 
offender's willingness to engage in therapy. Denial and minimization have also been found to be predictors of program attrition in sex offenders (Latendresse, 2007).

Lengthy offending careers are supported by an offender's internal beliefs, among other things (Serin \& Lloyd, 2009). In a comparison of active offenders and desisting exoffenders, active offenders tended to interpret negative events in their lives as being the product of internal, stable and global forces (Maruna, 2004). Positive events were perceived as the product of external, unstable and specific causes. These attributions demonstrate the differences in information processing for active and desisting offenders. In a study of reformed batterers, change was associated with an ability to put aside denial and minimization of their abusive behaviours (Scott \& Wolfe, 2000). Chambers and colleagues (2008) argue that an offender with a high degree of cognitive distortions is unmotivated to enter treatment and averse to suggestions to change their behaviour and thus may not be ready for rehabilitation. On the other hand, an admission of guilt and acceptance of personal responsibility have been found to be significantly related to positive treatment outcome (Barrett, Wilson, \& Long, 2003). It is evident that behavioural change and crime desistance require cognitive flexibility and diminished cognitive distortions.

\section{Inhibitory Control}

Related to cognitive flexibility is inhibitory control, which is the ability to inhibit a response when faced with a high-risk situation. Disinhibitory factors include sexual deviance (Love, 2006), substance abuse (Chamberlain \& Sahakian, 2007), callousness (Frick et al., 2003) and impulsivity (Van Voorhis, 1997). Treatment responsivity and program completion has been predicted by improved inhibitory control using 
computerized cognitive tasks (Fishbein et al., in press). On a larger scale, desistance from crime involves breaking a pattern of criminal behaviour and exercising control over impulses to commit further criminal acts (Serin \& Lloyd, 2009). The most adaptive forms of inhibition are self-management or control, as opposed to avoidance. Mann, Webster, Schofield, and Marshall (2004) suggest that teaching offenders approach goals (i.e., learning how to deal with risk situations) is more effective than avoidance goals (i.e., trying to avoid risk). Offenders will inevitably experience risky situations, thus they require the necessary competencies to handle these situations.

\section{Knowledge Acquisition and Application}

Lastly, the ability to acquire and apply knowledge and skills corresponds to the later stages of change in which the offender gains new knowledge from treatment and learns how to apply this new knowledge to real-life situations. This typically takes the form of skills-based training. Offenders must be able to take their new skills and apply them to real-word situations in the community in order to achieve success (Tierney \& McCabe, 2001). An offender who is ready and willing to change but does not have confidence in his or her ability to change may experience difficulty (Viets, Walker, \& Miller, 2002). Scott and Wolfe (2000) examined the variables related to change in abusive behaviour of reformed batterers through qualitative analyses of interviews. The reformed men placed high value on learning skills for conflict management and resolution. This included learning about risk factors and how to resolve problematic situations. In the Ayers and colleagues' (1999) study of the social development of adolescent offenders, male desistors had significantly greater skills for conventional involvement in society including social skills, school work skills and substance use 
refusal skills than de-escalators, stable moderate offenders and stable high offenders. These findings demonstrate that gaining skills for conventional involvement may be important in attaining behavioural change and desisting from crime. Strengths-based theories of offender rehabilitation also emphasize the importance of teaching offenders how to learn the skills necessary to achieve their desires through prosocial methods (Ward et al., 2007).

\section{Importance of Core Competencies}

The five core competencies can be viewed as responsivity factors. According to Kennedy and Serin (1999), treatment responsivity refers to client-based factors which influence the potential for offender change. It indicates the extent to which offenders are able to absorb program content based on their cognitive ability, learning style and values (Ward et al., 2004). Responsivity incorporates treatment readiness and is related to treatment outcome (Ward et al., 2004). Offenders may differ in terms of their level of competencies at the beginning of treatment, which will affect their likelihood of successful program performance. Responsivity is viewed as dynamic (Serin \& Kennedy, 1997); therefore it is also possible to acquire these competencies throughout the course of treatment. In either case, it is posited that the competencies provide the resources necessary to successfully engage in treatment and achieve significant change necessary for an offender to desist from crime. An initial need for change and motivation to enter treatment may lead to treatment attendance and participation. However, if an offender lacks the competencies necessary to succeed in treatment, this may result in a lack of progress, weakened motivation and ultimately dropout or expulsion. Conversely, 
offenders who are adept in the core competencies will maintain their initial motivation by achieving positive changes and progressing in treatment.

External factors such as the treatment itself, resources and events in the offender's life may also influence treatment progress. The FCM does not ignore the role of treatment experiences but instead recognizes that offender competencies interact with the nature and quality of treatment services. Although there is a link between motivation to change and treatment engagement, offenders may lack the capacity to do what the treatment approach requires.

\section{Treatment Readiness and Engagement}

Program suitability is thought to involve more than simply the presence of the characteristics associated with risk, but also the extent to which an individual is "ready" to engage in treatment and in the change process (Casey, Day, Howells, \& Ward, 2007). The more ready, willing and able an offender is to change, the greater probability of achieving success (Viets et al., 2002). Treatment readiness provides insight into how we understand, assess and intervene with offenders for whom rehabilitation has been identified as an important goal (Day, Howells, Casey, Ward, \& Birgden, 2007). Offender motivation and treatment readiness can be viewed as a precursor to engagement in treatment. In fact, intrinsic factors such as motivation and readiness are commonly considered more essential in successful rehabilitation than extrinsic factors such as sanctions and legal pressures (Joe, Simpson, \& Broome, 1998).

The constructs of motivation, treatability and treatment readiness are often used interchangeably (Serin, Mailloux, \& Kennedy 2007). Being ready for treatment implies not only an ability to attend programs but also to engage with the program content, 
facilitators and other group members (Day et al., 2007). Serin and Kennedy (1997) define treatment readiness as the probability that an individual enters into, continues and adheres to a treatment strategy. This includes intentions and competency, as opposed to a specific personality trait. Treatment readiness has been conceptualized as an overarching term that includes the internal components of responsivity (e.g., motivation, problem awareness and goals) and external components related to treatment environment (e.g., availability of programs and institutional social climate; Day, Howells, Casey, Ward, \& Birgden, 2007). The presence of these characteristics is likely to promote engagement in therapy and is thereby likely to influence offender change. Readiness indicates that the offender is motivated, is able to respond appropriately, perceives the treatment to be relevant and meaningful, and has the capacity to enter treatment (Ward, Day et al., 2004). Treatability can be seen as an aspect of responsivity which explains which offenders, under what treatment modalities and environmental conditions, will respond most favourably to treatment (Rogers \& Webster, 1989). Lastly, the current understanding of motivation is as an interactional and interpersonal process that can be influenced by internal and external factors (Kennedy \& Serin, 1999). From this view, motivation can be described as a dynamic trait and as a responsivity factor (Serin et al., 2007). It involves assessing whether or not an individual really wants to enter treatment and is willing to work on changing his or her behaviour (Ward et al., 2004).

Theories of Motivation and Treatment Readiness

A number of theories have been developed to explain motivation, treatment readiness and responsivity. For instance, the Texas Christian University (TCU) motivation model outlines the following three motivational stages before treatment is 
sought: problem recognition, desire for help and treatment readiness (Simpson \& Joe, 1993). The offender must move from a realization that his offending is a problem to a recognition that he needs help to change, along with a personal commitment to actively participate in treatment. Problem recognition and the desire for help have been found to be associated with cognitive indicators of therapeutic engagement (i.e., confidence in and commitment to treatment; Rosen, Hiller, Webster, Staton, \& Leukefeld, 2004). Hiller, Knight, Leukefeld, and Simpson (2002) found that a desire for help and treatment readiness were positively related to higher levels of personal involvement in treatment, better ratings of personal progress and stronger feelings of being psychologically safe in the program. These findings indicate that higher levels of motivation are associated with higher levels of treatment engagement.

Under the transtheoretical model (TTM) of change, an offender progresses through five stages while attempting to change problem behaviour: precontemplation, contemplation, preparation, action and maintenance (Prochaska, DiClemente, \& Norcross, 1992). An offender in the precontemplation stage does not view his behaviours as problematic and therefore does not consider changing them. In the contemplation stage, the offender recognizes that a problem exists and considers entering treatment, although he perceives that he is being coerced into treatment. In the preparation stage, the offender develops an intention to change, considers what change would be like and may have made some small behavioural changes. The offender makes a commitment to change in the action stage and is engaged in the treatment process. Lastly, the offender works to sustain the changes that he has made during treatment and works to prevent relapse in the maintenance stage. Depending on the stage of readiness for change, 
different therapeutic approaches or techniques need to be applied. Change is typically not a single event, but instead a process that involves a set chain of events. Progress toward maintenance is periodically interrupted by a return to previous stages and relapse is a predictable pattern in the change process. Although the TTM provides insight into the process of change while taking into account the concepts of readiness and responsivity, it has been met with numerous criticisms and appears to have only limited support in the application to offender populations (Casey et al., 2007). Bandura (1997) has argued that "human functioning is simply too multifaceted and multidetermined to be categorized into a few discrete stages" (p. 8). Factor analytic studies have consistently failed to confirm the existence of these distinct stages (De Leon, Melnick, \& Tims, 2001). Further, the stages of change model does not capture the self-perceptions, personality characteristics and attributions of the offender that may play a role in preventing relapse and predicting success (Serin \& Lloyd, 2009). Thus, a greater understanding and focus is needed on the individual differences that initiate and characterize life changes including behavioural change and desistance.

Importantly, the multifactor offender readiness model (MORM) builds on the TRRG model and highlights the importance of both internal and external conditions required for offenders to enter treatment (Ward et al., 2004). Treatment readiness is defined as the presence of characteristics within either the client or therapeutic environment which are likely to promote engagement. A lack of willingness to participate in treatment may reflect a range of internal and external factors which are unrelated to the desire to change a maladaptive behaviour. Therefore, contextual factors in addition to intrinsic motivation can influence treatment readiness and whether an 
offender can function in a therapeutic environment, and thereby benefit from treatment. From this perspective, engagement is a two-way process which requires appropriate support and resources for facilitators to work effectively (Day et al., 2007). Reductions in recidivism can be achieved only when readiness is addressed at the level of the offender, the program and the context. Although the MORM adequately accounts for the complexity of treatment readiness, it remains an untested framework (Serin et al., 2007).

\section{Predictors and Correlates of Readiness and Engagement}

Motivation for change and treatment readiness are precursors to treatment engagement. Treatment engagement encompasses more than simply participating in treatment, but also involves establishing a relationship with service providers, acknowledging a problem, making a commitment to working on problems and accepting some responsibility (Englebrecht, Peterson, Scherer, \& Naccarato, 2008). An engaged offender typically attends treatment, adheres to program rules and actively participates in the treatment process. Thus, engagement can be viewed in terms of intensity (e.g., participates frequently) and duration (e.g., completes treatment or stays in treatment for a relatively long period) of treatment participation (Fiorentine, Nakashima, \& Anglin, 1999). Engagement is viewed as a necessary element to achieve success in treatment and behavioural change.

Many correctional programs are using cognitive-behavioural treatment but it is important to gain an understanding of what offender characteristics are related to success in this type of program (Hubbard, 2007). According to Looman, Dickie, and Abracen (2005), responsivity factors have received little empirical attention. As a result, we do not know which offenders will succeed in treatment, who will achieve behavioural 
changes and ultimately who will desist from crime based on their abilities, expertise or knowledge. Kennedy and Serin (1999) categorize the factors that may interfere or facilitate learning into internal and external responsivity factors. Internal factors refer to the offender's characteristics, including motivation, personality characteristics (e.g., psychopathy, self-esteem), cognitive intellectual deficits (e.g., intelligence, problemsolving skills) and other demographic variables (e.g., age, gender). External factors refer to therapist and setting characteristics, which interact with offender characteristics to affect responsivity. These factors are important because they are associated with the offender's ability to benefit from treatment.

Tierney and McCabe (2002) summarized the cognitive, emotional and behavioural variables proposed to be associated with motivation in sex offenders. Offenders with low motivation are characterized by high denial, faulty beliefs and attitudes, and low cognitive dissonance. These offenders also tend to make attributions that are external, uncontrollable and unmodifiable as the cause of their behaviour. This group of offenders have low victim empathy and a shameful (as opposed to a guilty) emotional reaction to behaviour. Sex offenders with low motivation are likely to refuse to participate in treatment, have poor treatment behaviour and often drop out of treatment. They do not use relapse prevention strategies and are more like to reoffend than an offender with high motivation.

Treatment engagement depends on the type of program, what the offender perceives as the requirements of program attendance and how aversive these are perceived to be (Day, Tucker, \& Howells, 2004). Offenders who report more positive attitudes about treatment and expect to get more out of treatment are more likely to be 
engaged in the treatment process and complete programming (Barbaree, Seto, \& Maric, 1996). Acceptance of the problem, attendance, promptness and the level of participation in therapy have also been found to be predictive of success in cognitive-behavioural treatment (Jenkins-Hall, 1994). High-risk inmates with a strong sense of problem recognition have a greater probability of completing treatment than high-risk inmates who fail to appreciate the nature of their problems (Shuker, Falshaw, \& Newton, 2007). Englebrecht and colleagues (2008) also found that youths in a residential treatment program who accepted responsibility for their behaviour had higher levels of treatment engagement. These engaged youth also believed the treatment agency had something to offer. In a study of prison-based drug treatment, Welsh and McGrain (2008) found that motivation (measured by the treatment readiness scale of the Texas Christian University Resident Evaluation of Self and Treatment) was a significant predictor of therapeutic engagement. Counsellor competence, counsellor rapport and peer support were the strongest predictors of therapeutic engagement, highlighting the importance of the therapeutic alliance. Lastly, the magnitude of various predictors changed over time. For instance, the influence of static predictors (e.g., age, prior and current offence severity) was weak and diminished over time. The influence of social conformity on therapeutic engagement, on the other hand, increased over time.

Low motivation to change is associated with cognitive distortions including denial, minimization and justification (Looman et al., 2005). A greater negativity in criminal thinking (e.g., entitlement, criminal rationalization, cold-heartedness) has been found to be related to lower treatment engagement (Stanton-Tindall et al., 2007). Lower levels of minimizing or excusing crimes, on the other hand, predicts sex offender 
treatment program completion (Geer, Becker, Gray, \& Krauss, 2001). Levenson and Macgowan (2004) examined the relationship between denial, engagement and treatment progress. Denial and engagement were found to be negatively associated with each other, while treatment progress was related to higher levels of engagement. Offenders who actively contributed to the group, were connected to other members and to the therapist, and who were invested in the treatment were more likely to progress in treatment than those who were not. Hunter and Figueredo (1999) found that lower levels of denial at intake predicted successful program compliance in juvenile sex offenders. Lower levels of denial were also associated with attitudes of openness and accountability. The therapeutic atmosphere has been found to have a significant influence on treatment change. In a study by Beech and Fordham (1997), successful treatment groups were characterized by cohesiveness, effective leadership, a sense of group responsibility, encouragement of the expression of feelings and an instillation of hope. Greater changes in group members were seen in groups employing a positive approach, as opposed to a confrontational approach. These in-treatment changes included decreased cognitive distortions and the development of relapse prevention strategies. Beyko and Wong (2005) suggest that aggressive and disruptive behaviour interferes with the individual offender as well as the treatment of the other participants. Offenders that disrupt programming activities may negatively impact the ability of the treatment provider to deliver effective treatment to those who are motivated and engaged in the program (Burdon, Prendergast, Eisen, \& Messina, 2003). Therapeutic environments characterized by poor engagement (e.g., frequently missed sessions) hinder recovery efforts in terms of lower client confidence and commitment to recovery (Broome, Simpson, \& Joe, 1999). 
On the other hand, a strong recovery-oriented environment in which offenders receive support from fellow group members is related to better outcomes (Broome et al., 1999).

Related to the therapeutic atmosphere is the working or therapeutic alliance between the program staff and the offender. Ross, Polascheck, and Ward (2008) propose that the therapeutic alliance is a result of an interaction between the treatment setting, therapist and client characteristics, cognitions, perceptions and emotions, and therapist and client behaviour. According to Andrews and Bonta (2006), a positive therapeutic alliance between clinicians and offenders can facilitate learning. The working alliance has been positively associated with successful therapeutic outcome across a range of treatment populations and modalities (Connors, Carroll, DiClemente, Longabaugh, \& Donovan, 1997; Fiorentine et al., 1999; Martin, Garske, \& Davis, 2000; Simpson, Joe, Rowan-Szal, \& Greener, 1995; Simpson, Joe, Rowan-Szal, \& Greener, 1997; Taft, Murphy, King, Musser, \& DeDeyn, 2003). For instance, Lambert (1992) found that the working relationship accounted for almost one third of the change that occurs. Horvath and Symonds (1991) found a moderate relationship between a good working alliance and positive therapy outcome in a meta-analysis of 24 studies (mean effect size ( $r$ ) of .26 ). In order to be effective, the working alliance should be characterized by a positive emotional bond and perceived by the offender and the therapist as collaborative in nature (Day et al., 2007). An agreement should also be reached on the goals and tasks of treatment. In general, the personal variables of the therapist or program officer are important for effective intervention. Warmth and empathy has been associated with the development of appropriate skills and attitudes by offenders, including a reduction in minimization and denial of offending (Serran, Fernandez, Marshall, \& Mann, 2003). If 
the attitudes and competence of the therapist do not match the aims and content of the program, it may result in lowered treatment integrity and a reduction in effectiveness (Serin \& Kennedy, 1997).

Treatment providers must strike a balance between overcoming resistance and discouraging disruptive behaviours, while encouraging behaviours that promote participation and engagement in the treatment program (Burdon et al., 2003). Offenders who enter treatment with low motivation and readiness are unlikely to agree with the program officer on the goals and tasks of treatment and they may have difficulty developing a trusting therapeutic bond (Taft, Murphy, Musser, \& Remington, 2004). Empirical research has found a positive relationship between client motivation (including confidence in treatment and commitment to recovery) and rapport with counsellors and session attendance (Broome et al., 1999). Motivational readiness was found to be important for establishing a positive working alliance in cognitive-behavioural group therapy for partner violent men (Taft et al., 2004). In a drug abuse treatment, more positive therapeutic relationships were related to higher treatment engagement, lower drug use and longer retention in treatment (Simpson et al., 1997). This highlights the close link between the concepts of motivation, engagement and the therapeutic atmosphere.

\section{Outcomes of Treatment Resistant and Engaged Offenders}

There is a high dropout and non-completion rate in many correctional programs (Howells \& Day, 2006). A sufficient level of treatment motivation is crucial to becoming actively engaged (Hiller et al., 2002) and to demonstrating adept psychological functioning during treatment (Simpson et al., 1995). Further, readiness to change has 
been found to account for $9.4 \%$ of the variance in treatment outcome in a sample of alcohol-dependent inpatients (Demmel, Beck, Richter, \& Reker, 2004). Higher treatment readiness is associated with a greater likelihood of entering aftercare, which directly relates to lower recidivism and relapse (Melnick, De Leon, Thomas, Kressel, \& Wexler, 2001). Offenders with high readiness for treatment rate their counsellors, sessions and security staff higher, their meetings as more valuable and report 'working the program' more than offenders with low readiness (Sia, Dansereau, \& Czuchry, 2000). An offender that has high motivation and readiness for treatment will likely have higher levels of program participation and treatment gains. Treatment engagement (as measured by participation, counsellor rapport and client confidence in treatment) contributes to positive behavioural changes and improved psychosocial functioning following treatment (Simpson \& Knight, 2001). Offenders that have been labelled "treatment resistant" tend to be less motivated, be more resistant or non-compliant while in treatment, have higher attrition rates, demonstrate fewer behavioural changes while in treatment and have higher levels of recidivism (Preston \& Murphy, 1997).

De Leon and Jainchill (1986) tested four factors hypothesized to affect drug abuse treatment dropout: circumstances (i.e., extrinsic pressures), motivation (i.e., intrinsic pressures), readiness (i.e., need for treatment to make behavioural change) and suitability (i.e., appropriate match between individual and treatment modality). Short-term retention was predicted by readiness, suitability and motivation, but not by circumstances. Therefore, external pressures were a poor predictor of 30-day treatment retention, while readiness and suitability in particular were good predictors. Internal motivation is 
generally more important than external pressures in treatment and rehabilitation (De Leon et al., 2001).

In a study by Dowden and Serin (2001), both violent and non-violent recidivism rates in offenders were particularly high for those offenders that did not complete treatment. Offenders that dropped out of treatment had significantly higher levels of nonviolent recidivism (52\%) than those that did not receive treatment (30\%) and those who completed treatment $(10 \%)$. Violent recidivism rates followed the same pattern for the dropouts (40\%), the untreated (17\%) and the treated (5\%) groups. Hollin et al. (2008) replicated this finding, with treatment completers having lower rates of reconviction than offenders who dropped out of treatment or failed to start treatment after being assigned to a program. Seager, Jellicoe, and Dhaliwal (2004) replicated this finding in a sample of sex offenders, with the rate of sexual and violent recidivism six times higher in offenders who refused treatment or dropped out compared to treatment completers. It follows that treatment programs are not able to reduce risk if offenders do not attend them and may even increase risk if offenders begin programming but subsequently drop out. In a comparison to offenders who either completed or did not participate in the Counterpoint program, program dropouts were $26 \%$ more likely to have been suspended, $83 \%$ more likely to have been revoked and 39\% more likely to recidivate (Yessine \& Kroner, 2004). Also, it appears all program sessions must be completed to achieve lower rates of suspensions, revocations and recidivism.

There are psychological and demographic factors that differentiate treatment completers and non-completers. In a comparison of treatment completers and noncompleters by Nunes and Cortoni (2006), offenders who did not complete treatment due 
to withdrawal or expulsion differed from completers in their criminogenic needs and motivation. For both Aboriginal and non-Aboriginal men, non-completers were younger, had greater criminogenic needs and lower levels of motivation for treatment. NonAboriginal non-completers also had higher levels of static risk and scored higher on the Revised Statistical Information on Recidivism (SIR-R1). Browne, Foreman, and Middleton (1998) found that the same risk factors that predict recidivism can predict treatment non-completion in sex offenders. These risk factors include unemployment, alcohol/drug dependency, previous incarceration, previous offences, and deterioration and delinquent behaviour during treatment. Wormith and Olver (2002) also found that treatment attrition was related to denial, lack of motivation, general non-compliant behaviour and poor attitude toward treatment. A group of sex offenders that did not complete treatment had fewer extrinsic motivations for remaining in treatment and displayed rigidity, low self-esteem and a lack of concern about the consequences of their behaviour (Miner \& Dwyer, 1995). In a study of sex offenders, Beyko and Wong (2005) found disruptive and rule violating behaviours and poor treatment engagement predicted program attrition. This includes offenders who are non-compliant towards institutional rules, act aggressively during treatment and have histories of institutional misconduct. Shorter treatment retention and negative post-treatment outcomes have also been observed in drug offenders displaying noncompliant behaviours during treatment (Sung, Belenko, \& Feng, 2001). Hiller, Knight, and Simpson (1999) found support for the finding that the majority of the factors associated with treatment attrition are dynamic as opposed to fixed, and can thus be addressed in treatment to improve outcome. 
In a study of a cognitive skills program, McMurran and McCullogh (2007) found that non-completers were both motivated to stop offending and participate in treatment. However, they viewed the program as less relevant and less well-timed in relation to their current concerns than those offenders that completed the program. Other reasons for non-completion were that the program was too demanding, too slow and patronizing or the offenders disliked working in a group setting. To decrease the likelihood of dropout, non-completers suggested one-to-one support sessions to address difficulties with the treatment program, particularly in the early stages of the program. Joe, Simpson, and Hubbard (1991) observed lower treatment tenure in methadone maintenance clients who perceived the program as less accessible or less structured in its procedures. Higher tenure rates were found when service needs were addressed and client attitudes and satisfaction were high. Thus, the reasons for treatment resistance range from client variables (e.g., personality, client fears) and the client-clinician relationship to the type of treatment and treatment setting (Preston, 2000).

Beyko and Wong (2005) argue that offenders displaying aggressive and disruptive behaviour should not be expelled from treatment as they are the ones who need it the most. Howells and Day (2006) suggest that program effectiveness can be improved by focusing on the personal characteristics of offenders that are likely to influence engagement in treatment. A number of methods have been introduced to assess treatment readiness and motivation. For example, the Corrections Victoria Treatment Readiness Questionnaire (CVTRQ) is a 20-item self-report questionnaire which assesses treatment readiness, has good psychometric properties and can be administered easily and quickly (Casey et al., 2007). Serin et al. (2007) also developed a generic clinical scale for 
treatment readiness. Readiness was defined as both assets (which are related to higher readiness) and needs (which impede engagement). The final scale consists of readiness and interpersonal style domains, each of which is measured on eight items. The clinical rating scale was deemed to have acceptable reliability and accounts for $45 \%$ of variability in treatment readiness. Assessment tools such as these allow for the identification of offenders for whom pre-treatment interventions may enhance their treatment readiness.

\section{Crime Desistance}

Criminal careers can be viewed as a continuum from crime acquisition to desistance (Serin \& Lloyd, 2009). The current study focuses on the portion of this continuum in which the offender and ex-offender overlap. Offenders rating high in the competencies will likely have successfully participated in the program and accordingly, experience behavioural and/or cognitive change. For some offenders, this will mark the transition to crime desistance. It is important to view this transition as a process, one that does not occur instantaneously. The complete cessation of criminal behaviour is unlikely to occur suddenly, especially among offenders who have been highly involved in criminal activities from a young age (Kazemian, 2007). Further, desistance has been conceptualized as a change process involving multiple internal factors, tied to the psychological mechanisms that drive changes in behaviour (Maruna, 2001, Serin \& Lloyd, 2009). The five core offender competencies represent some of these internal factors that may drive changes in criminal behaviour patterns. Serin and Lloyd (2009) argue that offenders who desist from crime likely undergo a wide variety of other changes in behaviour, attitudes and life roles. 
Parhar and Wong (2004) proposed the Positive Self Change (PSC) theory to explain the process of crime desistance. The PSC theory proposes that offenders desist from criminal activities when there is an increased motivation to change, a reduction of criminogenic factors and an increase in protective factors. The views of parole officers and parolees about the factors considered important in desistance were assessed to test the validity of the PSC theory (Parhar \& Wong, 2007). Both were generally in agreement that the three components of the theory (i.e., motivation, criminogenic risks and protective strategies) are important in desisting from crime.

Maruna (2001) examined the processes that differentiated 30 desisting offenders and 20 active offenders. Evidence of the core competencies is present in the findings of this study. Maruna suggests that a re-evaluation of past behaviour and offending may be a precursor to the ability to change and desistance from crime. An offender would require cognitive flexibility and a sense of personal accountability to accomplish this in a candid manner. Some of the themes that separated desistors from persisters included: a positive sense of self, an optimistic perception of control over one's destiny, a desire to be productive and to give something back to others, and valuing life satisfaction. The ability to acquire and apply skills and knowledge learned in treatment may assist offenders in identifying with these values and beliefs. Lastly, the change in the desistors' behaviour was reported to be initiated by "turning points" (i.e., positive or negative external events) or an internal realization that their life was not going the way they wished. Either of these external or internal events may generate a fundamental core competency, the need for change. Inhibitory control is required to remain committed to this need for change, and exercising control in high-risk situations. 
The PIC-R perspective, proposed by Andrews and Bonta (2006), describes the factors that encourage or discourage criminal conduct. The occurrence of deviant and non-deviant behaviour are under the control of antecedent and consequent events. Both reinforcement (i.e., rewards) and punishment (i.e., costs) as a consequence of an act influence future behaviour. Further, rewards and costs can be additive or subtractive in that the event can be introduced or withdrawn. The strength of antecedents and consequences depend on the interaction of the individual with the environment, suggesting that there are many physical and cognitive characteristics that influence the capability to respond and learn. The probability of criminal conduct is a positive function of the rewards associated with that behaviour and a negative function of the associated costs. Based on the PIC-R, the likelihood of offender change and desistance from crime increases as the rewards for prosocial behaviour are raised, the rewards for antisocial behaviour are diminished and/or the costs for antisocial behaviour are raised.

The process of desistance can vary along a number of dimensions. For example, the change can be abrupt or gradual, begin early or late in the individual's criminal career, and begin at younger or older ages (Bushway, Thornberry, \& Krohn, 2003). Currently the specific factors that identify when offenders will and will not begin the transition to desistance are unclear (Serin \& Lloyd, 2009). Given the multidimensional nature of the process of change, it is unlikely that only one factor will account for a large amount of variance in offender change (Connors et al., 1997). The FCM captures the knowledge, abilities and expertise that are expected to be related to desistance from crime. A commitment to change and intrapersonal moderators work together to prime an offender to initiate and sustain a crime-free lifestyle (Serin \& Lloyd, 2009). This process 
requires cognitive flexibility, inhibitory control and personal accountability. A desisting offender must also be capable of learning and applying the knowledge and skills necessary to achieve behavioural changes. It is with hope that the FCM will advance our understanding of why some offenders desist from active involvement in crime.

\section{Measures of Offender Change}

Program completion, in and of itself, does not garner insight into the offenders' level of program participation or behavioural gains. Measures of offender change have been introduced as a method of indexing the level of program success or treatment gain. Few studies have measured behavioural change in the past 40 years and the existing studies tend to have brief measurement periods and use small samples (Smith \& Gendreau, 2007). Offenders' self-reports of how much he or she has benefited from treatment is viewed to be an insufficient index of change. Specifically, the validity of self-reports has been called in question due to the external motivators for participating in treatment and appearing to have experienced treatment gains (Casey, Day, \& Howells, 2005). For instance, parole is largely dependent on participation in treatment programs (Carroll \& Burke, 1990). Serin and Kennedy (1997) found a correlation between selfreported measures of social desirability and treatment readiness, suggesting offenders tend to respond in a socially desirable manner. No significant relationship was found between self-reports and behavioural measures of treatment readiness. On the other hand, some agreement has been found between clinical ratings and self-reports but only if continuous measures are used, as opposed to categorical stage assignments (Hodgins, 2001). It appears that inaccurate self-reports can bias measures of treatment outcome and program performance. It would seem to be clear that the use of corroborative evidence 
(e.g., behavioural ratings by program facilitators) is necessary to improve the validity and accuracy of assessments of offender change.

Hanson (2000) has identified the need for more clinical research measuring treatment targets using reliable measures. At present, there is little empirical evidence that the prediction of correctional outcomes can be improved by using change scores from programming pre- and post-test batteries (Serin, 2006). For example, the University of Rhode Island Change Assessment (URICA) scale has good concurrent validity for measures of treatment readiness but low predictive validity (Blanchard, Morenstern, Morgan, Labouvic, \& Bux, 2003). Further, the URICA may be less applicable to offender populations than other clinical populations (Serin \& Kennedy, 1997). One exception to the poor predictive validity of self-reports is a study by Yessine and Kroner (2004), in which outcome (e.g., suspension, revocation or new offence) was found to be related to reductions in measures of antisocial attitudes, neutralization and negative criminal attributions. It would appear a clear goal of offender programming is the need to develop measures to reliably predict correctional outcomes. Sound measures of the right constructs are necessary to assess an offender's progress in treatment. Accurately assessing behavioural change would also appear to be a crucial step in developing treatments suited to the needs of individual clients (Blanchard et al., 2003).

The Current Study

\section{Study Rationale}

Current leading research on offender rehabilitation suggests the requisite methods and principles for effective correctional treatment (i.e., RNR). However, this research fails to identify the personal characteristics held by offenders who are successful in 
treatment programs and achieve behavioural change. An offender's suitability for a program is likely to involve more than the presence of the characteristics associated with risk and need identified by Andrews and Bonta (2006). It also involves the extent to which an offender is "ready" to engage in treatment and in the change process (Casey et al., 2007). It is proposed that the FCM can help identify those offenders that meet a threshold for change and treatment gain. Processes of offender change, including spontaneous desistance and change related to treatment programs, are poorly understood and difficult to measure (Antiss, Polaschek, \& Wilson, 2008). Offenders respond differently to treatment and this is hypothesized to be a result of pre-existing characteristics of the offender which moderate the impact of correctional treatment. The purpose of this study is to test whether the five core competencies (need for change, personal accountability, cognitive flexibility, inhibitory control, and knowledge acquisition and application) are able to accurately predict program performance. Such findings would help determine if and when a particular offender will respond to treatment. This study will also involve re-conceptualizing the constructs that may be important in understanding offender change, and ultimately desistance from crime.

\section{Hypotheses}

Both threshold scores and change scores will be examined in the current study. Threshold scores represent program performance, focusing on the final level attained by the offender. Change scores represent behavioural change, calculated by subtracting preprogram scores from post-program scores. Program performance is of particular interest as it is expected that offenders with high competency levels are able to meet a minimum threshold for change. An offender may demonstrate considerable behavioural change, 
but fail to meet the threshold for sufficient treatment gain to lead to desistance from crime.

Three hypotheses will be tested:

1. It is proposed that offenders rating high in the competencies will have greater program performance than those rating low in the competencies.

2. It is proposed that offenders rating high in the competencies will have greater behavioural change than those rating low in the competencies.

3. It is proposed that treatment completers will have higher competency ratings than treatment non-completers.

\section{Method}

\section{Measures}

Research on offender competencies is in its infancy, therefore much of this research is exploratory and new measures must be used. As such, complete psychometric properties are not available for some of the measurement scales. A focus of this study will involve examining the reliability and validity of these new scales. The Offender Competency Index $(\mathrm{OCI})$ is a measure of offender competencies which will be derived from information that is routinely collected by CSC upon intake. This new measure is hypothesized to be positively correlated to the General Program Performance Measure, a measure of offender change which focuses on program performance and treatment engagement. Risk for recidivism, motivation for intervention, criminogenic needs, static risk, reintegration potential and the Custody Rating Scale will also be included as covariates in the analyses. The purpose of including these variables as covariates is to 
determine if the competency model explains incremental variance in program performance once accounting for these factors.

\section{Offender Competency Index}

The OCI was developed for this study. The construction of the scale is discussed in the Results. For the most part, these items are part of the Offender Intake Assessment (OIA), which involves a comprehensive assessment of static and dynamic factors to determine the level and type of intervention required to achieve the safe and timely reintegration of the offender (Motiuk, 1997). The OIA forms the basis of an individualized correctional plan, which addresses the factors that have been identified as contributing to an offender's criminal behaviour. With the exception of motivation, all of the proposed variables are derived from the assessment of dynamic factors, or criminogenic needs. The Dynamic Factor Identification and Analysis is based on information in official documents (e.g., official version of the offence, criminal history), interviews conducted during the intake process and supplementary assessments.

The reliability and validity of the Dynamic Factor Identification and Analysis (DFIA) was tested in a recent psychometric review (Brown \& Motiuk, 2005). The statistical reliability of each domain in terms of internal consistency ranged from acceptable to superior within all three release cohorts: men, women and Aboriginal offenders. The statistical reliability for the community functioning domain was relatively low in comparison to the other domains, particularly for women and Aboriginal offenders. However, only one item selected for the final version of the $\mathrm{OCI}$ is from the community functioning domain. The predictive validity for all DFIA domains (i.e., employment, marital/family, associates, community functioning, substance abuse, 
personal/emotional, attitudes) was demonstrated to range from moderate to strong. This indicates that offenders who were rated as having more serious problems across the seven domains were significantly more likely to be readmitted to federal custody during a threeyear follow-up period.

\section{Generic Program Performance Measure}

The GPPM (Stewart \& Price, 2005) is administered before and after the program as a measure of program performance and taps into the construct of offender change. The scale is an interview-based rating system, completed by the program facilitator (refer to Appendix A for the measure and scoring guide). The offender is rated on 19 items on a 5-point Likert-type scale from -2 to 2 : needs a lot of improvement (-2), needs some improvement (-1), satisfactory (0), good (1) and very good (2). A higher score indicates greater program performance. The 19 items comprise 3 scales: performance, effort, and responsivity. The performance items measure gains made in skills, attitude and knowledge. The effort items measure the extent to which the participant tries to address the objectives of the program (e.g., through completion of work, in-class participation). The responsivity items reflect factors that could affect the participant's progress in treatment that should be considered and addressed, as well as factors that may impinge on the participant's progress.

The GPPM is a standardized measure used within all CSC correctional programs. It is completed pre- and post-program participation. Before program participation, the program facilitator assesses the items with the use of file information (e.g., prior program reports, intake information, correctional plans, criminal profile, and psychological reports), a pre-program interview and assessment, and performance during the first two 
sessions. Only questions 6-17 are completed at the pre-program phase, while all of questions are completed post-program. Participants are rated based on their actual behaviour and ability, as opposed to their ranking relative to others in the group or their progress relative to where they were when they started the program. An analysis of the psychometric properties of the GPPM suggests good internal reliability, as demonstrated by high Cronbach's alpha $(\alpha=.96)$ and item-total correlations ( $M$ inter-item $r=.59$; Soh, 2008). Further research is necessary to assess the predictive validity of the GPPM to determine if higher GPPM scores are predictive of lower rates of recidivism. Statistical Information on Recidivism - Proxy (SIR-Proxy)

The SIR-Proxy will be used to classify the risk level of offenders included in the sample (refer to Appendix B for the items which comprise the SIR-Proxy). This scale combines measures of demographic information and criminal history to generate an estimate of risk for recidivism for federally sentenced inmates. A risk of re-offence within three years is estimated based on past and current offences, as well as the offender's criminogenic needs. Scores range from -27 to 29 , with lower scores indicating higher risk. The SIR-Proxy is a substitute measure of the Statistical Information on Recidivism - Revised 1 (SIR-RI; Nuffield, 1989) and was developed to expand the scope of re-offence probability estimates beyond non-Aboriginal males to females and Aboriginal offenders (Nafekh, 2003).

The SIR-Proxy is highly correlated with the SIR-R1 $(r=.90)$, has good internal consistency (Cronbach's alpha $=.78$ ) and good predictive validity for federally sentenced non-Aboriginal male offenders (AUC $=.75 ;$ Nafekh, 2003) and male Aboriginal offenders (AUC $=.68$, Motiuk \& Nafekh, 2001). In terms of release risk, approximately 
equal percentages of offenders score either good/very good on the SIR-R1 (44\%) or poor/very poor (40-41\%), while a smaller percentage of offenders receive a moderate score of fair (15-16\%; Motiuk \& Nafekh, 2001).

Criminogenic Need

Criminogenic need (i.e., dynamic risk) is based on the compilation of professional judgment and an assessment of the offender's criminogenic needs in seven domains: employment (35 indicators), marital/family (31 indicators), associates (11 indicators), substance abuse (29 indicators), community functioning (21 indicators), personal/emotional (46 indicators), and attitudes (24 indicators; Standard Operating Practice 700-04, Correctional Service of Canada). Employment refers to the value placed on work and the role of work in the offender's life. Marital/family involves the value placed on being with and receiving support from family. Associates/social interaction is concerned with the value placed on non-criminal associates and the opportunity for positive social interaction. Substance abuse refers to the value placed on living without reliance on alcohol and/or drugs. Community functioning involves the value placed on having the knowledge and skills necessary for daily living. Personal/emotional orientation represents the value placed on being in control of one's life. Finally, attitude is concerned with the value placed on living in law-abiding ways. Each need domain, with the exception of substance abuse and personal/emotional orientation, is assessed on a 4-point scale: 1) factor seen as an asset to community adjustment, 2) no immediate need for improvement, 3) some need for improvement, and 4) considerable need for improvement. Substance abuse and personal/emotional orientation are rated on a 3-pont 
scale from 'no immediate need for improvement' to 'considerable need for improvement.'

An overall rating of 'low,' 'medium' or 'high' level of intervention based on dynamic factors is then assigned by the case management officer, taking into account the degree or severity of need on each of the need domains as well as any immediate needs (e.g., mental health, medical, suicide risk potential). An offender with no identified dynamic factors (i.e., 'asset to community adjustment' and/or 'no immediate need for improvement') or relatively few dynamic factors rated as 'some need for improvement' would be rated 'low' need. On the other hand, an offender with multiple dynamic factors or few identified dynamic factors but rated as 'considerable need for improvement' would be rated 'high' need. A rating of 'medium' need is reserved for any combination of dynamic factor severity and number that lie outside of the guidelines for low and high need. Criminogenic need is first assessed at intake and again at various points during an offender's sentence.

\section{Motivation for Intervention}

As with criminogenic need, an offender's overall motivation for intervention is first assessed at intake and again throughout the sentence (Standard Operating Practice 700-04, Correctional Service of Canada). The level of motivation is determined based on all of the information gathered during the intake process. A classification of 'low,' 'medium' or 'high' is assigned based on an assessment of the degree to which the offender recognizes he or she has a problem, their level of responsibility for the problem and willingness to change. An offender must have the ability to effect change, thus evidence of positive behaviour change in the past is considered in the rating. A rating of 
'high' motivation indicates that the offender is self-motivated and will actively address problem areas. An offender is rated as 'medium' in motivation if he or she does not fully accept the overall assessment but will still participate in recommended programs or other interventions. Lastly, an offender is rated as being 'low' in motivation if he or she strongly rejects the need for change or is unwilling to participate in recommended programs or other interventions.

Static Risk

The Level of Intervention Based on Static Factors rating is a measure of static risk (Motiuk, 1997). The offender's static risk level is assessed based on a review of static risk information on the offender's criminal history, severity of the offence record, sex offence history and the results of the SIR-R1. A rating of 'low,' 'medium' or 'high' is assigned based on professional judgment of these factors. A rating of 'high' risk would be applied to an offender with considerable involvement with the criminal justice system, considerable sex offending, extremely severe offences and when applicable, a SIR-R1 score indicative of high risk. A rating of 'low' risk would be applied to an offender with little involvement with the criminal justice system, very few sex offences, low offence severity and when applicable, a SIR-R1 score indicative of low risk.

\section{Reintegration Potential}

Reintegration potential is a measure of the likelihood of safe reintegration into the community following release. It is calculated using the offender's individual scores on the Custody Rating Scale, SIR-R1, and static risk. For female and Aboriginal offenders, the Dynamic Factor Rating is substituted for the SIR-R1 to calculate reintegration potential. Reintegration potential guides sentence planning, as offenders with 'low' 
potential require more intensive programming and risk management strategies than those rated 'medium' or 'high.'

\section{Custody Rating Scale}

The Custody Rating Scale (CRS) assists parole officers in determining the most appropriate level of penitentiary security for the initial placement of the offender. It consists of two scales: institutional adjustment and security risk. The institutional adjustment scale measures risk to staff, other inmates and self caused by problems related to institutional adjustment (Luciani, 1997). The institutional adjustment score is calculated based on five items: the offender's history of involvement in institutional incidents, escape history, street stability (e.g., employment, family), alcohol/drug use and age at time of sentencing. An examination of the reliability of the CRS found that the overall coefficient alpha was .39 for the Institutional Adjustment subscale and all intercorrelations between items, with one exception, were significant $(p<.005$; Luciani, 1997).

The security risk score is the second dimension of the CRS, reflecting the offender's number of prior convictions, most severe outstanding charge, severity of current offence, sentence length, street stability, prior parole and/or statutory release, and age at first federal admission (seven items). This scale assesses risk to the public in the event of escape. The overall reliability coefficient alpha has been found to be 10 for the Security Risk subscale, and for only three of the seven items were the inter-correlations found to be significant (Luciani, 1997). The institutional adjustment score and security risk score are combined to determine whether the offender should be classified as minimum, medium or maximum security. Luciani, Motiuk, and Nafekh (1996) reported 
that item mean scores for CRS rating of maximum, medium and minimum were significantly different $(p<.001)$ for all 12 items. The correlations between the CRS and related risk measures were as follows: with the General Statistical Information on Recidivism (GSIR), $r=-.39$; with the OIA risk level, $r=.46$; and with the OIA need level, $r=.52$.

\section{Program Category}

The following program categories are examined: violent offender, family violence, sex offender, substance abuse, living skills and Counterpoint. Violent offender programs consist of high and moderate violence prevention programs, as well as a violence prevention program designed specifically for Aboriginal offenders. Family violence programs include moderate and high intensity programs as well as a high intensity program targeted toward Aboriginal offenders. Sex offender programs comprise of all national sex offender programs of low, moderate and high intensity levels and an Aboriginal-specific program. Substance abuse programs also consist of low, moderate and high national programs and an Aboriginal-specific program. The living skills category consists of a general crime prevention program for Aboriginal offenders (i.e., Basic Healing Program) as well as two programs that have since been discontinued (i.e., Anger \& Emotions, Reasoning \& Rehabilitation). Finally, the Counterpoint category includes a general crime prevention program (i.e., Alternatives, Associates and Attitudes) and the Counterpoint program, which has since been discontinued.

\section{Participants}

The sample consisted of all male offenders admitted to a federal institution within the $2006 / 2007$ and 2007/2008 fiscal years. The total sample of 9,504 offenders for which 
intake information was available from all regions and security levels was used in the development of the Offender Competency Index. Only offenders that participated in at least one correctional program during the timeframe were included in further analyses $(N$ $=3,774$ of the 9,504 offenders admitted). ${ }^{1}$ Only males were included in the sample, as females are generally more likely to engage in treatment and may differ in the factors which predict their levels of engagement (Fiorentine et al., 1999). In addition, the number of women meeting the requirements of the sample was too low to adequately address the research questions. ${ }^{2}$ Participants ranged in age from 17 to 84 with a mean age of 34.4 years. A majority of the offenders were Caucasian (66.0\%) while the remaining participants were Aboriginal (17.7\%), Black (7.8\%), Asian (4.7\%) or other (3.8\%). Most participants were currently unmarried (61.2\%) while $75.5 \%$ had been married or in a common law relationship in the past.

Slightly less than half of the sample (47.5\%) was incarcerated for a non-sexual violent offence, whether assault, robbery or murder. The remaining proportion of offenders was incarcerated for non-violent offences (40.9\%) and sexual offences (11.6\%). For those with determinate sentences $(96.5 \%)$, the mean current sentence length was 3.33 years, with a range from one day to 20 years. ${ }^{3}$ A small proportion of the sample (3.5\%) was serving indeterminate sentences (e.g., life). Most offenders had previously served a provincial term $(67.3 \%)$, while a minority had served a federal term $(28.3 \%)$. As can be seen in Table 1, a majority of offenders have moderate to high static risk and

\footnotetext{
${ }^{1}$ The 9,504 offenders for which intake information was available were used in the development the OCI while 3,774 of those that participated in a correctional program comprised the sample used in the remaining analyses (i.e., partial correlations, multiple regression and group difference analyses).

${ }^{2}$ While 626 female offenders were admitted during the study timeframe, 172 participated in a correctional program and only 108 of those completed treatment.

${ }^{3}$ Offenders with a sentence length of less than two years were incarcerated due to suspension or revocation.
} 
criminogenic needs. However, most offenders have moderate to high motivation and reintegration potential. Table 2 contains a summary of their criminogenic need domains. Substance abuse and the personal/emotional orientation domains appear to be particularly problematic for the offenders in the sample.

Table 1. Summary of Intake Assessment Information

\begin{tabular}{lccc}
\hline Intake variable & Low & Moderate & High \\
\hline Motivation & $13.5 \%$ & $67.1 \%$ & $19.4 \%$ \\
Risk & $15.3 \%$ & $41.6 \%$ & $43.1 \%$ \\
Need & $8.4 \%$ & $32.3 \%$ & $58.4 \%$ \\
Reintegration potential & $31.0 \%$ & $26.5 \%$ & $42.5 \%$ \\
\hline
\end{tabular}

Table 2. Summary of Criminogenic Need Domains

\begin{tabular}{lcccc}
\hline Domain & Asset & $\begin{array}{c}\text { No immediate } \\
\text { need }\end{array}$ & Some need & $\begin{array}{c}\text { Considerable } \\
\text { need }\end{array}$ \\
\hline Employment & $2.5 \%$ & $37.2 \%$ & $50.5 \%$ & $9.8 \%$ \\
Marital/family & $4.4 \%$ & $58.4 \%$ & $24.1 \%$ & $13.1 \%$ \\
Associates/social & $1.7 \%$ & $27.5 \%$ & $41.4 \%$ & $29.4 \%$ \\
interaction & & & & \\
Substance abuse & - & $28.0 \%$ & $21.9 \%$ & $50.1 \%$ \\
Community & $2.3 \%$ & $71.1 \%$ & $21.8 \%$ & $4.8 \%$ \\
functioning & & & & \\
Personal/emotional & - & $17.3 \%$ & $31.5 \%$ & $51.3 \%$ \\
Attitude & $1.6 \%$ & $34.0 \%$ & $33.0 \%$ & $31.4 \%$ \\
\hline
\end{tabular}




\section{Procedure}

Archival data were used to examine the relationship between offender competencies and treatment program performance. Data were collected on offenders who were admitted to a federal institution between April 2006 and March 2008 and participated in at least one program during this timeframe. Offenders participating in any type of core intervention program (e.g., substance abuse, sex offender, violence prevention) were included in the sample, while offenders participating in other programs (e.g., education, employment, leisure activities) were not included. Only one offender participated in more than one program during the data collection period, therefore data from the first correctional program in which the offender participated was analysed. All of the data were taken from data collected at intake, thus in all cases the variables preceded the treatment program and outcome data.

Offenders who dropped out or were expelled from treatment were retained in the sample in order to allow for comparisons between completers and non-completers on competency level and treatment engagement. Consistent with Nunes and Cortoni (2006), treatment completers were coded as offenders who successfully completed or attended all sessions of a treatment program. A 'successful completion' indicates that offenders were successful and compliant in the program. A designation of 'attended all sessions' indicates that offenders completed the program but failed to meet the program requirements. ${ }^{4}$ Treatment non-completers were coded as offenders who dropped out or were expelled from a treatment program (i.e., suspension). Offenders who did not complete treatment for administrative reasons or personal circumstances beyond the

\footnotetext{
${ }^{4} \mathrm{~A}$ 'successful completion' implies that offenders received a rating in between 0 and 2 on the GPPM. A designation of 'attended all sessions' implies that offenders were rated between -2 and 0 on the GPPM.
} 
control of the offender (i.e., transferred, program cancelled, temporarily reassigned, released, Warrant Expiry date reached) were grouped separately.

Results

\section{Scale Construction and Psychometrics}

\section{Offender Competency Index}

The development of the OCI was a multi-stage process. Based on the conceptualizations of each of the core competencies, an item pool was generated. Before any statistical analyses were performed, competency subscales were calculated by summing the items proposed to relate to each competency. Next, the sample of 9,504 male offenders for which intake information was available was randomly split in half into a development sample and a cross-validation sample. A factor analysis was first performed on the development sample to determine if the items clustered as anticipated along the five competencies. A second factor analysis was performed on the crossvalidation sample to assess whether the factor structure could be replicated. Finally, factor scores were created in order to provide a score for each factor for each participant in the sample.

Item pool development. Items were selected to correspond to each of the core competencies based on a review of all the variables available in the Offender Management System, the Correctional Service of Canada's automated database containing offender information. Operational staff and other experts were consulted to review the intake variables that are proposed to capture the competencies. The variables outlined in Table 3 were identified as potential items to comprise the OCI. With the exception of motivation which is rated on a 3-point scale consisting of 'low,' 'medium' 
and 'high' motivation, these indicators are binary (i.e., yes/no). ${ }^{5}$ The 30 proposed variables were selected to represent the competencies as accurately as possible based on available data as described in the Functional Competency Model.

\footnotetext{
${ }^{5}$ Ideally factor analysis should be conducted on continuous variables, as opposed to dichotomous or categorical variables as is the case in the current study. Dichotomous variables result in relatively little variability and the correlations between items may be small and unreliable. However, these limitations are minimized by using a large sample size and a large subject-to-variable ratio (Kline, 1994).
} 
Table 3. Variables proposed to comprise the Offender Competency Index

\begin{tabular}{|c|c|c|}
\hline Competency & Variable & Description (OIA help message) \\
\hline \multirow{3}{*}{$\begin{array}{l}\text { Need for } \\
\text { change }\end{array}$} & Motivation & - \\
\hline & $\begin{array}{l}\text { Negative attitude towards } \\
\text { rehabilitation }\end{array}$ & - \\
\hline & Narrow and rigid thinking & $\begin{array}{l}\text { Unable to accept new ideas, does } \\
\text { not look beyond own view of the } \\
\text { world }\end{array}$ \\
\hline \multirow[t]{6}{*}{$\begin{array}{l}\text { Personal } \\
\text { accountability }\end{array}$} & Feels especially self-important & $\begin{array}{l}\text { Offender makes himself appear } \\
\text { more important than reality (Self- } \\
\text { aggrandizement) }\end{array}$ \\
\hline & $\begin{array}{l}\text { Incapable of understanding the } \\
\text { feelings of others }\end{array}$ & $\begin{array}{l}\text { Offender makes decisions without } \\
\text { considering others, lacks } \\
\text { awareness and sensitivity to other } \\
\text { peoples' thoughts and feelings }\end{array}$ \\
\hline & Has disregard for others & $\begin{array}{l}\text { Offender does not consider the } \\
\text { effects of his/her actions on others }\end{array}$ \\
\hline & Socially unaware & - \\
\hline & Hostile & $\begin{array}{l}\text { Offender's demeanour and attitude } \\
\text { is belligerent }\end{array}$ \\
\hline & Is not conscientious & $\begin{array}{l}\text { Offender is not persistent in goal- } \\
\text { oriented behaviour }\end{array}$ \\
\hline \multirow[t]{5}{*}{$\begin{array}{l}\text { Cognitive } \\
\text { flexibility }\end{array}$} & $\begin{array}{l}\text { Has difficulties solving } \\
\text { interpersonal problems }\end{array}$ & $\begin{array}{l}\text { Example: uses instant solutions, } \\
\text { uses drugs/alcohol to deal with } \\
\text { interpersonal problems }\end{array}$ \\
\hline & Unable to recognize problem areas & $\begin{array}{l}\text { Offender does not recognize the } \\
\text { early signs or cues that may lead to } \\
\text { interpersonal problems }\end{array}$ \\
\hline & Poor conflict resolution & $\begin{array}{l}\text { To deal with conflict, the offender } \\
\text { becomes aggressive, turns to } \\
\text { substance abuse, withdraws, etc. }\end{array}$ \\
\hline & Copes with stress poorly & $\begin{array}{l}\text { In dealing with stressful situations, } \\
\text { the offender becomes aggressive, } \\
\text { turns to substance abuse, } \\
\text { withdraws, etc. }\end{array}$ \\
\hline & Unable to generate choices & $\begin{array}{l}\text { Offender does not think of } \\
\text { alternatives to problems }\end{array}$ \\
\hline
\end{tabular}


Unaware of consequences

Offender is unable to project the consequences of his/her behaviour on oneself and/or others

\begin{tabular}{|c|c|c|}
\hline \multirow[t]{5}{*}{$\begin{array}{l}\text { Inhibitory } \\
\text { control }\end{array}$} & Impulsive & $\begin{array}{l}\text { Unable to resist temptation, unable } \\
\text { to stop and think before acting, } \\
\text { looks for immediate gratification }\end{array}$ \\
\hline & Takes risks inappropriately & - \\
\hline & Thrill seeking & $\begin{array}{l}\text { Seeks situations that cause } \\
\text { emotional excitement }\end{array}$ \\
\hline & Has low frustration tolerance & $\begin{array}{l}\text { Has difficulty dealing } \\
\text { appropriately with daily stresses }\end{array}$ \\
\hline & Non-reflective & $\begin{array}{l}\text { Offender does not reflect on the } \\
\text { appropriateness of his/her } \\
\text { behaviour in different situations }\end{array}$ \\
\hline \multirow{10}{*}{$\begin{array}{l}\text { Knowledge } \\
\text { acquisition } \\
\text { and } \\
\text { application }\end{array}$} & Finds learning difficult & $\begin{array}{l}\text { Offender has difficult time in } \\
\text { school grasping certain concepts }\end{array}$ \\
\hline & Learning disabilities & $\begin{array}{l}\text { Learning disabilities (e.g., } \\
\text { dyslexia) were confirmed through } \\
\text { formal assessment }\end{array}$ \\
\hline & Memory problems & - \\
\hline & Concentration problems & - \\
\hline & Problems with reading & - \\
\hline & Problems with numeracy & $\begin{array}{l}\text { Offender lacks basic math skills } \\
\text { (e.g., addition, subtraction) }\end{array}$ \\
\hline & $\begin{array}{l}\text { Difficulty comprehending } \\
\text { instructions }\end{array}$ & - \\
\hline & $\begin{array}{l}\text { Problems with writing } \\
\text { (employment domain) }\end{array}$ & $\begin{array}{l}\text { Offender cannot complete simple } \\
\text { written exercises (e.g., writing } \\
\text { cheques, request forms) }\end{array}$ \\
\hline & $\begin{array}{l}\text { Has problem writing (community } \\
\text { functioning domain) }\end{array}$ & - \\
\hline & Unable to express verbally & - \\
\hline
\end{tabular}

The items selected from OMS largely correspond to the FCM, but there are some omissions. The need for change is represented by scoring positively on motivation and by not demonstrating a negative attitude toward rehabilitation or narrow or rigid thinking. 
Measurement of this competency would be further enhanced by incorporating additional indices of a readiness to change, demonstrating a concern for others, a lack of egocentricity and an external locus of control. The items selected to represent personal accountability are comprehensive, with the exception of omitting more direct measures of humility and entitlement. Cognitive flexibility is represented by six items which relate to problem solving, but lack measures of cognitive distortions. The items selected to be a sign of inhibitory control capture some disinhibitory factors but fail to capture the exercise of control over impulses to commit further criminal acts. Finally, the items chosen to correspond to knowledge acquisition and application focus mainly on the characteristics that may hinder an offender's ability to gain knowledge regarding their criminal behaviour. There were no variables available which represented the knowledge application component of the competency.

The 30 items were used to calculate composite scores for each of the competencies. For ease of interpretation, the composite variables were reverse-scored so that higher scores correspond to greater proficiency in the competency. As demonstrated in Table 4, the internal consistency was poor for each of the scales with the exception of knowledge acquisition. Cronbach's alpha ranged from .58 to .68 for the remaining scales (refer to Appendix $\mathrm{C}$ for complete reliability analyses). This may suggest that the items chosen do not represent a single underlying latent variable. Accordingly, factor analytic procedures were employed to refine the item pool and enhance scale development. 
Table 4. Internal Consistency and Descriptive Statistics for Competency Scales

\begin{tabular}{lccccc}
\hline Competency Scale & $\alpha$ & $M$ & $S D$ & Range & $\begin{array}{c}\text { \# of } \\
\text { items }\end{array}$ \\
\hline Need for change & .58 & 2.57 & 1.10 & $1-5$ & 3 \\
Personal accountability & .68 & 2.02 & 1.65 & $0-6$ & 6 \\
Cognitive flexibility & .67 & 3.68 & 1.76 & $0-6$ & 6 \\
Inhibitory control & .59 & 2.70 & 1.46 & $0-5$ & 5 \\
Knowledge acquisition & .85 & 1.95 & 2.54 & $0-10$ & 10 \\
\hline
\end{tabular}

Factor analysis in development sample. An exploratory factor analysis was

performed to determine if the 30 variables clustered as predicted on the five competencies. Exploratory factor analysis is used to describe and summarize data by grouping together correlated variables (Tabachnick \& Fidell, 2007) ${ }^{6}$ The development sample size of 4,772 was ideal for generating reliable and replicable factors. Despite most communalities being lower than .5 , the present sample size is able to produce reliable factors (MacCallum, Widaman, Zhang, \& Hong, 1999). Kaiser-Meyer Olkin's measure of sampling adequacy $(\mathrm{KMO}=.89)$ suggests the present data are adequate for conducting factor analysis. The ratio of subjects to variables is highly adequate at a ratio of 159:1.

\footnotetext{
${ }^{6}$ Confirmatory factor analysis (CFA) was not employed since it is typically used in the advanced stages of the research process when testing a theory about latent processes (Tabachnick \& Fidell, 2007). CFA is not informative regarding whether other models have better fit (Kline, 1994). Exploratory factor analysis (EFA) is typically used in the early stages of research, and the variables entered may or may not have been chosen with potential underlying processes in mind (i.e., a priori notions regarding the nature and number of factors being sought; Tabachnick \& Fidell, 2007). It is especially reassuring, however, when items group together as suspected because the analysis has not been instructed to identify a specific pattern (DeVellis, 2003). Also, EFA is employed in the present research rather than principal components analysis (PCA) since PCA is a purely empirical test wherein theory does not drive the decision making process. EFA is more appropriate than PCA when there are a priori notions regarding the nature and number of factors being sought.
} 
A Pearson correlation matrix was examined to determine the factorability of the data and to check for singularity and multicollinearity. The matrix consisting of 30 crosscorrelated items yielded 465 correlations. Of these, 91 were .30 or greater. The highest correlation was .72. However, despite the lack of correlations in excess of .90, the determinant of the $\mathbf{R}$ matrix (<.0001) suggests multicollinearity may exist within the data. 'Problems with writing' (employment domain) had high correlations with a number of other items, including $r=.56$ with 'has problem writing' (community functioning domain). After removing this variable and performing the factor analysis on the remaining 29 variables, the determinant increased to .001 , indicating that multicollinearity is no longer an issue. Finally, Bartlett's test of sphericity was significant $\left(\chi^{2}(\mathrm{df}=406)=24,339.32, p<.001\right)$; given the number of correlations greater than .30 and the results of this test, evidence suggests factor analysis would be worthwhile.

An initial solution was created using principal factors analysis with promax rotation $(\kappa=0)$. The principal factors extraction method was used to analyze common variance while eliminating unique and error variance from variables. The promax rotation method was chosen to allow factors to correlate while maximizing the simplicity of the factors and clarifying which variables do and do not correlate with each factor (Tabachnick \& Fidell, 2007). ${ }^{7}$ The solution identified six factors with eigenvalues greater than 1.0. Kaiser's criterion (i.e., retaining eigenvalues greater than 1.0 ) is generally accurate when there are less than 30 variables and communalities after extraction are greater than .7 or when the sample size exceeds 250 and the average

\footnotetext{
${ }^{7}$ Orthogonal rotation methods (e.g., varimax) should only be used when there is a strong theoretical reason for assuming factors to be orthogonal (Kline, 1993). Oblique rotation methods are ideal as they do not exclude the possibility of an orthogonal structure being detected (Kline, 1994).
} 
communality is greater than .6 (Field, 2005). Although there are 29 variables and a large sample size, there are no communalities greater than .7 and the average communality is only .37. Based on these grounds, Kaiser's criterion may not be accurate. An examination of the scree plot's point of inflexion also suggests six components should be retained. Lastly, when eigenvalues derived from a randomly generated dataset with equivalent features (i.e., parallel analysis; number of cases $=3,393$; number of variables $=29 ; 100$ replicated datasets were employed) were compared to observed eigenvalues, both analyses suggested the first six factors should be retained. Parallel analysis has been shown to be one of the most reliable strategies for component retention (Zwick \& Velicer, 1986). The six identified factors explain $38.7 \%$ of the variance. Within the six factors, 28 of the 29 items were represented using a loading criterion of .30 (Kline, 1993). Four of these were complex variables that loaded on more than one factor.

The stability of the present solution was examined using two additional extraction methods. First, the generalized least squares extraction method was employed. This method was chosen because it weights items that share substantial variance with other variables. If multicollinearity exists within the data, it was assumed that substantially different findings would be produced by this extraction method. Second, the alpha factoring extraction method was employed. This method was chosen since scale construction is the main goal of this analysis and this extraction method maximizes the internal consistency of the components. Results indicated that the factor structure resulting from both extraction methods were essentially identical to that derived from principal factors analysis in terms of the number of factors extracted, factor loadings and the proportion of variance accounted for by the factor structure. Since the factor structure 
does not fundamentally change depending on the method of extraction, the component structure generated can be considered quite stable.

As can be seen in Table A in Appendix D, Factor 1 represents elements of both the need for change and personal accountability. This is likely a result of the conceptual similarities of these competencies. 'Socially unaware' did not load onto the personal accountability factor as expected. 'Low frustration tolerance', on the other hand, clustered on this first factor, although it also loaded with inhibitory control items as expected. Thus, Factor 1 was identified as personal accountability and need for change. Factor 2 contains items related to knowledge acquisition, particularly literacy and numeracy problems. This factor will be labelled literacy and numeracy. The items in Factor 4 represent an additional aspect of knowledge acquisition, namely problems that may interfere with learning; thus, this factor will be designated knowledge acquisition ability. Factors 3, 5 and 6 were less cohesive with items that mostly represented cognitive flexibility and inhibitory control. This may be due to the overly broad definitions of the indicators. For example, 'copes with stress poorly' is considered present when the offender becomes aggressive, turns to substance abuse, withdraws, etc. Similarly, 'low frustration tolerance' is considered present when the offender has difficulty dealing appropriately with daily stresses. These definitions allow room for subjective interpretation and may account for the somewhat haphazard factor structure for these two competencies. Factor 3 was named cognitive flexibility as the items correspond mostly to information processing deficits. The items of Factor 5 indicate the ability to generate and evaluate solutions and an awareness of social situations; this factor was termed cognitive awareness. Factor 6 best represents the impulsivity and risk taking 
items for inhibitory control. 'Poor oral' did not load significantly onto any of the factors; therefore, this item was removed from further analyses to create a more parsimonious 28item version of the model.

While the pattern matrix in Table A in Appendix D contains information about the unique contribution of a variable to a factor, the structure matrix in Table B in Appendix D does not ignore shared variance. An examination of the structure matrix suggests most variables load highly onto more than one factor. This is not surprising given the strong inter-correlations among the factors displayed in Table 5. Factors 2 and 4 both represent aspects of knowledge acquisition and have a particularly large correlation. Likewise, Factors 3 and 5 both capture features of cognitive flexibility and have a medium correlation.

Table 5. Inter-correlations among Identified Factors

\begin{tabular}{cccccc}
\hline Factor & 2 & 3 & 4 & 5 & 6 \\
\hline 1 & .16 & .52 & .20 & .56 & .44 \\
2 & & .20 & .64 & .19 & .04 \\
3 & & .30 & .43 & .33 \\
4 & & & .24 & .10 \\
5 & & & & & .28 \\
\hline
\end{tabular}

Finally, Table 6 shows the internal consistency of the identified factors using Cronbach's alpha. Factors 1, 2, 3 and 4 demonstrate acceptable internal consistency while Factors 5 and 6 demonstrate poor internal consistency. This may be a result of the limited number of items that contribute to these factors. Internal consistency would not be improved by deleting any of the items on any of the factors. The mean inter- 
correlations ranged from .28 to .46 for each of the factor score subscales. Inter-item correlations are displayed in Appendix E.

Table 6. Internal Consistency and Descriptive Statistics for Identified Factors in Development Sample

\begin{tabular}{lcccc}
\hline Factors & $\alpha$ & $M$ & $S D$ & $\begin{array}{c}\text { \# of } \\
\text { items }\end{array}$ \\
\hline $\begin{array}{l}\text { F1. Personal accountability and need for } \\
\text { change }\end{array}$ & .79 & 5.21 & 2.76 & 10 \\
F2. Literacy and numeracy & .72 & .76 & 1.14 & 4 \\
F3. Cognitive flexibility & .75 & 3.82 & 1.88 & 6 \\
F4. Knowledge acquisition ability & .77 & .87 & 1.26 & 4 \\
F5. Cognitive awareness & .66 & 2.35 & 1.57 & 5 \\
F6. Inhibitory control & .54 & 1.72 & 1.00 & 3 \\
\hline
\end{tabular}

Factor analysis in cross-validation sample. The next stage of scale development involved replicating the factor structure in the cross-validation sample. ${ }^{8}$ A principal factors analysis with promax rotation $(\kappa=4)$ was performed on the remaining 28 variables (i.e., after removing 'problems with writing' and 'poor oral') in the crossvalidation sample. The sample size of 3,414 was adequate to generate reliable factors that can be replicated. Kaiser-Meyer Olkin's measure of sampling adequacy (KMO = .89) suggests the present data are appropriate for conducting factor analysis. A Pearson correlation matrix was examined to determine the factorability of the data and to check for singularity and multicollinearity. The matrix consisting of 28 cross-correlated items yielded 406 correlations. Of these, 136 were .30 or greater. The determinant was .001 , indicating that multicollinearity is not present within the data. Finally, Bartlett's test of

\footnotetext{
${ }^{8}$ Exploratory factor analysis was also used in the cross-validation sample as opposed to confirmatory factor analysis, since two variables were removed from the analysis.
} 
sphericity was significant $\left(\chi^{2}(\mathrm{df}=378)=24,568.92, p<.001\right)$ suggesting that factor analysis would be worthwhile.

As can be seen in Appendix F, the factor structure which emerged in the development sample was replicated in the cross-validation sample. Almost all items loaded onto same factors as previously: personal accountability and need for change, literacy and numeracy, cognitive flexibility, knowledge acquisition ability, cognitive awareness, and inhibitory control. Again, decisions regarding the number of factors to retain were made using Kaiser's criterion, the scree plot and parallel analysis. The six identified factors explain $38.7 \%$ of the variance. There were a few minor differences in the factor loadings, hovering around the loading criterion of .30. 'Non-reflective' did not cluster on personal accountability and need for change, while 'unable to generate choices' did not cluster on cognitive flexibility. 'Unable to recognize problem areas' clustered on personal accountability and need for change, and 'learning difficulty' clustered on literacy and numeracy. Table 7 shows the internal consistency of the identified factors using Cronbach's alpha. The mean inter-correlations ranged from .27 to .47 for each of the factor score subscales (refer to Appendix $G$ for the complete reliability analyses). The reliability of the factors demonstrated in the development sample was replicated in the cross-validation sample. Again, less confidence can be placed on the cognitive awareness and inhibitory control factors due to low reliability. 
Table 7. Internal Consistency and Descriptive Statistics for Identified Factors in Crossvalidation Sample

\begin{tabular}{lcccc}
\hline Factors & $\alpha$ & $M$ & $S D$ & $\begin{array}{c}\text { \# of } \\
\text { items }\end{array}$ \\
\hline $\begin{array}{l}\text { F1. Personal accountability and need for } \\
\text { change }\end{array}$ & .79 & 5.25 & 2.76 & 10 \\
F2. Literacy and numeracy & .79 & 1.12 & 1.50 & 5 \\
F3. Cognitive flexibility & .74 & 3.28 & 1.62 & 5 \\
F4. Knowledge acquisition ability & .78 & .91 & 1.29 & 4 \\
F5. Cognitive awareness & .67 & 2.42 & 1.56 & 5 \\
F6. Inhibitory control & .52 & 1.74 & .98 & 3 \\
\hline
\end{tabular}

Factor scores. Factor scores were created by employing regression. The factor scores provide a single indicator on each of the six factors for every participant; these scores are calculated from participants' responses on the items that comprise the factor. The regression method uses factor score coefficients as weights and takes the initial correlations between variables into account to stabilize differences in units of measurement and variable variances (Field, 2005). The factor scores were calculated using the entire sample (i.e., cases derived from both the development and crossvalidation sample). Any differences between factor loadings for the development and cross-validation samples were due to using a strict .30 loading criterion, (e.g., 'learning difficulty' had a factor loading of .40 on literacy and numeracy in the cross-validation sample, but only .26 in the development sample). Since the factor score coefficients rather than the loading criteria were used for calculating factor scores, differences between the samples do not affect these calculations. For ease of interpretation, all factor 
scores were multiplied by -1 . As a result, higher factor scores correspond to a greater proficiency in the competency (e.g., greater inhibitory control).

\section{Generic Program Performance Measure}

Given its novelty, the psychometric properties of the GPPM were also evaluated. The high internal reliability demonstrated by this measure in past studies was replicated in the current sample. Cronbach's alpha $(\alpha=.96)$ and item-total correlations $(M$ interitem $r=.58$ ) were both acceptable for the overall GPPM post-test score. Correlations indicated that the internal reliability of the scale would increase only minimally if the first item (punctuality at sessions) was removed. The analyses for the current study were performed using all items, as Cronbach's alpha would only increase by .004 if this item were deleted. Reliability analyses were also conducted individually on each subscale of the GPPM, with the Performance subscale demonstrating the highest Cronbach's alpha $(\alpha=.95)$, and the Responsivity and Effort subscales demonstrating Cronbach's alpha values of .85 and .82 respectively. The inter-correlations between scales ranged from .71 to .88 (see Appendix $\mathrm{H}$ for a full summary of the results of the GPPM reliability analyses including item-total correlations).

\section{Partial Correlations}

Correlations among the competency factor scores and intake variables are displayed in Table 8. Due to the low internal consistency of the composite competency scales, the focus will be restricted to the competency factor scores. Competency scores are related to intake assessment measures, indicating offenders high on competencies tend to also show higher functioning at intake. For the most part, these correlations are small to medium in magnitude. The competency scores are positively correlated with one 
another as well as reintegration potential and the SIR-Proxy. This indicates that offenders scoring high in the competencies have a higher likelihood of reintegrating safely into the community following release and a lower probability of reoffending. The competency scores are also negatively correlated with criminogenic need, static risk, institutional adjustment and security risk. Thus, offenders scoring high on the competencies have fewer or less severe criminogenic needs and require a lower level of intervention based on their static risk factors. These offenders are also a lower risk to staff, other inmates and self due to institutional adjustment problems and represent a lower risk to the public in the event of an escape. 


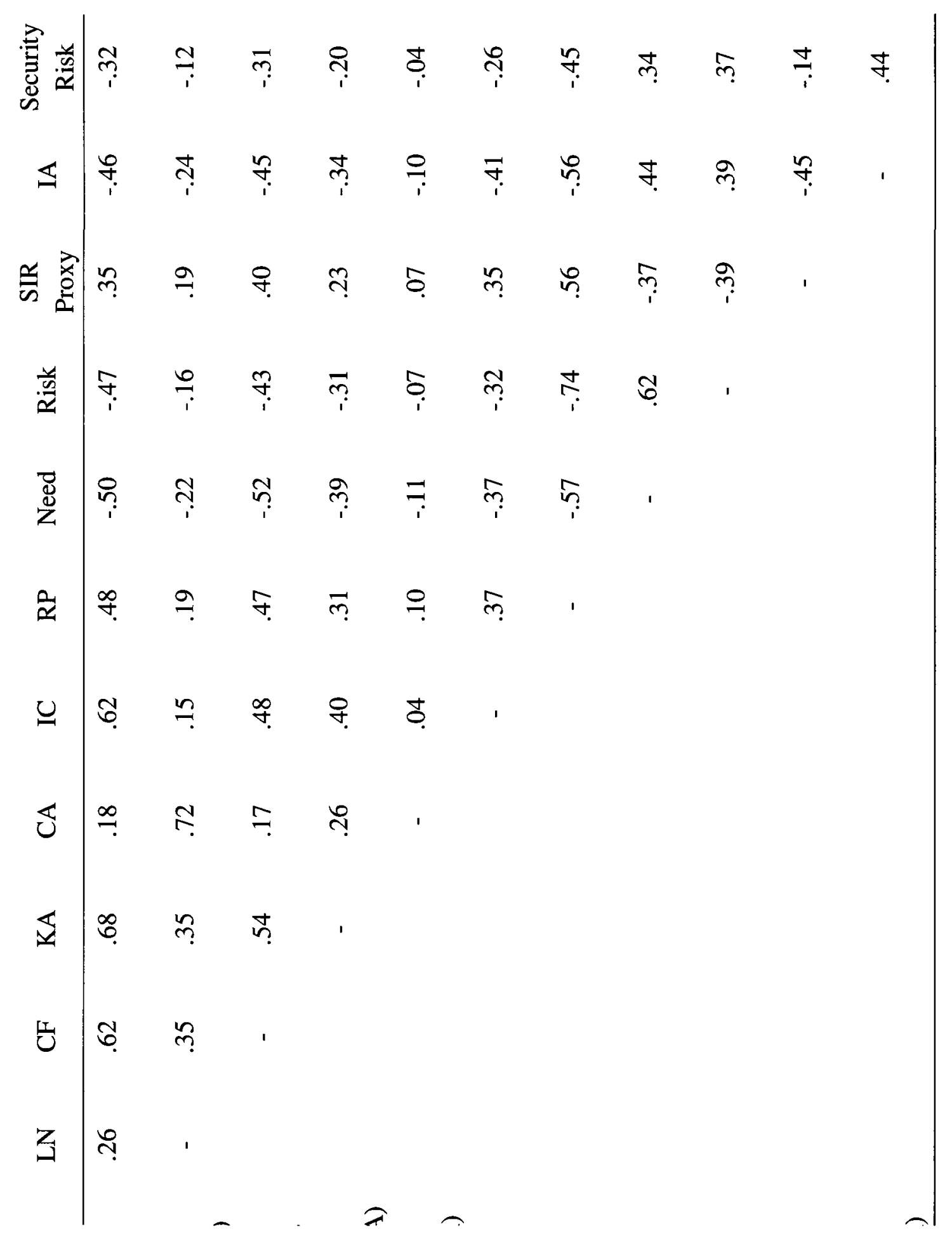


Inter-correlations between the independent variables and dependent variables were used to initially evaluate the hypotheses that competencies predict both program performance and behavioural change. As can be seen in Table 9, personal accountability and need for change, literacy and numeracy, cognitive flexibility, knowledge acquisition ability, cognitive awareness and inhibitory control are positively correlated to both program performance and behavioural change. While significant, it should also be noted that the correlations are small in magnitude. Also, correlations between competency scores and program performance are larger than the correlations between competency scores and behavioural change. This is as expected given that the behavioural change scores take into account an offender's pre-treatment level of program engagement. Thus, if an offender has a high competency level at the start of treatment and scores high at both the pre-test and post-test stages, his behaviour change score will be small. Low observed correlations between competency measures and behavioural change suggest that fewer offenders start treatment with low competency levels but succeed in achieving large behavioural changes.

Global intake variables were also correlated with the indices of offender change. While few were significantly correlated to behavioural change, all were correlated to program performance, although to a lesser degree than the competency scores. Higher program performance was related to higher reintegration potential and lower risk, static risk, need, institutional adjustment and security risk. Thus, it appears that the specific competency scores have a stronger relationship to program performance and behavioural change than global intake assessment variables. The sole exception is the institutional adjustment score which has comparable correlations to both outcome measures. 
Table 9. Correlations between Competency Scores, Intake Assessment Variables, Behavioural Change and Program Performance

\begin{tabular}{lcc}
\hline Variables & $\begin{array}{c}\text { Program } \\
\text { Performance } \\
\text { (GPPM post- } \\
\text { score) }\end{array}$ & $\begin{array}{c}\text { Behavioural } \\
\text { Change } \\
\text { (GPPM pre-post } \\
\text { difference) }\end{array}$ \\
\hline Competency Scores & $.19^{* * *}$ & $.12^{* * *}$ \\
Personal accountability \& need for change & $.20^{* * *}$ & $.13^{* * *}$ \\
Literacy and numeracy & $.11^{* * *}$ & $.09^{* * *}$ \\
Cognitive flexibility & $.19^{* * *}$ & $.13^{* * *}$ \\
Knowledge acquisition ability & $.19^{* * *}$ & $.12^{* * *}$ \\
Cognitive awareness & $.07^{* *}$ & $.05^{*}$ \\
Inhibitory control & & $.05^{*}$ \\
Intake Assessment Variables & $.07^{* * *}$ & -.02 \\
SIR-Proxy & $-.07^{* * *}$ & $-.04^{*}$ \\
Static risk & $-.10^{* * *}$ & .03 \\
Criminogenic need & $.08^{* * *}$ & $-.13^{* * *}$ \\
Reintegration potential & $-.04^{* *}$ & \\
CRS: Institutional adjustment & & -02 \\
CRS: Security risk & & \\
\hline
\end{tabular}

${ }^{*} p<.05 ; * * p<.01 ; * * * p<.001$.

In addition, the relationship between competency level and the outcome measures were examined while controlling for global intake assessment variables. These analyses were performed to determine if the competency model can account for differences in program performance and behavioural change while removing any variance that is shared 
with global intake assessment scores. First, simple inter-correlations were re-calculated with risk to re-offend entered as a covariate, as measured by the SIR-Proxy (displayed in Table 10). For the most part, neither the significance nor the magnitude of the correlations changed while controlling for risk. The sole exception was inhibitory control, which was no longer significantly correlated with behavioural change. The relationship between inhibitory control and behavioural change was also attenuated by controlling for criminogenic need (Table 11), reintegration potential (Table 12) and institutional adjustment score (Table 13). However, the relationship did not change with static risk (Table 14) nor security risk score (Table 15) entered as covariates. These findings indicate that the variance shared between inhibitory control and behavioural change is also accounted for within the measures of risk, need, reintegration potential and institutional adjustment. Furthermore, the relationship between inhibitory control and program performance was attenuated when reintegration potential and institutional adjustment score were partialled out. The relationship between program performance and the remaining competencies was not affected by controlling for intake variables. These findings suggest that overall the competency model may explain more variance in program performance and behavioural change than existing global intake variables. Multiple regression analyses were employed to ascertain this conclusion. 
Table 10. Correlations between Competency Scores, Behavioural Change, and Program Performance while controlling for Risk to Re-offend

\begin{tabular}{lcc}
\hline Competency Score & Program & Behavioural \\
& Performance & Change \\
\hline Personal accountability \& need for change & $.18^{* * *}$ & $.11^{* * *}$ \\
Literacy and numeracy & $.19^{* * *}$ & $.12^{* * *}$ \\
Cognitive flexibility & $.10^{* * *}$ & $.08^{* * *}$ \\
Knowledge acquisition ability & $.17^{* * *}$ & $.13^{* * *}$ \\
Cognitive awareness & $.18^{* * *}$ & $.12^{* * *}$ \\
Inhibitory control & .04 & .03 \\
\hline
\end{tabular}
$* * * p<.001$

Table 11. Correlations between Competency Scores, Behavioural Change, and Program Performance while controlling for Need

Competency Score

Program Behavioural

Performance Change

\begin{tabular}{lcc}
\hline Personal accountability \& need for change & $.17^{* * *}$ & $.12^{* * *}$ \\
Literacy and numeracy & $.19^{* * *}$ & $.13^{* * *}$ \\
Cognitive flexibility & $.09^{* * *}$ & $.08^{* * *}$ \\
Knowledge acquisition ability & $.17^{* * *}$ & $.13^{* * *}$ \\
Cognitive awareness & $.18^{* * *}$ & $.12^{* * *}$ \\
Inhibitory control & $.05^{*}$ & .04
\end{tabular}

$* p<.05 ; * * * p<.001$. 
Table 12. Correlations between Competency Scores, Behavioural Change, and Program Performance while controlling for Reintegration Potential

Competency Score

Program

Performance

Personal accountability \& need for change

Literacy and numeracy

Cognitive flexibility

Knowledge acquisition ability

Cognitive awareness

Inhibitory control

$.17^{* * *}$

$.18^{* * *}$

.04
Behavioural

Change

$\begin{array}{ll}.17^{* * *} & .12^{* * *} \\ .19^{* * *} & .13^{* * *} \\ .09^{* * *} & .08^{* * *}\end{array}$

$.13^{* * *}$

$.12^{* * *}$

$* * * p<.001$.

Table 13. Correlations between Competency Scores, Behavioural Change, and Program Performance while controlling for Institutional Adjustment Score

Competency Score

Program Behavioural

Performance Change

Personal accountability \& need for change

$.15^{* * *}$

$.10^{* * *}$

Literacy and numeracy

$.18^{* * *}$

$.12^{* * *}$

Cognitive flexibility

$.07^{* * *}$

$.06^{* * *}$

Knowledge acquisition ability

$.15^{* * *}$

$.12^{* * *}$

Cognitive awareness

$.18^{* * *}$

$.12^{* * *}$

Inhibitory control

.02

.02 
Table 14. Correlations between Competency Scores, Behavioural Change, and Program Performance while controlling for Static Risk

\begin{tabular}{lcc}
\hline Competency Score & Program & Behavioural \\
& Performance & Change \\
\hline Personal accountability \& need for change & $.18^{* * *}$ & $.13^{* * *}$ \\
Literacy and numeracy & $.20^{* * *}$ & $.13^{* * *}$ \\
Cognitive flexibility & $.10^{* * *}$ & $.09^{* * *}$ \\
Knowledge acquisition ability & $.18^{* * *}$ & $.14^{* * *}$ \\
Cognitive awareness & $.18^{* * *}$ & $.12^{* * *}$ \\
Inhibitory control & $.06^{*}$ & $.05^{*}$ \\
\hline
\end{tabular}

$* p<.05 ; * * * p<.001$

Table 15. Correlations between Competency Scores, Behavioural Change, and Program Performance while controlling for Security Risk Score

Competency Score

Program Behavioural

Performance Change

Personal accountability \& need for change

$.19^{* * *} \quad .12^{* * *}$

Literacy and numeracy

$.20^{* * *}$

Cognitive flexibility

$.11^{* * *}$

$.09^{* * *}$

Knowledge acquisition ability

$.18^{* * *}$

$.13^{* * *}$

Cognitive awareness

$.19^{* * *}$

$.12^{* * *}$

Inhibitory control

$.06^{* * *}$

$.05^{*}$

${ }^{*} p<.05 ;{ }^{* * *} p<.001$ 


\section{Multiple Regression Analysis}

A series of linear regression analyses were performed to determine whether the competencies accurately predict program performance and behavioural change. First, the six competency factor scores were entered as independent variables into the regression and program performance was entered as a dependent variable. The resulting model and their parameters are displayed in Table 16. The combination of competency scores accounted for a significant proportion of variance in program performance; $F(6,2028)=$ $26.68, p<.001$. The $R^{2}$ value is .07 , indicating that $7 \%$ of variance in program performance is accounted for by the model. With the exception of cognitive flexibility, all of the competency scores were significant predictors. Personal accountability and need for change and literacy and numeracy were the two competency scores which contributed most to the prediction of program performance.

Table 16. Summary of Regression Analysis for Variables Predicting Program Performance $(N=2034)$

\begin{tabular}{lccc}
\hline \multicolumn{1}{c}{ Variable } & $B$ & $S E B$ & $\beta$ \\
\hline Personal accountability \& need for change & .15 & .03 & $.18^{* * *}$ \\
Literacy and numeracy & .10 & .03 & $.12^{* * *}$ \\
Cognitive flexibility & -.04 & .03 & -.04 \\
Knowledge acquisition ability & .05 & .03 & $.06 *$ \\
Cognitive awareness & .07 & .03 & $.08^{*}$ \\
Inhibitory control & -.05 & .03 & $-.06^{*}$ \\
\hline
\end{tabular}

Note. $R^{2}=.07(p<.001)$.

$* p<.05 ; * * * p<.001$. 
As previously shown in Table 9, institutional adjustment, criminogenic need and reintegration potential were the intake assessment variables with the highest correlations with program performance. Thus, a hierarchal linear regression was performed in which these three global intake variables were entered into the first block and the five competency scores were entered into the second block. Cognitive flexibility was not included in the regression as it did not reach significance in the preceding analysis. This analysis tests the hypothesis that the core competencies account for variance in program performance above and beyond what is accounted for by existing intake variables. The resulting model and their parameters are displayed in Table 17. Institutional adjustment, need and reintegration potential accounted for $2 \%$ of the variance in program performance. With the inclusion of both global intake and competency measures, the second model is shown to account for $8 \%$ of variance. The following competencies were found to be significant predictors of program performance: personal accountability and need for change, literacy and numeracy, cognitive awareness and inhibitory control. 
Table 17. Summary of Hierarchal Regression Analysis for Variables Predicting Program Performance $(N=2035)$

Variable

Step 1

CRS: Institutional adjustment

Criminogenic need

Reintegration potential

Step 2

CRS: Institutional adjustment

Criminogenic need

Reintegration potential

Personal accountability \& need for change

Literacy and numeracy

Knowledge acquisition ability

Cognitive awareness

Inhibitory control
$B$

$S E B$
$-.12 * * *$

$-.00$

.00

.03

$-.03$

$-.04$

.02

.01

$\begin{array}{lll}.01 & .02 & .01\end{array}$

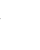


$1 \%$ of the variance in behavioural change. With the addition of the competency measures, the second model is shown to account for $3 \%$ of variance. The following competencies were found to be significant predictors of program performance: personal accountability and need for change and knowledge acquisition ability.

Table 18. Summary of Hierarchal Regression Analysis for Variables Predicting Behavioural Change $(N=2037)$

$\begin{array}{llll}\text { Variable } & B & S E B & \beta\end{array}$

Step 1

CRS: Institutional adjustment $-.03$

.01 $-.07 * *$

SIR-Proxy

.02

.05

Criminogenic need

.25

.42

.02

Step 2

CRS: Institutional adjustment $-.02$

SIR-Proxy

$-.01$

.05

Criminogenic need

Personal accountability \& need for change

.99

Literacy and numeracy

Cognitive flexibility

Knowledge acquisition ability

.80

Cognitive awareness

Inhibitory control

$-.49$

Note. $R^{2}=.01$ for Step $1(p<.01) ; \Delta R^{2}=.02$ for Step $2(p<.001)$.

${ }^{*} p<.05 ; * * p<.01$. 


\section{Program Category}

Lastly, separate linear regressions were performed for each program category to determine if the relationship between competency level and program performance is altered depending on program category. The six competency scores were entered as the independent variables and program performance score was entered as the dependent variable. Six regressions were performed for the following program categories: violent offender, sex offender, substance abuse, family violence, living skills and Counterpoint. With the exception of the Counterpoint program, the overall model was significant in all program categories. However, the competency scores found to be significant predictors of program performance differed by program category. Each program will be discussed in turn.

Violent offender programs. The competency scores account for a significant proportion of variance in violent offender program performance; $F(6,156)=2.26, p=$ .04. The proportion of variance accounted for by the model is $8 \%$, which is comparable to the $R^{2}$ value for all program categories. As can be seen in Table 19, literacy and numeracy contributed most to the prediction of program performance and was the only significant predictor in the model. This suggests knowledge acquisition and application may be particularly important for violent offenders, while the other competencies contribute less to treatment program performance. 
Table 19. Summary of Regression Analysis for Variables Predicting Program Performance in Violent Offender Programs $(N=163)$

\begin{tabular}{lccc}
\hline \multicolumn{1}{c}{ Variable } & $B$ & $S E B$ & $\beta$ \\
\hline Personal accountability \& need for change & .06 & .10 & .07 \\
Literacy and numeracy & .21 & .10 & $.26^{*}$ \\
Cognitive flexibility & .00 & .10 & .00 \\
Knowledge acquisition ability & .08 & .10 & .09 \\
Cognitive awareness & -.12 & .11 & -.12 \\
Inhibitory control & .03 & .09 & .03 \\
\hline
\end{tabular}

Note. $R^{2}=.08(p<.05)$.

$* p<.05$.

Sex offender programs. The relationship between offender competencies and program performance was most pronounced in sex offender programs, as shown in Table 20. The competency scores account for a significant proportion of variance in program performance; $F(6,104)=5.35, p<.001$. Approximately $24 \%$ of the variance is explained by the model, which is considerably higher than the $R^{2}$ value for all program categories. Similar to the findings for all program categories, personal accountability and need for change and literacy and numeracy contributed most to the prediction of program performance. 
Table 20. Summary of Regression Analysis for Variables Predicting Program Performance in Sex Offender Programs $(N=111)$

\begin{tabular}{lccc}
\hline \multicolumn{1}{c}{ Variable } & $B$ & $S E B$ & $\beta$ \\
\hline Personal accountability \& need for change & .25 & .12 & $.33^{*}$ \\
Literacy and numeracy & .33 & .11 & $.42^{* *}$ \\
Cognitive flexibility & -.18 & .10 & -.22 \\
Knowledge acquisition ability & .12 & .10 & .14 \\
Cognitive awareness & -.03 & .10 & -.04 \\
Inhibitory control & -.15 & .10 & -.18 \\
\hline
\end{tabular}

Note. $R^{2}=.24(p<.001)$.

${ }^{*} p<.05 ; * * p<.01$.

Substance abuse programs. The competency scores also account for a significant proportion of variance in substance abuse program performance; $F(6,1167)=16.75, p<$ .001 . As can be seen in Table 21 , cognitive awareness significantly contributed to the prediction of program performance, even more so than literacy and numeracy. Although cognitive awareness was found to be a significant predictor of program performance when all treatment categories were examined together, the only program category in which it emerged as a significant predictor was substance abuse programs. Personal accountability and need for change contributed the most to the prediction of program performance. The proportion of variance accounted for by the model is $8 \%$, which is comparable to the $R^{2}$ value for all program categories. 
Table 21. Summary of Regression Analysis for Variables Predicting Program Performance in Substance Abuse Programs $(N=1174)$

\begin{tabular}{lccc}
\hline \multicolumn{1}{c}{ Variable } & $B$ & $S E B$ & $\beta$ \\
\hline Personal accountability \& need for change & .18 & .04 & $.21^{* * *}$ \\
Literacy and numeracy & .06 & .03 & $.08^{* *}$ \\
Cognitive flexibility & -.09 & .03 & -.10 \\
Knowledge acquisition ability & .05 & .03 & .06 \\
Cognitive awareness & .10 & .03 & $.12^{* *}$ \\
Inhibitory control & -.03 & .03 & -.04 \\
\hline
\end{tabular}

Note. $R^{2}=.08(p<.001)$.

$* * p<.01 ; * * *<<.001$.

Family violence programs. The combination of competency scores account for a significant proportion of variance in family violence programs; $F(6,132)=2.85, p=.01$. However, none of the competency scores in Table 22 reached significance as predictors of program performance. This may be a result the competency scores being correlated, and thus explaining the same portion of the variation in program performance. The proportion of variance accounted for by the model is $12 \%$, which is higher than the $R^{2}$ value for all program categories. 
Table 22. Summary of Regression Analysis for Variables Predicting Program Performance in Family Violence Programs $(N=139)$

\begin{tabular}{lccc}
\hline \multicolumn{1}{c}{ Variable } & $B$ & $S E B$ & $\beta$ \\
\hline Personal accountability \& need for change & .15 & .10 & .19 \\
Literacy and numeracy & .13 & .11 & .16 \\
Cognitive flexibility & -.10 & .13 & -.08 \\
Knowledge acquisition ability & .14 & .10 & .16 \\
Cognitive awareness & -.08 & .10 & -.10 \\
Inhibitory control & .02 & .09 & .02 \\
\hline
\end{tabular}

Note. $R^{2}=.12(p<.05)$.

Living skills programs. A significant proportion of variance in living skills program performance was accounted for by the competency scores; $F(6,191)=2.94, p=$ .01 . Personal accountability and need for change emerged as particularly predictive of program performance, as shown in Table 23. The proportion of variance accounted for by the competency scores (9\%) was comparable to all program categories. 
Table 23. Summary of Regression Analysis for Variables Predicting Program

Performance in Living Skills Programs $(N=198)$

\begin{tabular}{lccc}
\hline \multicolumn{1}{c}{ Variable } & $B$ & $S E B$ & $\beta$ \\
\hline Personal accountability \& need for change & .17 & .09 & $.20^{*}$ \\
Literacy and numeracy & .06 & .08 & .08 \\
Cognitive flexibility & -.02 & .10 & -.02 \\
Knowledge acquisition ability & .02 & .08 & .02 \\
Cognitive awareness & .12 & .08 & .14 \\
Inhibitory control & -.06 & .08 & -.06 \\
\hline
\end{tabular}

Note. $R^{2}=.09(p<.01)$.

$* p<.05$.

Counterpoint programs. Finally, the model did not reach significance for

Counterpoint programs; $F(6,243)=1.83, p=.10$. Likewise, none of the competencies

displayed in Table 24 emerged as significant predictors of program performance.

Table 24. Summary of Regression Analysis for Variables Predicting Program

Performance in Counterpoint Programs $(N=250)$

\begin{tabular}{lccc}
\hline \multicolumn{1}{c}{ Variable } & $B$ & $S E B$ & $\beta$ \\
\hline Personal accountability \& need for change & .06 & .09 & .07 \\
Literacy and numeracy & .09 & .08 & .08 \\
Cognitive flexibility & .12 & .07 & .15 \\
Knowledge acquisition ability & .01 & .08 & .01 \\
Cognitive awareness & .04 & .08 & .04 \\
Inhibitory control & -.14 & .09 & -.14 \\
\hline
\end{tabular}

Note. $R^{2}=.05(p=10)$. 


\section{Group Differences}

Due to the influence of a large sample size in finding significant results, a decision rule was established in the calculation of effect sizes. In the analyses of group differences, only small or larger effect sizes (Cohen's $d \geq 0.20$ ) were considered indicative of a meaningful difference. Similarly sized effects are commonly found and considered meaningful in Forensic Psychology, and offender populations in particular (Nunes \& Cortoni, 2006). For instance, Gendreau, Little, and Goggin (1996) found small to medium effect sizes in their meta-analysis for many predictors of criminal recidivism.

\section{Comparing Low and High Competency Scores}

Hypotheses were further tested by dichotomously splitting the competency variables along their medians. Two groups were created for each variable, one group comprised of those who scored above the median and the other group comprised of those who scored below the median. These groups were compared on program performance and behavioural change using independent samples t-tests. For each dependent variable, family-wise error rate was maintained at $\alpha=.05$ with Tukey's HSD test (i.e., $\alpha=.008$ for each of the six tests).

As demonstrated in Table 25, greater program performance was observed in those who scored high versus low on the following competency scores: personal accountability and need for change, learning ability, cognitive flexibility, knowledge acquisition and cognitive awareness. An examination of the effect sizes indicates a meaningful difference between low and high competency offenders on all of the competency scores with the exception of cognitive flexibility and inhibitory control. Those who scored high 
on these competencies showed no meaningful differences in program performance scores compared to those who scored low.

Table 25. Differences in Program Performance Scores for High versus Low Scores on Competencies

\section{Mean Score on}

Competency

\begin{tabular}{lccccc}
\cline { 2 - 4 } Competency Score & Low & High & $t$ & df & Cohen's $d$ \\
\hline Personal accountability & $.54(.73)$ & $.79(.65)$ & $8.13 * * *$ & 2033 & .36 \\
$\quad \&$ need for change & & & & & \\
Literacy and numeracy & $.54(.72)$ & $.78(.68)$ & $7.99 * * *$ & 2033 & .34 \\
Cognitive flexibility & $.60(.73)$ & $.74(.67)$ & $4.54 * * *$ & 2033 & .12 \\
Knowledge acquisition & $.55(.75)$ & $.77(.65)$ & $7.12 * * *$ & 2033 & .31 \\
Cognitive awareness & $.57(.71)$ & $.75(.69)$ & $5.79 * * *$ & 2033 & .26 \\
Inhibitory control & $.63(.73)$ & $.70(.68)$ & $2.02 *$ & 2033 & .10 \\
\hline
\end{tabular}

Note. Standard deviations appear in parentheses.

${ }^{*} p<.05 ; * * * p<.001$.

Similar findings were observed using behavioural change as the dependent variable. As shown in Table 26, greater behavioural change was observed in those who scored high versus low on the following competency scores: personal accountability and need for change, learning ability, cognitive flexibility, knowledge acquisition and cognitive awareness. However, the effects are small but meaningful as indicated by the effect sizes. Those above the median on inhibitory control showed no significant differences from those who scored below the median on behavioural change. 
Table 26. Differences in Behavioural Change Scores for High versus Low Scores on Competencies

\begin{tabular}{|c|c|c|c|c|c|}
\hline \multirow[b]{2}{*}{ Competency } & \multicolumn{2}{|c|}{$\begin{array}{l}\text { Mean Score on } \\
\text { Competency }\end{array}$} & \multirow[b]{2}{*}{$t$} & \multirow[b]{2}{*}{$d f$} & \multirow[b]{2}{*}{ Cohen's $d$} \\
\hline & Low & High & & & \\
\hline Personal accountability & 14.23 & 16.51 & $5.07 * * *$ & 2035 & .23 \\
\hline$\&$ need for change & $(10.63)$ & $(9.53)$ & & & \\
\hline Literacy and numeracy & $\begin{array}{c}14.19 \\
(10.37)\end{array}$ & $\begin{array}{l}16.41 \\
(9.88)\end{array}$ & $4.95^{* * *}$ & 2035 & .22 \\
\hline Cognitive flexibility & $\begin{array}{c}14.54 \\
(10.41)\end{array}$ & $\begin{array}{l}16.28 \\
(9.81)\end{array}$ & $4.54 * * *$ & 2035 & .17 \\
\hline Knowledge acquisition & $\begin{array}{c}14.19 \\
(10.50)\end{array}$ & $\begin{array}{l}16.46 \\
(9.72)\end{array}$ & $5.07 * * *$ & 2035 & .22 \\
\hline Cognitive awareness & $\begin{array}{c}14.42 \\
(10.34)\end{array}$ & $\begin{array}{l}16.14 \\
(9.96)\end{array}$ & $3.81 * * *$ & 2035 & .17 \\
\hline Inhibitory control & $\begin{array}{c}15.03 \\
(10.60)\end{array}$ & $\begin{array}{l}15.68 \\
(9.64)\end{array}$ & 1.44 & 2035 & .06 \\
\hline
\end{tabular}

Note. Standard deviations appear in parentheses.

$* * * p<.001$

A Comparison of Treatment Completers and Non-completers

Offender participants did not complete programs as a result of dropout/expulsion ( $n=186)$, personal circumstances $(n=108)$ or administrative reasons $(n=40)$. Due to the unequal sample size between treatment completers $(n=2,024)$ and non-completers $(n$ =334), each of the analyses were first performed comparing treatment completers and 
non-completers as a single subgroup. If significant differences were found, a second comparison was performed separating non-completers by reason for non-completion. Offenders who did not complete due to personal circumstances or administrative reasons were grouped together due to the small sample size of the administrative reason noncompletion group and because both did not complete due to circumstances beyond the control of the offender.

Competency factor scores. A Multivariate Analysis of Variance (MANOVA) was performed to compare treatment completers and non-completers on the competency scores. The multivariate result was significant for treatment completion, Hotelling's $T^{2}=$ $.034, F(6,2351)=14.78, p<.001$, indicating a difference in the level of competency between treatment completers and non-completers. Program completion status accounted for only $4 \%$ of the variance in the composite competency score, partial $\eta^{2}=.04$. As can be seen in Table 27, the univariate $F$ tests showed there was a significant difference between treatment completers and non-completers on the competency scores for personal accountability and need for change, literacy and numeracy, cognitive flexibility, knowledge acquisition ability, cognitive awareness and inhibitory control. Treatment completers scored significantly higher than non-completers on all six competency scores. The effect sizes ranged from small to medium. 
Table 27. Significant Univariate Effects for Treatment Program Status for Competency Factor Scores (at $p<.001$ level)

\begin{tabular}{|c|c|c|c|c|c|c|}
\hline $\begin{array}{l}\text { Dependent } \\
\text { variable }\end{array}$ & $d f$ & $d f$ error & $t$ & $\begin{array}{c}\text { Program } \\
\text { status }\end{array}$ & $M(S D)$ & $\begin{array}{c}\text { Cohen's } \\
d\end{array}$ \\
\hline $\begin{array}{l}\text { Personal } \\
\text { accountability } \\
\text { \& need for } \\
\text { change }\end{array}$ & 1 & 2356 & -7.39 & $\begin{array}{l}\text { Complete } \\
\text { Non-complete }\end{array}$ & $\begin{array}{l}-.01(.84) \\
-.38(.88)\end{array}$ & .43 \\
\hline $\begin{array}{l}\text { Literacy and } \\
\text { numeracy }\end{array}$ & 1 & 2356 & -6.84 & $\begin{array}{l}\text { Complete } \\
\text { Non-complete }\end{array}$ & $\begin{array}{c}.05(.85) \\
-.30(.98)\end{array}$ & .38 \\
\hline $\begin{array}{l}\text { Cognitive } \\
\text { flexibility }\end{array}$ & 1 & 2356 & -4.70 & $\begin{array}{l}\text { Complete } \\
\text { Non-complete }\end{array}$ & $\begin{array}{l}-.13(.79) \\
-.35(.78)\end{array}$ & .28 \\
\hline $\begin{array}{l}\text { Knowledge } \\
\text { acquisition }\end{array}$ & 1 & 2356 & -6.07 & $\begin{array}{l}\text { Complete } \\
\text { Non-complete }\end{array}$ & $\begin{array}{l}.00(.82) \\
-.30(.85)\end{array}$ & .36 \\
\hline $\begin{array}{l}\text { Cognitive } \\
\text { awareness }\end{array}$ & 1 & 2356 & -4.05 & $\begin{array}{l}\text { Complete } \\
\text { Non-complete }\end{array}$ & $\begin{array}{c}.07(.83) \\
-.13(.93)\end{array}$ & .23 \\
\hline $\begin{array}{l}\text { Inhibitory } \\
\text { control }\end{array}$ & 1 & 2356 & -3.31 & $\begin{array}{l}\text { Complete } \\
\text { Non-complete }\end{array}$ & $\begin{array}{l}-.09(.75) \\
-.23(.72)\end{array}$ & .19 \\
\hline
\end{tabular}

A second MANOVA was performed on the competency scores to compare treatment completers to those who did not complete due to dropout/expulsion and those who did not complete due to personal circumstances or administrative reasons beyond the control of the offender. Inhibitory control was not included as a dependent variable given that a meaningful difference was not detected between completers and non-completers, according to the Cohen's $d$ decision rule. The multivariate result was significant for treatment program status, Hotelling's $T^{2}=.042, F(10,4700)=9.98, p<.001$, indicating a difference in the overall level of competency between treatment completers, dropouts/expulsions and personal/administrative non-completers. Program completion status accounted for only $2 \%$ of the variance in the overall competency score, partial $\eta^{2}=$ .02 
To determine which groups contributed to the significant multivariate effect, all possible pairwise multivariate tests were performed. The significance level was set at .05 for the three tests. Treatment completers were significantly different from dropouts/expulsions (Hotelling's $T^{2}=.032, F(5,2204)=13.97, p<.001$, partial $\eta^{2}=.03$ ) and personal/administrative non-completers (Hotelling's $T^{2}=.017, F(5,2166)=7.41, p<$ .001 , partial $\eta^{2}=.02$ ) in overall competency level. Dropouts/expulsions also differed significantly from personal/administrative non-completers in overall competency level; Hotelling's $T^{2}=.038, F(5,328)=2.47, p=.03$, partial $\eta^{2}=.04$.

Lastly, all significant pairwise multivariate tests were followed up with Tukey's Honestly Significant Difference (HSD) test. Five tests were performed for each of the dependent variables (i.e., competency scores). Means and standard deviations for each of the competency scores are displayed in Table 28. The Tukey HSD procedure revealed a number of significant pairwise differences among means, $p<.05$. Treatment completers had significantly higher competency scores than dropouts/expulsions for personal accountability and need for change, literacy and numeracy, cognitive flexibility, knowledge acquisition ability and cognitive awareness. Treatment completers also had significantly higher competency scores than personal/administrative non-completers for personal accountability and need for change, literacy and numeracy, knowledge acquisition ability and cognitive awareness. Personal/administrative non-completers did not differ significantly from dropouts/expulsions on any of the competency scores. Thus, reason for non-completion did not differentiate between non-completers on the competency scores. 
Table 28. Means and Standard Deviations for Competency Scores for Program Status

\begin{tabular}{lccc}
\hline \multicolumn{1}{c}{ Competency Score } & Completers & Dropout/expulsion & $\begin{array}{c}\text { Personal/ } \\
\text { administrative }\end{array}$ \\
\hline $\begin{array}{l}\text { Personal } \\
\text { accountability \& } \\
\text { need for change }\end{array}$ & $-.01(.84)$ & $-.44(.89)$ & $-.30(.87)$ \\
$\begin{array}{l}\text { Literacy and } \\
\text { numeracy }\end{array}$ & $.05(.85)$ & $--.32(.98)$ & $-.27(.98)$ \\
$\begin{array}{l}\text { Cognitive flexibility } \\
\text { Knowledge } \\
\text { acquisition }\end{array}$ & $-.13(.79)$ & $-.41(.71)$ & $-.27(.85)$ \\
Cognitive awareness & $.00(.82)$ & $-.26(.83)$ & $-.35(.87)$ \\
& $.07(.83)$ & & $-.16(.94)$ \\
\hline
\end{tabular}

Note. Standard deviations appear in parentheses.

Intake variables. Treatment completers and non-completers were also compared on the following variables measured upon admission to an institution: reintegration potential, criminogenic need, static risk, institutional adjustment, security risk and the SIR-Proxy. Before performing the MANOVA, reintegration potential and the SIR-Proxy were reverse-coded so that higher scores on all variables corresponded to negative endorsement of the construct (e.g., lower reintegration potential, higher risk). The MANOVA was significant for treatment completion; Hotelling's $T^{2}=.046, F(6,3053)=$ 23.53, $p<.001$, indicating a difference in the level of functioning upon intake between treatment completers and non-completers. Program completion status accounted for only $4 \%$ of the variance in the composite intake score, partial $\eta^{2}=.04$. As can be seen in Table 29, the univariate $F$ tests showed there was a significant difference between treatment completers and non-completers on the scores for reintegration potential, criminogenic need, static risk, SIR-Proxy, security risk and institutional adjustment. Treatment completers scored significantly lower than non-completers on all six intake 
variables, indicating higher reintegration potential and lower need, risk, security risk and institutional adjustment. The effect sizes ranged from small to medium.

Table 29. Significant Univariate Effects for Treatment Program Status for Intake Variables (at $p<.001$ level)

\begin{tabular}{|c|c|c|c|c|c|c|}
\hline $\begin{array}{c}\text { Dependent } \\
\text { variable }\end{array}$ & $d f$ & df error & $t$ & $\begin{array}{c}\text { Program } \\
\text { status }\end{array}$ & $M(S D)$ & $\begin{array}{c}\text { Cohen's } \\
d\end{array}$ \\
\hline $\begin{array}{l}\text { Reintegration } \\
\text { potential }\end{array}$ & 1 & 3093 & 7.09 & $\begin{array}{l}\text { Complete } \\
\text { Non-complete }\end{array}$ & $\begin{array}{l}1.90(.82) \\
2.18(.81)\end{array}$ & .34 \\
\hline Need & 1 & 3093 & 5.15 & $\begin{array}{l}\text { Complete } \\
\text { Non-complete }\end{array}$ & $\begin{array}{l}2.57(.58) \\
2.71(.51)\end{array}$ & .26 \\
\hline Static risk & 1 & 3093 & 4.54 & $\begin{array}{l}\text { Complete } \\
\text { Non-complete }\end{array}$ & $\begin{array}{l}2.32(.66) \\
2.46(.61)\end{array}$ & .22 \\
\hline SIR-Proxy & 1 & 3093 & 7.07 & $\begin{array}{l}\text { Complete } \\
\text { Non-complete }\end{array}$ & $\begin{array}{c}2.97(5.68) \\
.94(5.57)\end{array}$ & .36 \\
\hline $\begin{array}{l}\text { CRS: } \\
\text { Institutional } \\
\text { adjustment }\end{array}$ & 1 & 3093 & 11.75 & $\begin{array}{l}\text { Complete } \\
\text { Non-complete }\end{array}$ & $\begin{array}{l}48.95(27.98) \\
65.64(31.38)\end{array}$ & .56 \\
\hline $\begin{array}{l}\text { CRS: } \\
\text { Security risk }\end{array}$ & 1 & 3093 & 5.81 & $\begin{array}{l}\text { Complete } \\
\text { Non-complete }\end{array}$ & $\begin{array}{l}74.75(22.09) \\
81.20(23.32)\end{array}$ & .28 \\
\hline
\end{tabular}

A second MANOVA was performed on the global intake measures to compare treatment completers to non-completers by reason for non-completion. The multivariate result was significant for treatment program status, Hotelling's $T^{2}=.053, F(12,6026)=$ $13.36, p<.001$, indicating a difference in the level of functioning upon intake between treatment completers, dropouts/expulsions and non-completers due to personal or administrative reasons. Program completion status accounted for only $3 \%$ of the variance in the composite competency score, partial $\eta^{2}=.03$.

To determine which groups contributed to the significant multivariate effect, all possible pairwise multivariate tests were performed. The significance level was set at .05 
for the three tests. Treatment completers were significantly different from dropouts/expulsions (Hotelling's $T^{2}=.038, F(6,2817)=17.94, p<.001$, partial $\eta^{2}=.04$ ) and personal/administrative non-completers (Hotelling's $T^{2}=.023, F(6,2750)=10.68, p$ $<.001$, partial $\eta^{2}=.02$ ) in global intake variables. The difference between dropouts/expulsions and personal/administrative non-completers did not reach significance; Hotelling's $T^{2}=.055, F(6,456)=4.17, p=.052$. Thus, reason for noncompletion did not differentiate between non-completers on the global intake measures.

Lastly, all significant pairwise multivariate tests were followed up with Tukey's Honestly Significant Difference (HSD) test. Five tests were performed for each of the dependent variables (i.e., intake variables) to compare treatment completers to dropouts/expulsions and to personal/administrative non-completers. Means and standard deviations for each of the competency scores are displayed in Table 30. The Tukey HSD procedure revealed a number of significant pairwise differences among means, $p<0.05$. Treatment completers had significantly higher reintegration potential and lower need, static risk, institutional adjustment, security risk and risk to reoffend than offenders who dropped out or were expelled from a program. Completers also had higher reintegration potential and lower static risk, institutional adjustment and risk to reoffend than offenders who did not complete treatment due to personal circumstances or administrative reasons. 
Table 30. Means and Standard Deviations for Competency Scores for Intake Variables

\begin{tabular}{lccc}
\hline \multicolumn{1}{c}{ Competency Score } & Completers & Dropout/expulsion & $\begin{array}{c}\text { Personal/ } \\
\text { administrative }\end{array}$ \\
\hline $\begin{array}{l}\text { Reintegration } \\
\text { potential }\end{array}$ & $1.89(.82)$ & $2.23(.79)$ & $2.11(.83)$ \\
Need & $2.57(.58)$ & $2.77(.45)$ & $2.63(.55)$ \\
Static risk & $2.31(.66)$ & $2.44(.60)$ & $2.48(.62)$ \\
& $48.94(27.98)$ & $65.83(29.54)$ & $64.44(33.21)$ \\
$\begin{array}{l}\text { Institutional } \\
\text { adjustment }\end{array}$ & & \\
Security risk & $74.74(22.12)$ & $82.36(20.75)$ & $78.28(24.71)$ \\
SIR-Proxy & $.03(5.68)$ & $2.34(5.19)$ & $1.67(6.05)$ \\
\hline Note. Standard & & & \\
\hline
\end{tabular}

Note. Standard deviations appear in parentheses.

GPPM pre-test scores. Lastly, treatment completers and non-completers were compared on their GPPM scores before participating in a treatment program. An independent samples t-test using the pre-test average found a significant difference between treatment completers and non-completers, $t(1,3055)=11.83, p<.001$.

Treatment completers $(M=-.37, S D=.65)$ scored higher than treatment non-completers $(M=-.78, S D=.63)$ at the pre-test stage. The effect size is considered medium to large (Cohen's $d=.64$ ).

A one-way ANOVA was then conducted to test the hypothesis that treatment completers, dropouts/expulsions and personal/administrative non-completers differed in their GPPM pre-test scores. The overall model was significant; $F(2,3054)=82.16, p<$ .001. Post-hoc Tukey HSD tests showed that completers $(M=-.37, S D=.65)$ had significantly higher GPPM pre-test scores than both dropouts/expulsions $(M=-.91, S D=$ $.58)$ and personal/administrative non-completers $(M=-.59, S D=.65)$ at the .05 level of 
significance. Offenders who did not complete the program due to personal circumstances or administrative reasons also had higher GPPM pre-test scores than offenders who dropped out or were expelled from the program.

\section{Discussion}

The findings of this study suggest offender competencies may be an innovative way of understanding offender change (Serin, 2006). It is well established that correctional programs that adhere to the principles of risk, need and responsivity are effective in reducing recidivism. The reasons why correctional programs may be unsuccessful for some offenders has received less attention. The overarching goal of this study was to determine why some offenders are successful while others fail in their attempts to change their behaviour. The FCM was found to account for some of the variation in treatment outcome. Support was found for the three hypotheses of the current study. Offender competencies were found to be predictive of program performance and to a lesser degree, behavioural change. More competent offenders had greater program performance and behavioural change than less competent offenders. Further, treatment completers had higher competency than non-completers.

These results, if replicated, may be of practical importance given that services should be targeted to those offenders who have both a high level of need and are likely to respond to the particular intervention (Andrews, Bonta, \& Hoge, 1990). Competent offenders are more likely to respond to treatment, while offenders with lower levels of competency may warrant extra attention and preparatory interventions before participating in correctional treatment programs. Inappropriate referrals to treatment can result in low rates of engagement, program non-completion or dropout (Day et al., 2009). 
Identifying the characteristics of offenders who are likely to benefit most from a particular treatment program allows interventions to be most effectively targeted. This maximizes the benefits to all participants, reduces the demands on budgets and ultimately produces larger reductions in recidivism (Williamson, Day, Howells, Bubner, \& Jauncey, 2003).

The correlational analyses indicated the competency scores demonstrated a stronger relationship with program performance than behavioural change. These findings are consistent with the notion that it is more important that an offender meets a minimum threshold of program performance rather than reaches a particular degree of change. An offender may demonstrate varying levels of change throughout the course of treatment, but they may still lack the competency level to achieve a sufficient level of program performance to lead to treatment gain and desistance from crime. To demonstrate this, offenders were grouped into those with low versus high competency scores. Those who scored high on the competencies showed larger gains than those who scored low on the competencies. This suggests that offenders who do not demonstrate the necessary competency level at the start of treatment have difficulty achieving a sufficient threshold of program performance. Thus, not only is their degree of change insufficient, but they are unable to meet the threshold for successful program performance. Offenders in the low competency group also have greater variability in their program performance and behavioural change scores than those in the high competency group. This may be explained by some offenders gaining a sufficient competency level during treatment or eliminating factors that may have impeded their ability to utilize their competencies (e.g., substance abuse). Thus, offenders in the high competency group not only have greater 
performance and behavioural change, but are similar in their treatment gains (i.e., gather around the mean scores). Although it is not a requirement for an offender to have a high competency level at the start of treatment, these findings suggest that without it they will face a greater obstacle to succeeding in treatment.

Although the competency scores predicted program performance, the proportion of variance accounted for was only $7 \%$. This leaves a large amount of unexplained variance and suggests conclusions regarding the predictive validity of the competency model should remain tentative. It is possible that a more comprehensive and precise measure of offender competencies may improve this level of prediction. As previously discussed, the OCI omits some aspects of each of the core competencies. In addition, while the full combination of competency scores were robust predictors of program performance and behavioural change using various analytical strategies, the findings pertaining to inhibitory control were less stable. The complexity of inhibitory control as it is conceptualized in the FCM was not well represented by the few items available to represent the competency. As a result, the inhibitory control scale had a restricted range which also appeared to affect the reliability of the scale. Future research should aim to develop a more multifaceted measurement of inhibitory control and the remaining competencies.

Personal accountability and the need for change emerged as the strongest predictor of both program performance and behavioural change. The importance of this competency was evident in most of the program categories. This is consistent with empirical evidence indicating motivation and readiness to change act as important precursors to treatment engagement and offender change (Joe et al., 1998; Viets et al., 
2002). These findings are encouraging given the recent focus on offender accountability in CSC. According to the CSC review panel, offender accountability must be strengthened in order to provide greater public safety results (CSC Review Panel, 2007). Specifically, for rehabilitation to occur and be sustained, it must be a shared responsibility of CSC and the offender. While CSC has the responsibility of providing offenders with the opportunities and tools necessary to achieve change, an offender must seize these opportunities and tools. A sense of personal accountability and a need for change thus permits an offender to engage in the rehabilitation process.

Although the competency model was developed to be pertinent to all offender types, the relationship between competency level and program performance was examined by program category. Personal accountability, the need for change, literacy and numeracy contributed most to the prediction of program performance overall. While these emerged as important predictors when examining by program category, cognitive awareness appeared equally as important in substance abuse programs. Further, the competency scores did not significantly predict program performance in Counterpoint programs. This suggests that certain competencies may be more vital to program performance and behaviour change depending on program type and accordingly, offender type. The various levels of treatment intensity (e.g., low, moderate and high) were merged together to examine each program category. Accordingly, it is possible that there are differences between treatment intensity levels within program categories. Given the differential findings for program categories, future research should also seek to assess the validity of the offender competency model in various offender populations. For instance, 
differences in competency level may be observed by race and particularly when comparing Aboriginal and non-Aboriginal offenders.

Offender competencies may also be used to explain failure to enter, continue in, comply with and succeed in treatment. An initial need for change and motivation to enter treatment may lead to improved treatment attendance and participation. However, if an offender lacks the competencies necessary to succeed in treatment, this may result in a lack of progress, weakened motivation and ultimately dropout or expulsion. Conversely, competent offenders may maintain their initial motivation by achieving positive changes and progressing in treatment. Notably, treatment completers scored higher than noncompleters in all competency areas: personal accountability and need for change, literacy and numeracy, cognitive flexibility, knowledge acquisition ability, cognitive awareness and inhibitory control. There were no differences in competency scores or global intake measures between those offenders who dropped out or were expelled from a treatment program and those who did not complete due to administrative reasons or personal circumstances beyond the control of the offender. In that many correctional programs are using cognitive-behavioural treatment, it is important to determine if specific offender characteristics are related to success in this type of program (Hubbard, 2007). The findings of this study suggest offender competencies can accurately differentiate successful offenders from those who fail to complete treatment; potentially contributing to the development of more effective correctional treatment programs. Further, program effectiveness can be improved by attending to the personal characteristics of offenders that are likely to influence engagement in treatment (Howells \& Day, 2006). In that the proportion of variance accounted for by completion status (i.e., completers vs. non- 
completers) was similar for global intake variables and competency scores, this may indicate that functioning at intake is sufficient to differentiate completers from noncompleters. Non-completers also scored lower on the GPPM at the start of the program than completers, suggesting the potential merits of motivational priming. Offenders who are not competent, either at intake or at the pre-program stage, will likely score low on the GPPM. Again, this may be an informative indication that extra attention is warranted for these offenders.

Offender competencies provide a further strategy for differentiating among offenders in terms of program needs and outcomes. Offenders with low core competency may require pre-treatment primers or induction strategies. For instance, a pre-treatment intervention could be created to elicit a need for change in offenders, improve cognitive flexibility and inhibitory control, and encourage personal accountability, while emphasizing the importance of knowledge acquisition and application. An intervention such as this would serve to increase treatment readiness and therefore reduce program attrition and improve program participation. Blankenship, Dansereau, and Simpson (1999) tested the efficacy of a four-session treatment readiness program consisting of various cognitive engagement strategies. The program was successful in improving client confidence and motivation, especially in offenders with less education. A pretreatment primer such as this incorporating the five core competencies may be effective in increasing motivation and treatment engagement and accordingly, reducing recidivism upon release. Blankenship and colleagues highlight the importance of initial induction, described as enhancing treatment readiness by helping offenders examine the 
consequences of treatment engagement, and helping them identify internal and external resources that can be used in maximizing treatment.

The competency scores were correlated to existing global intake measures, namely reintegration potential, criminogenic need, static risk, the SIR-Proxy and the CRS (i.e., institutional adjustment and security risk). Based on their scores on these additional measures, competent offenders have a higher likelihood of reintegrating safely into the community following release and a lower probability of reoffending in comparison to those not competent. Competent offenders have fewer or less severe criminogenic needs and require a lower level of intervention based on their static risk factors. These offenders are also a lower risk to staff, other inmates and self caused by problems related to institutional adjustment and also represent a lower risk to the public in the event of an escape. The relationship between offender competencies and existing measures is noteworthy since these measures are related to offender behaviour and functioning while incarcerated and once released into the community. For instance, security classifications using the CRS are associated with institutional behaviour, conditional release decisions and performance on conditional release (Luciani et al., 1996). Offenders rated as lower security have been found to be better adjusted (i.e., lower frequencies of institutional incidents) and lower risk (i.e., higher frequencies of discretionary release and post-release success) than offenders rated as higher risk. The relationship between the CRS and offender competencies suggests the potential for the core competencies to act as intraindividual indices of offender change.

This study represents an attempt to advance the knowledge of intra-individual change important for offender programming and specifically the responsivity principle, 
which has received relatively little attention. Treatment responsivity is an important research area due to the role of treatment process factors in predicting outcomes such as program performance and treatment retention. The current research endeavour is also consistent with the recent focus in the correctional literature on strengths-based approaches to explaining offender change. These perspectives utilize an offender's preferences and values to motivate them to make better life choices (Whitehead, Ward, \& Collie, 2007). It encourages therapists to instruct offenders with respect to competency (i.e., internal resources) and to provide opportunities (i.e., external events) to implement treatment plans based on his or her preferences and values. This relationship between the FCM and treatment outcome provides evidence that personal competencies should be developed and supported in treatment in order to achieve change. The strengths-based approach largely remains untested to date; thus, it is still unclear to what extent these ideas can inform and enhance offender rehabilitation.

Finally, this study lays the foundation to gain a better understanding of the transition from offending to crime desistance. Currently, a lack of understanding of the transition process prevents more specifically targeted interventions designed to spark transition or to guide offenders through the transition to desistance (Serin \& Lloyd, 2009). Accurate identification of those offenders more likely to desist from crime would provide a greater foundation for examining the offenders' natural desistance processes. Since competent offenders are more successful in treatment, they may be more adept in weighing the costs and benefits to achieving change and desisting from crime. Future research should establish the threshold level of competencies required to achieve treatment gains and desist from crime. 


\section{Limitations and Future Directions}

While the findings of this study are promising, certain limitations of the present research should be reviewed. The wealth of existing variables measured at intake and at various points throughout an offender's sentence allowed for the development of a proxy measure of offender competencies. An initial assessment suggests that for the most part, the Offender Competency Index is psychometrically sound. The practical utility of this measure remains to be seen due to impending changes to the Offender Intake Assessment. A number of variables which comprise the OCI will no longer be collected, while other items which may represent the core competencies will be added to the assessment process. As previously discussed, the OCI represented the best available measure of offender competencies using data in CSC's existing database. The weakness of this approach is that the measure was lacking some components of the competency model. Ideally for both clinical and research purposes, a measure should be developed specifically to measure competency level.

An additional limitation of the current study is the reliance solely on file information as a measure of offender competencies. The five offender competencies are conceptualized as complex, multi-dimensional dynamic factors. In order to accurately capture these constructs, both behavioural indices and offender self-reports should be employed. Collecting self-reported treatment gains and ratings of competency level by the offender as corroborative evidence may increase the validity of measurement. Future research will aim to collect various types of measures of competencies and offender change. Incorporating behavioural ratings, self-reports and file information would represent an innovative and sophisticated measure of offender competencies. 
Finally, this study is limited in its inability to test the predictive validity of the offender competencies in terms of long-term offender change and desistance from crime. Without recidivism outcome data, our level of confidence in the measure of treatment progress and offender change (i.e., GPPM) is limited. This limitation can be addressed in future research by collecting follow-up data.

Much of the value of the present research lies in its application to future research. The findings of this study provide support for a model of offender competencies using a sound research design. The large sample size and cross-national design allows for generalizability, while a sizeable number of different types of offenders made it possible to examine group differences. As well, the pre/post-test measurement of treatment engagement permitted an examination of both program performance and behavioural change. Encouragingly, this preliminary study provides an empirical foundation for future research for the development and measurement of offender competencies. 


\section{References}

Andrews, D. A., \& Bonta, J. (2006). The psychology of criminal conduct (4th ed.). Cincinnati, $\mathrm{OH}$ : Anderson.

Andrews, D. A., Bonta, J., \& Hoge, R. D. (1990). Classification for effective rehabilitation: Rediscovering psychology. Criminal Justice and Behavior, 17, 19 52.

Andrews, D. A., \& Kiessling, J. J. (1980). Program structure and effective correctional practices: A summary of CaVIC research. In R. R. Ross \& P. Gendreau (Eds.), Effective Correctional Treatment (pp. 439-463). Toronto: Butterworth.

Andrews, D. A., Zinger, I., Hoge, R. D., Bonta, J., Gendreau, P., \& Cullen, F. T. (1990). Does correctional treatment work? A clinically-relevant and psychologically informed meta-analysis. Criminology, 28, 369-404.

Andrews, D. A., \& Dowden, C. (2005). Managing correctional treatment for reduced recidivism: A meta-analytic review of program integrity. Legal and Criminological Psychology, 10, 173-187.

Antiss, B., Polaschek, D. L. L., \& Wilson, M. J. (2008). Motivational interviewing intervention with prisoners: When you lead a horse to water, sometimes it drinks of its own accord. Unpublished manuscript, Victoria University of Wellington, Wellington, New Zealand.

Ayers, C. D., Williams, J. H., Hawkins, J. D., Peterson, P. L., Catalano, R. F., \& Abbott, R. D. (1999). Assessing correlates of onset, escalation, deescalation, and desistance of delinquent behavior. Journal of Quantitative Criminology, 15(3), $277-306$. 
Bandura, A. (1997). The anatomy of stages of change. American Journal of Health Promotion, 12, 8-10.

Barbaree, H. E., Seto, M. C., \& Maric, A. (1996). Sex offender characteristics, response to treatment, and correctional release decisions at the Warkworth Sexual Behaviour Clinic. Toronto, ON: Clarke Institute of Psychiatry.

Barrett, M., Wilson, R. J., \& Long, C. (2003). Measuring motivation to change in sexual offenders from institutional intake to community treatment. Sexual Abuse: A Journal of Research and Treatment, 15(4), 269-283.

Baxter, D. J., Marion, A., \& Goguen, B. (1995). Predicting treatment response in correctional settings. Forum on Corrections Research, 7(3).

Beech, A., \& Fordham, A. (1997). Therapeutic climate of sexual offender treatment programs. Sexual Abuse: Journal of Research \& Treatment, 9(3), 219-238.

Bettman, M. (1998). Social cognition, criminal violence, and psychopathy. Unpublished doctoral dissertation. Queens University, Ontario, Canada.

Beyko, M. J., \& Wong, S. C. P. (2005). Predictors of treatment attrition as indicators for program improvement not offender shortcomings: A study of sex offender treatment attrition. Sexual Abuse: A Journal of Research and Treatment, 17(4), 375-389.

Blanchard, K. A., Morgenstern, J., Morgan, T. J., Labouvie, E., \& Bux, D. A. (2003). Motivational subtypes and continuous measures of readiness for change: Concurrent and predictive validity. Psychology and Addictive Behaviors, 17, 5665. 
Blankenship, J., Dansereau, D. F., \& Simpson, D. D. (1999). Cognitive enhancements of readiness for corrections-bade treatment for drug agues. The Prison Journal, 79(4), 431-445.

Broome, K. M., Simpson, D. D., \& Joe, G. W. (1999). Patient and program attributes related to treatment process indicators in DATOS. Drug and Alcohol Dependence, $57,127-135$.

Brown, S. L., \& Motiuk, L. L. (2005). The Dynamic Factors Identification and Analysis (DFIA) component of the Offender Intake Assessment (OIA) process: A metaanalytic, psychometric and consultative review. Report 164. Ottawa, ON: Correctional Service of Canada.

Browne, K. D., Foreman, L., \& Middleton, D. (1998). Predicting treatment dropout in sex offenders. Child Abuse Review, 7, 402-419.

Burdon, W. M., Prendergast, M. L., Eisen, V., \& Messina, N. P. (2003). Sanctions and rewards in prison-based therapeutic community treatment. Federal Probation, 67(2), 47-52.

Bushway, S. D., Thornberry, T. P., \& Krohn, M. D. (2003). Desistance as a development process: A comparison of static and dynamic approaches. Journal of Quantitative Criminology, 19(2), 129-152.

Carroll, J. S., \& Burke, P. A. (1990). Evaluation and prediction in expert parole decisions. Criminal Justice and Behavior, 17(3), 315-332.

Casey, S., Day, A., \& Howells, K. (2005). The application of the transtheoretical model to offender populations: Some critical issues. Legal and Criminology Psychology, $10,157-171$. 
Casey, S., Day, A., Howells, K., \& Ward, T. (2007). Assessing suitability for offender rehabilitation: Development and validation of the Treatment Readiness Questionnaire. Criminal Justice and Behavior, 34(11), 1427-144.

Chamberlain, S. R., \& Sahakian, B. J. (2007). The neuropsychiatry of impulsivity. Current Opinion in Psychiatry, 20(3), 255-261.

Chambers, J. C., Eccleston, L., Day, A., Ward, T., \& Howells, K. (2008). Treatment readiness in violent offenders: The influence of cognitive factors on engagement in violence programs. Aggression and Violent Behavior, 13, 276-284.

Chandler, M. J. (1973). Egocentrism and antisocial behavior: The assessment and training of social perspective-taking skills. Development Psychology, 9(3), 326332.

Connors, G. J., Carroll, K. M., DiClemente, C. C., Longabaugh, R., \& Donovan, D. M. (1997). The therapeutic alliance and its relationship to alcoholism treatment participation and outcome. Journal of Consulting and Clinical Psychology, 65(4), $588-598$.

Correctional Service of Canada Review Panel (2007, October). A roadmap to strengthening public safety. Ottawa: Minister of Public Works and Government Services Canada.

Day, A., Howells, K., Casey, S., Ward, T., \& Birgden, A. (2007). Treatment readiness: An overview of Australasian work. Issues in Forensic Psychology, 7, 21-25.

Day, A., Howells, K., Casey, S., Ward, T., Chambers, J. C., \& Birgden, A. (2009). Assessing treatment readiness in violent offenders. Journal of Interpersonal Violence, 24(4), 618-635. 
Day, A., Tucker, K., \& Howells, K. (2004). Coerced offender rehabilitation: A defensible practice? Psychology, Crime, \& Law, 10(3), 259-269.

De Leon, G., \& Jainchill, N. (1986). Circumstance, motivation, readiness and suitability as correlates of treatment tenure. Journal of Psychoactive Drugs, 18(3), 203-208.

De Leon, G., Melnick, G., \& Tims, F. M. (2001). The role of motivation and readiness in treatment and recovery. In J. J. Platt, F. M. Tims, \& C. Leukefeld (Eds.), Relapse and Recovery Process in the Addictions (pp. 143-171). Newhaven, CT: Yale University Press.

Demmel, R., Beck, B., Richter, D., \& Reker, T. (2004). Readiness to change in a clinical sample of problem drinkers: Relation to alcohol use, self-efficacy, and treatment outcome. European Addiction Research, 10, 133-138.

DeVellis, R. F. (2003). Scale development: Theory and applications (2nd ed.). Thousand Oaks, CA: Sage Publications, Inc.

Dowden, C., \& Andrews, D. A. (2000). Effective correctional treatment and violent reoffending: A meta-analysis. Canadian Journal of Criminology, 42, 449-467.

Dowden, C., \& Serin, R. (2001). Anger management programming for offenders: The impact of program performance measures (Research Report No R-106). Ottawa, Canada: Correctional Service Canada.

Englebrecht, C., Peterson, D., Scherer, A., \& Naccarato, T. (2008). "It's not my fault": Acceptance of responsibility as a component of engagement in juvenile residential treatment. Children and Youth Services Review, 30, 466-484.

Field, A. (2005). Discovering statistics using SPSS (2nd ed.). London: Sage Publications. 
Fishbein, D., Sheppard, M., Hyde, C., Hubal, R., Newlin, D., Serin, R. C., Chrousos, G., \& Alesci, S. (in press). Neurocognitive and emotional regulatory deficits predict treatment responsivity in prison inmates. Law and Human Behavior.

Fiorentine, R., Nakashima, J., \& Anglin, D. (1999). Client engagement in drug treatment. Journal of Substance Abuse Treatment, 17(3), 199-206.

Frick, P. J., Cornell, A. H., Bodin, S. D., Dane, H. E., Barry, C. T., \& Loney, B. R. (2003). Callous-unemotional traits and development pathways to severe conduct problems. Development Psychology, 39(2), 246-260.

Geer, T. M., Becker, J. V., Gray, S. R., \& Krauss, D. (2001). Predictors of treatment completion in a correctional sex offender treatment program. International Journal of Offender Therapy and Comparative Criminology, 45(3), 302-313.

Gendreau, P., Little, T., \& Goggin, C. (1996). A meta-analysis of the predictors of adult offender recidivism: What works! Criminology, 34, 401-433.

Hanson, R. K. (2000). Treatment outcome and evaluation problems (and solutions). In D. R. Laws, S. Hudson, \& T. Ward (Eds.), Remaking relapse prevention with sex offenders: A sourcebook (pp. 485-500). Thousand Oaks, CA: Sage.

Henderson, M., \& Hewstone, M. (1984). Prison inmates' explanations for interpersonal violence: Accounts and attributions. Journal of Consulting and Clinical Psychology, 52, 789-794.

Hiller, M. L., Knight, K., Leukefeld, C., \& Simpson, D. D. (2002). Motivation as a predictor of therapeutic engagement in mandated residential substance abuse treatment. Criminal Justice and Behavior, 29(1), 56-75. 
Hiller, M. L., Knight, K., \& Simpson, D. D. (1999). Risk factors that predict dropout from corrections-based treatment for drug abuse. The Prison Journal, 79(4), 411430.

Hodgins, D. C. (2001). Stages of change assessments and alcohol problems: Agreement across self- and clinician-reports. Substance Abuse, 22(2), 87-96.

Hollin, C. R., McGuire, J., Hounsome, J. C., Hatcher, R. M., Bilby, C. A. L., \& Palmer, E. J. (2008). Cognitive skills behavior programs for offenders in the community: A reconviction analysis. Criminal Justice and Behavior, 35(3), 269-283.

Horvath, A. O., \& Symonds, B. D. (1991). Relation between working alliance and outcome in psychotherapy: A meta-analysis. Journal of Counselling Psychology, 38(2), 139-149.

Howells, K., \& Day, A. (2006). Affective determinants of treatment engagement in violent offenders. International Journal of Offender Therapy and Comparative Criminology, 50(2), 174-186.

Hubbard, D. J. (2007). Getting the most out of correctional treatment: Testing the responsivity principle on male and female offenders. Federal Probation, 71(1), 28.

Hunter, J. A., \& Figueredo, A. J. (1999). Factors associated with treatment compliance in a population of juvenile sex offenders. Sexual Abuse: A Journal of Research and Treatment, 11(1), 49-67.

Jenkins-Hall, K. (1994). Outpatient treatment of child molesters: Motivational factors and outcome. In Young victims, young offenders (pp. 139-150). Binghamton, NY: Haworth Press. 
Joe, G. W., Simpson, D. D., \& Broome, K .M. (1998). Effects of readiness for drug abuse treatment on client retention and assessment of process. Addiction, 93(8), 11771190.

Joe, G. W., Simpson, D. D., \& Hubbard, R. L. (1991). Treatment predictors of tenure in methadone maintenance. Journal of Substance Abuse, 3, 73-84.

Kazemian, L. (2007). Desistance from crime: Theoretical, empirical, methodological, and policy considerations. Journal of Contemporary Criminal Justice, 23(1), 5-27.

Kennedy, S., \& Serin, R. (1999). Examining offender readiness to change and the impact on treatment outcome. In P. M. Harris (Ed.), Research to results: Effective community corrections (pp. 215-232). Arlington, VA: American Correctional Association.

Kline, P. (1993). The handbook of psychological testing. London: Routledge.

Kline, P. (1994). An easy guide to factor analysis. New York: Routledge.

Krause, M. S. (1967). Behavioral indexes of motivation for treatment. Journal of Counseling Psychology, 14, 426-435.

Lambert, M. J. (1992). Psychotherapy outcome research: Implications for integrative and eclectic therapists. In J. C. Norcross, \& M. R. Goldfried (Eds.), Handbook of psychotherapy integration (pp. 94-129). New York, NY: Basic Books, Inc.

Latendresse, M. (2007). Predicting sex offender program attrition: The role of denial, motivation and treatment readiness. Forum on Corrections Research, 19(1), 1518.

Latessa, E. J. (2004). The challenge of change: Correctional programs and evidencebased practices. Criminology and Public Policy, 3, 547-559. 
Levenson, J. S., \& Macgowan, M. J. (2004). Engagement, denial, and treatment progress among sex offenders in group therapy. Sexual Abuse: A Journal of Research and Treatment, 16(1), 49-63.

Looman, J., Dickie, I., \& Abracen, J. (2005). Responsivity issues in the treatment of sexual offenders. Trauma, Violence, \& Abuse, 6(4), 330-353.

Love, S. R. (2006). Illicit sexual behavior: A test of self-control theory. Deviant Behavior, 27(5), 503-516.

Luciani, F. (1997). Tried and true: Proof that the Custody Rating Scale is still reliable and valid. Forum on Corrections Research, 9(1).

Luciani, F. P., Motiuk, L. L., \& Nafekh, M. (1996). An operational review of the Custody Rating Scale: Reliability, validity and practical utility. (Research Report, R-47). Ottawa, ON: Correctional Service of Canada.

MacCallum, R. C., Widaman, K. F., Zhang, S., \& Hong, S. (1999). Sample size in factor analysis. Psychological Methods, 4(1), 84-99.

Mann, R. E., Webster, S. D., Schofield, C., \& Marshall, W. L. (2004). Approach versus avoidance goals in relapse prevention with sex offenders. Sexual Abuse: A Journal of Research and Treatment, 16(1), 65-75.

Martin, D. J., Garske, J. P., \& Davis, M. K. (2000). Relation of the therapeutic alliance with outcome and other variables: A meta-analytic review. Journal of Consulting and Clinical Psychology, 68(3), 438-450.

Maruna, S. (2001). Making good: How ex-convicts reform and rebuild their lives. Washington, DC: American Psychological Association Books. 
Maruna, S., \& LeBel, T. P. (2003). Welcome home? Examining the "re-entry court" from a strengths-based perspective. Western Criminology Review, 4(2), 91-107.

Maruna, S. (2004). Desistance from crime and explanatory style: A new direction in the Psychology of reform. Journal of Contemporary Criminal Justice, 20(2), 184200.

McMurran, M., \& McCulloch, A. (2007). Why don't offenders complete treatment? Prisoners' reasons for non-completion of a cognitive skills programme. Psychology, Crime \& Law, 13(4), 345-354.

Meisenhelder, T. (1977). An exploratory study of exiting from criminal careers. Criminology, 15(3), 319-334.

Melnick, G., De Loen, G., Thomas,G., Kressel, D., \& Wexler, H.K. (2001). Treatment process in prison therapeutic communities: Motivation, participation, and outcome. American Journal of Drug and Alcohol Abuse, 27(4), 633-650.

Miner, M. H., \& Dwyer, S. M. (1995). Analysis of dropouts from outpatient sex offender treatment. Journal of Psychology \& Human Sexuality, 7(3), 77-93.

Motiuk, L. (1997). Classification for correctional programming: The Offender Intake Assessment (OIA) process. Forum on Corrections Research, 9(1), 18-22.

Motiuk, L., \& Nafekh, M. (2001). Using reintegration potential at intake to better identify safe release candidates. Forum on Corrections Research, 13(1), 11-13.

Nafekh, M. (2003). Using proxy measures for correctional research. Forum on Corrections Research, 15(2), 41-43.

Nuffield, J. (1989). The SIR scale: Some reflections on its applications. Forum on Corrections Research, 1(2), 19-22. 
Nunes, K. L., \& Cortoni, F. (2006). The heterogeneity of treatment non-completers (Research Report No. R-176). Ottawa, Canada: Correctional Service Canada.

Parhar, K., \& Wong, S. C. P. (2004). "Seeing the light": Positive self change theory of desistance from crime. Crime Scene, 11(3), 9.

Parhar, K., \& Wong, S. C. P. (2007). Seeing eye to eye: Parole officer and parolee views of crime desistance. Forum on Corrections Research, 19(1), 23-27.

Preston, D. L. (2000). Treatment resistance in corrections. Forum on Corrections Research, 12(2), 24-28.

Preston, D. L., \& Murphy, S. (1997). Motivating treatment-resistant clients in therapy. Forum on Corrections Research, 9(2), 39-43.

Prochaska, J. O., DiClemente, C. C., \& Norcross, J. (1992). In search of how people change: Applications to addictive behaviors. American Psychologist, 47, $1102-$ 1114.

Rex, S. (1999). Desistance from offending: Experiences of probation. The Howard Journal, 38(4), 366-383.

Rogers, R., \& Webster, C. D. (1989). Assessing treatability in mentally disordered offenders. Law and Human Behavior, 13(1), 18-29.

Rosen, P. J., Hiller, M. L., Webster, J. M., Staton, M., \& Leukefeld, C. (2004). Treatment motivation and therapeutic engagement in prison-based substance use treatment. Journal of Psychoactive Drugs, 36(3), 387-396.

Ross, E. C., Polaschek, D. L. L., \& Ward, T. (2008). The therapeutic alliance: A theoretical revision for offender rehabilitation. Unpublished manuscript, Victoria University of Wellington, Wellington, New Zealand. 
Scott, K. L., \& Wolfe, D. A. (2000). Change among batterers: Examining men's success stories. Journal of Interpersonal Violence, 15(8), 827-842.

Seager, J. A., Jellicoe, D., \& Dhaliwal, G. K. (2004). Refusers, dropouts, and completers: Measuring sex offender treatment efficacy. International Journal of Offender Therapy and Comparative Criminology, 48(5), 600-612.

Serin, R. C. (2006). Functional competency model for offenders: Programming for crime desistance. Unpublished manuscript, Carleton University, Ottawa, Canada.

Serin, R. C., \& Brown, S. L. (2004). Social cognition in psychopaths: Implications for offender assessment and treatment. In M. McMurran, \& J. McGuire (Eds.), Social problem solving and offending (pp. 249-264). West Sussex, England: John Wiley $\&$ Sons.

Serin, R. C., Derkzen, D., Helmus, L., Lloyd, C. D., \& Luong, D. (2009). Indices of offender change: Evidence of predictive validity. Manuscript in preparation.

Serin, R. C., \& Kennedy, S. (1997). Treatment readiness and responsivity: Contributing to effective correctional programming. (Research Report, R-54). Ottawa, ON: Correctional Service of Canada.

Serin, R. C., \& Lloyd, C. D. (2009). Examining the process of offender change: The transition to crime desistance. Psychology, Crime, \& Law, 15, 347-364.

Serin, R. C., Mailloux, D. L., \& Kennedy, S. M. (2007). Development of a clinical rating scale for offender readiness: Implications for assessment and offender change. Issues in Forensic Psychology, 7, 70-80. 
Serran, G., Fernandez,Y., Marshall, W. L., \& Mann, R. E. (2003). Process issues in treatment: Application to sexual offender programs. Professional Psychology: Research and Practice, 34(4), 368-374.

Shuker, R., Falshaw, L., \& Newton, M. (2007). Risk and treatment readiness: The impact of historical and psychosocial variables on treatment completion. Issues in Forensic Psychology, 7, 87-96.

Sia. T. L., Dansereau, D. F., \& Czuchry, M. L. (2000). Treatment readiness training and probationers' evaluation of substance abuse treatment in a criminal justice setting. Journal of Substance Abuse Treatment, 19, 459-467.

Simpson, D. D., \& Joe, G. W. (1993). Motivation as a predictor of early dropout from drug abuse treatment. Psychotherapy, 30(2), 357-368.

Simpson, D. D., Joe, G. W., Rowan-Szal, G. A., \& Greener, J. M. (1995). Client engagement and change during drug abuse treatment. Journal of Substance Abuse Treatment, 7, 117-134.

Simpson, D. D., Joe, G. W., Rowan-Szal, G. A., \& Greener, J. M. (1997). Drug abuse treatment process components that improve retention. Journal of Substance Abuse Treatment, 14(6), 565-572.

Simpson, D. D., \& Knight, K. (2001). The TCU model of treatment process and outcomes in correctional settings. Offender Substance Abuse Report, 1, 51-58.

Smith, P., \& Gendreau, P. (2007). The relationship between program participation, institutional misconduct and recidivism among federally sentenced adult male offenders. Forum on Corrections Research, 19(1), 6-10. 
Smith, P., Gendreau, P, \& Swartz, K. (2008). Validating the principles of effective intervention: A systematic review of the contributions of meta-analysis in the field of corrections. Unpublished manuscript, University of Cincinnati, Cincinnati, $\mathrm{OH}$.

Soh, D. (2008). Evaluating program performance of federally incarcerated sex offenders. Unpublished undergraduate thesis, Carleton University, Ottawa, ON.

Stanton-Tindall, M., Garner, B. R., Morey, J. T., Leukefeld, C., Krietemeyer, J., Saum, C. A., \& Oser, C. B. (2007). Gender differences in treatment engagement among a sample of incarcerated substance abusers. Criminal Justice and Behavior, 34(9), 1143-1156.

Stein, K. F., \& Markus, H. R. (1996). The role of the self in behavioral change. Journal of Psychotherapy Integration, 6(4), 349-384.

Stewart, L., \& Price, L. (2005). Generic Program Performance Measure. Unpublished document: Correctional Service of Canada, Ottawa, ON, Canada.

Sung, H., Belenko, S., \& Feng, L. (2001). Treatment compliance in the trajectory of treatment progress among offenders. Journal of Substance Abuse Treatment, 20, $153-162$.

Tabachnick, B. G., \& Fidell, L. S. (2007). Using multivariate statistics (5th ed.). Boston, MA: Pearson Education, Inc.

Taft, C. T., Murphy, C. M., King, D. W., Musser, P. H., \& DeDeyn, J. M. (2003). Process and treatment adherence factors in group cognitive-behavioral therapy for partner violent men. Journal of Consulting and Clinical Psychology, 71(4), 812-820. 
Taft, C. T., Murphy, C. M., Musser, P. H., \& Remington, N. A. (2004). Personal, interpersonal, and motivational predictors of the working alliance in group cognitive-behavioral therapy for partner violent men. Journal of Consulting and Clinical Psychology, 72(2), 349-354.

Tierney, D. W., \& McCabe, M. P. (2002). Motivation for behavior change among sex offenders: A review of the literature. Clinical Psychology Review, 22, 113-129.

Van Voorhis, P. (1997). Correctional classification and the "responsivity principle." Forum on Corrections Research, 9(1), 46-50.

Viets, V. L., Walker, D. D., \& Miller, W. R. (2002). What is motivation to change? A scientific analysis. In M. McMurran (Ed.), Motivating offenders to change: A guide to enhancing engagement in therapy (pp. 15-30). West Sussex, England: John Wiley \& Sons.

Ward, T., Day, A., Howells, K., \& Birgden, A. (2004). The multifactor offender readiness model. Aggression and Violent Behavior, 9, 645-6723.

Ward, T., Mann, R. E., \& Gannon, T. A. (2007). The good lives model of offender rehabilitation: Clinical implications. Aggression and Violent Behaviour, 12, 87107.

Ward, T., Melser, J., \& Yates, P. M. (2007). Reconstructing the Risk-Need-Responsivity model: A theoretical elaboration and evaluation. Aggression and Violent Behavior, 12, 208-228.

Welsh, W. N., \& McGrain, P. N. (2008). Predictors of therapeutic engagement in prisonbased drug treatment. Drug and Alcohol Dependence, 96, 271-280. 
Whitehead, P. R., Ward, T., \& Collie, R. M. (2007). Time for a change: Applying the good lives model of rehabilitation to a high-risk violent offender. International Journal of Offender Therapy and Comparative Criminology, 51(5), 578-598.

Williamson, P., Day, A., Howells, K., Bubner, S., \& Jauncey, S. (2003). Assessing offender readiness to change problems with anger. Psychology, Crime \& Law, 9(4), 295-307.

Wormith, J. S., \& Olver, M. E. (2002). Offender treatment attrition and its relationship with risk, responsivity, and recidivism. Criminal Justice and Behavior, 29(4), 447-471.

Yessine, A. K., \& Kroner, D. G. (2004). Altering antisocial attitudes among federal male offenders on release: A preliminary analysis of the Counter-point community program (Research Report No R-152). Ottawa, Canada: Correctional Service Canada.

Yochelson, S., \& Samenow, S. E. (1976). The criminal personality, volume 1: A profile for change. New York: Jason Aronson Publishers.

Zwick, W. R., \& Velicer, W. F. (1986). Comparison of five rules for determining the number of components to retain. Psychological Bulletin, 99(3), 432-442. 


\section{Appendix A: Generic Program Performance Measure}

Participant name:

Facilitator(s) name(s):

Site:

Date:

Session:

\section{Assessment period:}

Pre

\begin{tabular}{|c|c|c|c|c|c|}
\hline 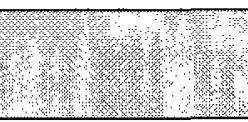 & $\begin{array}{l}\text { Needs a lot of } \\
\text { inprovement }\end{array}$ & $\begin{array}{l}\text { Needs some } \\
\text { improvement }\end{array}$ & Safisfactory & $\begin{array}{l}+1 / 3 \\
\mathrm{Good}\end{array}$ & very Good \\
\hline 1. Punctuality (E) & $\begin{array}{l}\text { Frequent } \\
\text { unauthorised late } \\
\text { arrivals. }\end{array}$ & $\begin{array}{l}\text { Occasional } \\
\text { unauthorised late } \\
\text { arrivals. }\end{array}$ & $\begin{array}{l}\text { No unauthorised } \\
\text { late arrivals. } \\
\text { Some authorised } \\
\text { late arrivals. }\end{array}$ & $\begin{array}{l}\text { No unauthorised } \\
\text { late arrivals. } \\
\text { Very few } \\
\text { authorised late } \\
\text { arrivals. }\end{array}$ & $\begin{array}{l}\mathrm{He} / \mathrm{she} \text { is always } \\
\text { punctual. }\end{array}$ \\
\hline $\begin{array}{l}\text { 2. Participation } \\
\text { (E) }\end{array}$ & $\begin{array}{l}\text { Rarely or never } \\
\text { participates in } \\
\text { group } \\
\text { discussions and } \\
\text { exercises. }\end{array}$ & $\begin{array}{l}\text { Occasionally } \\
\text { participates in } \\
\text { group } \\
\text { discussions and } \\
\text { exercises. }\end{array}$ & $\begin{array}{l}\text { Usually } \\
\text { participates in } \\
\text { group } \\
\text { discussions and } \\
\text { exercises. }\end{array}$ & $\begin{array}{l}\text { Consistently } \\
\text { participates in } \\
\text { group } \\
\text { discussions and } \\
\text { exercises. }\end{array}$ & $\begin{array}{l}\text { Consistently } \\
\text { participates in } \\
\text { group } \\
\text { discussions and } \\
\text { exercises in an } \\
\text { open and active } \\
\text { manner. }\end{array}$ \\
\hline $\begin{array}{l}\text { 3. Completes } \\
\text { required assigned } \\
\text { work }(\mathrm{E})\end{array}$ & $\begin{array}{l}\text { Rarely or never } \\
\text { completes } \\
\text { assigned work. }\end{array}$ & $\begin{array}{l}\text { Occasionally } \\
\text { completes } \\
\text { assigned work. }\end{array}$ & $\begin{array}{l}\text { Usually } \\
\text { completes } \\
\text { assigned work. }\end{array}$ & $\begin{array}{l}\text { Consistently } \\
\text { completes } \\
\text { assigned work. }\end{array}$ & $\begin{array}{l}\text { Consistently } \\
\text { completes } \\
\text { assigned work in } \\
\text { a timely and high } \\
\text { quality }\end{array}$ \\
\hline $\begin{array}{l}\text { 4. Attentive to } \\
\text { program (E) }\end{array}$ & $\begin{array}{l}\text { Rarely or never } \\
\text { pays attention to } \\
\text { program } \\
\text { information. }\end{array}$ & $\begin{array}{l}\text { Occasionally } \\
\text { pays attention to } \\
\text { program } \\
\text { information. }\end{array}$ & $\begin{array}{l}\text { Usually pays } \\
\text { attention to } \\
\text { program } \\
\text { information. }\end{array}$ & $\begin{array}{l}\text { Consistently } \\
\text { pays attention to } \\
\text { program } \\
\text { information }\end{array}$ & $\begin{array}{l}\text { Consistently } \\
\text { pays attention to } \\
\text { and appears very } \\
\text { interested in } \\
\text { program } \\
\text { information } \\
\text { (e.g., active } \\
\text { particpaiton, } \\
\text { brings examples } \\
\text { to group, etc.) }\end{array}$ \\
\hline $\begin{array}{l}\text { 5. Applies } \\
\text { program content } \\
\text { to own personal } \\
\text { situation }(\mathrm{P})\end{array}$ & $\begin{array}{l}\text { Shows no ability } \\
\text { or motivation to } \\
\text { apply program } \\
\text { content to own } \\
\text { personal } \\
\text { situation. }\end{array}$ & $\begin{array}{l}\text { Makes an effort } \\
\text { but not able to } \\
\text { apply much } \\
\text { program content } \\
\text { to own personal } \\
\text { situation. }\end{array}$ & $\begin{array}{l}\text { Usually applies } \\
\text { program content } \\
\text { to own personal } \\
\text { situation. }\end{array}$ & $\begin{array}{l}\text { Applies program } \\
\text { content to own } \\
\text { personal } \\
\text { situation and is } \\
\text { able to } \\
\text { generalise } \\
\text { material to many } \\
\text { areas of his/her } \\
\text { life. }\end{array}$ & $\begin{array}{l}\text { Consistently } \\
\text { applies program } \\
\text { content to own } \\
\text { personal } \\
\text { situation and } \\
\text { generalises the } \\
\text { content to many } \\
\text { problematic } \\
\text { areas of his/her } \\
\text { life. }\end{array}$ \\
\hline
\end{tabular}




\begin{tabular}{|c|c|c|c|c|c|}
\hline $\begin{array}{l}\text { 6. Interpersonal } \\
\text { relationship with } \\
\text { facilitator(s) [R] }\end{array}$ & $\begin{array}{l}\text { Very resistant, or } \\
\text { confrontational, } \\
\text { or } \\
\text { argumentative, } \\
\text { or disruptive } \\
\text { with } \\
\text { facilitator(s). No } \\
\text { working alliance } \\
\text { established }\end{array}$ & $\begin{array}{l}\text { Somewhat } \\
\text { resistant, or } \\
\text { argumentative } \\
\text { and/or disruptive } \\
\text { with } \\
\text { facilitator(s). } \\
\text { Minimum effort } \\
\text { made to } \\
\text { participate in } \\
\text { establishing a } \\
\text { working alliance. }\end{array}$ & $\begin{array}{l}\text { Attitude and } \\
\text { behaviour } \\
\text { towards } \\
\text { facilitator(s) are } \\
\text { appropriate. } \\
\text { Working alliance } \\
\text { established. }\end{array}$ & $\begin{array}{l}\text { Responsive and } \\
\text { pleasant with } \\
\text { facilitator(s). } \\
\text { Good working } \\
\text { alliance } \\
\text { established. }\end{array}$ & $\begin{array}{l}\text { Very responsive } \\
\text { and pleasant } \\
\text { with } \\
\text { facilitator(s). } \\
\text { Good working } \\
\text { alliance } \\
\text { established. }\end{array}$ \\
\hline $\begin{array}{l}\text { 7. Mutual } \\
\text { agreement on } \\
\text { goals of treatment } \\
\text { [R] }\end{array}$ & $\begin{array}{l}\text { Does not work } \\
\text { with facilitator(s) } \\
\text { on establishing } \\
\text { and meeting } \\
\text { mutual goals of } \\
\text { treatment. }\end{array}$ & $\begin{array}{l}\text { Makes minimal } \\
\text { attempt to work } \\
\text { with facilitator(s) } \\
\text { on establishing } \\
\text { and meeting } \\
\text { mutual goals of } \\
\text { treatment. }\end{array}$ & $\begin{array}{l}\text { Often works } \\
\text { with facilitator(s) } \\
\text { on establishing } \\
\text { and meeting } \\
\text { mutual goals of } \\
\text { treatment. } \\
\text { Usually in the } \\
\text { upper ones }\end{array}$ & $\begin{array}{l}\text { Usually works } \\
\text { with facilitator(s) } \\
\text { on establishing } \\
\text { and meeting } \\
\text { mutual goals of } \\
\text { treatment. }\end{array}$ & $\begin{array}{l}\text { Works } \\
\text { consistently and } \\
\text { well with } \\
\text { facilitator(s) on } \\
\text { establishing and } \\
\text { meeting mutual } \\
\text { goals of } \\
\text { treatment. }\end{array}$ \\
\hline $\begin{array}{l}\text { 8. Motivation to } \\
\text { change behaviour } \\
\text { (R\} }\end{array}$ & $\begin{array}{l}\text { Not motivated to } \\
\text { change, no } \\
\text { perceived } \\
\text { genuine interest } \\
\text { in changing } \\
\text { problem } \\
\text { behaviour, or no } \\
\text { belief that s/he } \\
\text { can change or } \\
\text { that change is } \\
\text { worthwhile. } \\
\text { (Precontemplatio } \\
\text { n) }\end{array}$ & $\begin{array}{l}\text { Motivation to } \\
\text { change is } \\
\text { inconsistent or } \\
\text { transient; } \\
\text { thinking about } \\
\text { making changes } \\
\text { but not yet } \\
\text { committed to } \\
\text { taking action. } \\
\text { (Contemplation) }\end{array}$ & $\begin{array}{l}\text { Intends to } \\
\text { change and may } \\
\text { have already } \\
\text { taken steps } \\
\text { towards making } \\
\text { changes. } \\
\text { (Preparation/Acti } \\
\text { on) }\end{array}$ & $\begin{array}{l}\text { Actively } \\
\text { engaged in } \\
\text { making changes. } \\
\text { (Action) }\end{array}$ & $\begin{array}{l}\text { Actively } \\
\text { engaged in } \\
\text { making changes } \\
\text { for several } \\
\text { months; } \\
\text { successfully } \\
\text { coped with } \\
\text { difficult } \\
\text { situations; high } \\
\text { self-efficacy. } \\
\text { (Acton or } \\
\text { Maintenance) }\end{array}$ \\
\hline $\begin{array}{l}\text { 9. Accepts } \\
\text { responsibility for } \\
\text { his/her role in } \\
\text { criminal, } \\
\text { antisocial, and/or } \\
\text { problematic } \\
\text { behaviour [P] }\end{array}$ & $\begin{array}{l}\text { Accepts no } \\
\text { responsibility for } \\
\text { his/her role in } \\
\text { criminal, } \\
\text { antisocial and/or } \\
\text { problematic } \\
\text { behaviour (e.g., } \\
\text { uses excuses or } \\
\text { blaming; does } \\
\text { not see actions as } \\
\text { criminal). }\end{array}$ & $\begin{array}{l}\text { Accepts partial } \\
\text { responsibility for } \\
\text { his/her role in } \\
\text { criminal, } \\
\text { antisocial and/or } \\
\text { problematic } \\
\text { behaviour (e.g., } \\
\text { sometimes uses } \\
\text { excuses or } \\
\text { blaming). }\end{array}$ & $\begin{array}{l}\text { Accepts } \\
\text { responsibility for } \\
\text { his/her role in } \\
\text { criminal, } \\
\text { antisocial and/or } \\
\text { problematic } \\
\text { behaviour (e.g., } \\
\text { rarely uses } \\
\text { excuses or } \\
\text { blaming). }\end{array}$ & $\begin{array}{l}\text { Consistently } \\
\text { accepts } \\
\text { responsibility for } \\
\text { his or her role in } \\
\text { criminal, } \\
\text { antisocial and/or } \\
\text { problematic } \\
\text { behaviour. }\end{array}$ & $\begin{array}{l}\text { Fully recognises } \\
\text { his/her own role } \\
\text { and consistently } \\
\text { accepts full } \\
\text { responsibility in } \\
\text { criminal, } \\
\text { antisocial and/or } \\
\text { problematic } \\
\text { behaviour. }\end{array}$ \\
\hline $\begin{array}{l}\text { 10. Prosocial } \\
\text { goal SETTING } \\
{[\mathrm{P}]}\end{array}$ & $\begin{array}{l}\text { Has not set goals } \\
\text { to address } \\
\text { criminogenic } \\
\text { needs, or goals } \\
\text { are very } \\
\text { unrealistic, or not } \\
\text { prosocial. }\end{array}$ & $\begin{array}{l}\text { Has set some } \\
\text { goals to address } \\
\text { criminogenic } \\
\text { needs, but goals } \\
\text { are somewhat } \\
\text { unrealistic or } \\
\text { inappropriate or } \\
\text { does not plan or } \\
\text { take } \\
\text { responsibility for } \\
\text { achieving goals. }\end{array}$ & $\begin{array}{l}\text { Has set realistic } \\
\text { goals to address } \\
\text { criminogenic } \\
\text { needs and has } \\
\text { some idea how to } \\
\text { achieve goals. }\end{array}$ & $\begin{array}{l}\text { Sets appropriate } \\
\text { goals to address } \\
\text { criminogenic } \\
\text { needs and has a } \\
\text { realistic plan to } \\
\text { achieve goals. }\end{array}$ & $\begin{array}{l}\text { Sets appropriate } \\
\text { goals to address } \\
\text { all criminogenic } \\
\text { needs, sees the } \\
\text { importance of } \\
\text { short and long } \\
\text { term goals, and } \\
\text { has a realistic } \\
\text { plan to achieve } \\
\text { goals. }\end{array}$ \\
\hline
\end{tabular}




\begin{tabular}{|c|c|c|c|c|c|}
\hline $\begin{array}{l}\text { 11. Understands } \\
\text { the consequences } \\
\text { of criminal, } \\
\text { antisocial, and/or } \\
\text { problematic } \\
\text { behaviour to self } \\
\text { and others [P) }\end{array}$ & $\begin{array}{l}\text { Does not } \\
\text { understand the } \\
\text { consequences to } \\
\text { self and others. }\end{array}$ & $\begin{array}{l}\text { Insufficient or } \\
\text { inconsistent } \\
\text { understanding of } \\
\text { the consequences } \\
\text { to self and } \\
\text { others. }\end{array}$ & $\begin{array}{l}\text { Satisfactory } \\
\text { understanding of } \\
\text { the consequences } \\
\text { to self and } \\
\text { others. }\end{array}$ & $\begin{array}{l}\text { Good } \\
\text { understanding of } \\
\text { the consequence } \\
\text { of his/her } \\
\text { behaviour to self } \\
\text { and others } \\
\text { including } \\
\text { victim(s), family } \\
\text { and community. }\end{array}$ & $\begin{array}{l}\text { Thorough } \\
\text { understanding of } \\
\text { the short and } \\
\text { long term } \\
\text { consequences for } \\
\text { the full range of } \\
\text { targets - } \\
\text { victim(s), self, } \\
\text { work, family, } \\
\text { friends, } \\
\text { community and } \\
\text { society. }\end{array}$ \\
\hline $\begin{array}{l}\text { 12. Shows } \\
\text { concern for } \\
\text { consequences of } \\
\text { criminal, } \\
\text { antisocial, and/or } \\
\text { problematic } \\
\text { behaviour to self } \\
\text { and others }(\mathrm{P})\end{array}$ & $\begin{array}{l}\text { Does not show } \\
\text { concern for } \\
\text { consequences of } \\
\text { behaviour to self } \\
\text { and others. }\end{array}$ & $\begin{array}{l}\text { Insufficient or } \\
\text { inconsistent } \\
\text { concern for } \\
\text { consequences of } \\
\text { behaviour to self } \\
\text { and others. }\end{array}$ & $\begin{array}{l}\text { Concern for the } \\
\text { consequences to } \\
\text { self and others is } \\
\text { Satisfactory. } \\
\text { Actions are } \\
\text { usually } \\
\text { consistent with } \\
\text { expressed } \\
\text { concern. }\end{array}$ & $\begin{array}{l}\text { Consistently } \\
\text { shows concern } \\
\text { for the } \\
\text { consequences of } \\
\text { behaviour to self } \\
\text { and others. }\end{array}$ & $\begin{array}{l}\text { Consistently } \\
\text { shows genuine } \\
\text { and deep concern } \\
\text { for the } \\
\text { consequences of } \\
\text { behaviour to self } \\
\text { and others. }\end{array}$ \\
\hline $\begin{array}{l}\text { 13. Prosocial } \\
\text { attitudes, beliefs } \\
\text { and values }(\mathrm{P})\end{array}$ & $\begin{array}{l}\text { Never or rarely } \\
\text { demonstrates } \\
\text { prosocial } \\
\text { attitudes, beliefs } \\
\text { and values. }\end{array}$ & $\begin{array}{l}\text { Sometimes } \\
\text { demonstrates } \\
\text { prosocial } \\
\text { attitudes, beliefs } \\
\text { and values. }\end{array}$ & $\begin{array}{l}\text { Usually } \\
\text { demonstrates } \\
\text { prosocial } \\
\text { attitudes, beliefs } \\
\text { and values. }\end{array}$ & $\begin{array}{l}\text { Consistently } \\
\text { demonstrates } \\
\text { prosocial beliefs, } \\
\text { attitudes and } \\
\text { values. }\end{array}$ & $\begin{array}{l}\text { Consistently and } \\
\text { fully } \\
\text { demonstrates } \\
\text { prosocial } \\
\text { attitudes, beliefs } \\
\text { and values. }\end{array}$ \\
\hline $\begin{array}{l}\text { 14. Knows a } \\
\text { range of self } \\
\text { management } \\
\text { skills (e.g., } \\
\text { thought stopping; } \\
\text { problem solving, } \\
\text { relaxation) and } \\
\text { social skills (e.g., } \\
\text { active listening) } \\
\text { (P) }\end{array}$ & $\begin{array}{l}\text { No knowledge of } \\
\text { self management } \\
\text { and social skills. }\end{array}$ & $\begin{array}{l}\text { Limited } \\
\text { awareness of self } \\
\text { management and } \\
\text { social skills. }\end{array}$ & $\begin{array}{l}\text { Satisfactory } \\
\text { knowledge of } \\
\text { self management } \\
\text { and social skills } \\
\text { (e.g., describes } \\
\text { some skills, } \\
\text { provides some } \\
\text { examples of } \\
\text { skills use). }\end{array}$ & $\begin{array}{l}\text { Demonstrates } \\
\text { good knowledge } \\
\text { of many self } \\
\text { management and } \\
\text { social skills (e.g., } \\
\text { paraphrases to } \\
\text { show } \\
\text { understanding, } \\
\text { provide } \\
\text { appropriate } \\
\text { examples). }\end{array}$ & $\begin{array}{l}\text { Thorough } \\
\text { understanding of } \\
\text { a full range of } \\
\text { skills, including } \\
\text { personalising and } \\
\text { integrating } \\
\text { information. }\end{array}$ \\
\hline $\begin{array}{l}\text { 15. Demonstrates } \\
\text { he or she can use } \\
\text { a range of self } \\
\text { management } \\
\text { skills (e.g., } \\
\text { thought stopping; } \\
\text { problem solving, } \\
\text { relaxation) and } \\
\text { social skills } \\
\text { (e.g.,active } \\
\text { listening) (P) }\end{array}$ & $\begin{array}{l}\text { Demonstrates no } \\
\text { use of self } \\
\text { management and } \\
\text { social skills. }\end{array}$ & $\begin{array}{l}\text { Demonstrates } \\
\text { only partial or } \\
\text { insufficient use } \\
\text { of self } \\
\text { management and } \\
\text { social skills. }\end{array}$ & $\begin{array}{l}\text { Satisfactory use } \\
\text { of a range of self } \\
\text { management and } \\
\text { social skills. }\end{array}$ & $\begin{array}{l}\text { Competently } \\
\text { uses a range of } \\
\text { self management } \\
\text { and social skills. }\end{array}$ & $\begin{array}{l}\text { Competently } \\
\text { uses a range of } \\
\text { self management } \\
\text { skills and applies } \\
\text { skills in } \\
\text { appropriate } \\
\text { situations. }\end{array}$ \\
\hline $\begin{array}{l}\text { 16. Recognition } \\
\text { of relevant } \\
\text { factors related to } \\
\text { his/her offence } \\
\text { pattern }(P)\end{array}$ & $\begin{array}{l}\text { Demonstrates no } \\
\text { recognition of } \\
\text { the relevant } \\
\text { factors. }\end{array}$ & $\begin{array}{l}\text { Recognises some } \\
\text { relevant factors. }\end{array}$ & $\begin{array}{l}\text { Recognises most } \\
\text { critical relevant } \\
\text { factors. }\end{array}$ & $\begin{array}{l}\text { Recognises most } \\
\text { of the relevant } \\
\text { factors. }\end{array}$ & $\begin{array}{l}\text { Thorough } \\
\text { recognition of } \\
\text { the relevant } \\
\text { factors. }\end{array}$ \\
\hline
\end{tabular}




\begin{tabular}{|c|c|c|c|c|c|}
\hline $\begin{array}{l}\text { 17. Develops a } \\
\text { self- } \\
\text { management/ } \\
\text { relapse } \\
\text { prevention plan } \\
\text { to address the } \\
\text { relevant risk } \\
\text { factors }(\mathrm{P})\end{array}$ & $\begin{array}{l}\text { Did not develop } \\
\text { a plan. }\end{array}$ & $\begin{array}{l}\text { Plan is } \\
\text { insufficient or } \\
\text { unrealistic. }\end{array}$ & $\begin{array}{l}\text { Plan is fairly } \\
\text { realistic and } \\
\text { addresses many } \\
\text { of the relevant } \\
\text { risk factors. It is } \\
\text { adequate }\end{array}$ & $\begin{array}{l}\text { Plan is realistic } \\
\text { and addresses } \\
\text { most of the } \\
\text { relevant risk } \\
\text { factors. }\end{array}$ & $\begin{array}{l}\text { Plan is very } \\
\text { detailed and } \\
\text { realistic, } \\
\text { including } \\
\text { application of } \\
\text { skills, personal } \\
\text { strengths and } \\
\text { community } \\
\text { resources to } \\
\text { address all of the } \\
\text { relevant risk } \\
\text { factors. }\end{array}$ \\
\hline Prof & $\begin{array}{l}\text { Wertingely to } \\
\text { impede progress }\end{array}$ & $\begin{array}{l}\text { Somewhat likely } \\
\text { to impede. } \\
\text { progress }\end{array}$ & $\begin{array}{l}0 \\
\text { No problem }\end{array}$ & $\begin{array}{l}+1 \\
\text { likely to } \\
\text { facillate } \\
\text { progress }\end{array}$ & $\begin{array}{l}12 \\
\text { Very likely to } \\
\text { facilitare } \\
\text { progress }\end{array}$ \\
\hline $\begin{array}{l}\text { 18. Ability to } \\
\text { learn program } \\
\text { material }(\mathrm{R}]\end{array}$ & $\begin{array}{l}\text { Substantial } \\
\text { problems } \\
\text { learning material } \\
\text { (e.g., agitated or } \\
\text { restless; poor } \\
\text { attention or } \\
\text { concentration; } \\
\text { unable to } \\
\text { assimilate } \\
\text { content; } \\
\text { disorganised; } \\
\text { evidence of } \\
\text { learning } \\
\text { disability or } \\
\text { being heavily } \\
\text { medicated). }\end{array}$ & $\begin{array}{l}\text { Some problems } \\
\text { learning } \\
\text { material. }\end{array}$ & $\begin{array}{l}\text { Usually appears } \\
\text { able to learn } \\
\text { program } \\
\text { materials (e.g., } \\
\text { rarely agitated, } \\
\text { rare lapses in } \\
\text { attention; no } \\
\text { learning } \\
\text { disability or } \\
\text { medications). }\end{array}$ & $\begin{array}{l}\text { Good ability to } \\
\text { learn program } \\
\text { material. }\end{array}$ & $\begin{array}{l}\text { Very good } \\
\text { ability to learn } \\
\text { program material } \\
\text { (e.g., attentive, } \\
\text { learns quickly; } \\
\text { sees relevance of } \\
\text { the material). }\end{array}$ \\
\hline $\begin{array}{l}\text { 19. Relevance of } \\
\text { program material } \\
\text { for the } \\
\text { participant }[R]\end{array}$ & $\begin{array}{l}\text { Program material } \\
\text { fails to respond } \\
\text { the cultural } \\
\text { background and } \\
\text { circumstances of } \\
\text { participant. }\end{array}$ & $\begin{array}{l}\text { Program material } \\
\text { inadequately } \\
\text { responds to the } \\
\text { cultural } \\
\text { background and } \\
\text { circumstances of } \\
\text { the participant. }\end{array}$ & $\begin{array}{l}\text { Program material } \\
\text { generally } \\
\text { responds to the } \\
\text { cultural } \\
\text { background and } \\
\text { circumstances } \\
\text { background of } \\
\text { the participant. }\end{array}$ & $\begin{array}{l}\text { Program material } \\
\text { is relevant to the } \\
\text { cultural } \\
\text { background and } \\
\text { circumstances of } \\
\text { the participant. }\end{array}$ & $\begin{array}{l}\text { Program material } \\
\text { is very relevant } \\
\text { to the cultural } \\
\text { background and } \\
\text { circumstances of } \\
\text { the participant. }\end{array}$ \\
\hline
\end{tabular}

\section{Absences (Mid and Post only)}

1. Number of authorised absences

2. Number of unauthorised absences

3. Total number of absences out of out of out of sessions. sessions. 


\section{GPPM Scoring Guide}

\section{General description and purpose}

The GENERIC PROGRAM PERFORMANCE MEASURE (GPPM) is based on a rating system used in a number of programs and clinical situations that allows the intervener to systematically assess the progress of a participant on the goals of the intervention. A similar measure is used in several CSC programs. One version has been shown (Hogue, 1993; 1994) to have good psychometric properties indicating that the tool is reliable (e.g., two people rating a participant using the same measure would provide similar ratings). The GPPM, though based on the facilitator's opinion, should permit a reliable degree of agreement between raters because the scores are anchored by descriptive details. This version of the measure will be used across all program areas.

Rating systems of any kind work best when the rater seeks information from a variety of sources. Best practice is for two facilitators who know the participant well to complete the measure together so that they can confirm their rating. Note that the rating is based on behavioural indicators such as the quality of the participant's participation in role-plays, group exercises, quality of homework, indication of skill development and application. A reliable observation of these indices would mean that anyone watching the participant in group or outside group would agree on the rating. Do not rate based on the RISK of the participant (your concern that he or she will reoffend), or on his or her progress relative to where he or she was when they started. For example, participants who have poor skills but make limited progress should not be rated +1 or +2 simply because they did better than expected of them. Do not rate participants based on their ranking relative to others in the group. For example, a participant whose skill use and knowledge base is good, but the rest of participants in the group have better skills should not receive a minus rating. Participants should be rated on the basis of their actual behaviour and ability.

\section{Directions for completing the ratings}

The measure is composed of 3 scales that tap Performance (items marked P), that is, skill, attitude and knowledge gain; a scale that assesses Effort (items marked E), that is, the extent to which the participant tries to address the objectives of the program (through completion of work, in class participation, etc.) and a scale that taps Responsivity (items marked R), that reflect factors that could affect the participant's progress in treatment that should be considered and, if possible, addressed in order to maximize his or her potential for a positive outcome. The last three responsivity items assess three factors that may impinge on the participant's progress in the program.

The first rating should be completed based on the participant's early performance in group (the first 2-3 sessions). The midterm assessment should be completed after the mid point session and the final rating is completed at the end of the program (after the last session). The objectives of the measure have been selected because they are common to most of the correctional programs. However, some items may be harder to rate because the program does not explicitly teach the objective. For example, the Reasoning and 
Rehabilitation program does not have a Relapse Prevention or Self Monitoring component, but CPOs may still assess the extent to which they are aware of their risk factors, and the extent to which they know how to address them. Use your observation of the participant's knowledge and behaviour to rate the item as best you can. It will also be difficult to assess the participant on items that are not introduced until later in the program (e.g., self monitoring/relapse prevention). You will have to rely on your observations early in the program of the extent of his or her possible performance on the item. DO NOT provide a rating of Not Applicable or a rating in between the rating levels.

\section{The Rating Guide}

The measure itself has descriptions of elements of the key objectives for a -2 rating and a +2 rating. The ratings from -1 to +1 are not usually described in the same detail. With the exception of the last three items, in general, ratings correspond to the following:

-2 should indicate no evidence of the elements of the program objective. On the Performance ratings, sources of evidence of a -2 rating may be presence of risky thinking and/or behavioural patterns and an overall poor performance on the program objective. On the Effort items, a score of -2 in the mid or post treatment evaluation indicates the participant is making no effort or has no realisation of the need to address the objective. A level of -2 would mean that the participant is not meeting the expectations of a successful completion of the program on this element.

-1 should indicate limited or inconsistent evidence of the element of the program objective. On the Performance ratings, sources of evidence of a score of -1 in mid or post treatment would indicate limited or inconsistent use of the skills and/or continued evidence of antisocial attitude. On the Effort ratings -1 in the mid or post treatment evaluation indicates an inconsistent or limited effort exerted associated with the goal objective. Participants scoring at this level are not up to the level expected for successful completion of the program on this objective.

0 should represent an acceptable level of performance on the elements of the objective. On the Performance ratings, a score of 0 should indicate that there is usually evidence that the participant demonstrates the elements of the specific program objective and very rare evidence of continued problematic thinking or behaviour. On the Effort ratings, participants who score 0 at mid or post program usually provide evidence that they make an acceptable effort to meet the program goal. They have achieved a level of performance on elements of skill development, attitude change or knowledge gain to have successfully completed this objective of the program.

+1 should represent a good level of performance on the elements of the objective. On the Performance rating, a score of +1 should indicate that there is consistent evidence of prosocial skills, and attitude and knowledge and no evidence of 
continued problematic thinking or behaviour. On the Effort items there is evidence of consistently good motivation to achieve the program objective. A score of +1 at mid or end of program indicates positive participation, successful program completion and a positive evaluation on this objective of the program.

+2 should represent a consistently excellent level of performance on the objective. On the Performance rating, a score of +2 should indicate consistent evidence of a high level of prosocial skill use, positive prosocial attitude and knowledge. On the Effort items, the work toward meeting the objective should be a model to other participants. There would be no lapses in behaviour. A score of +2 at the mid and post program assessment, should be evidence that $\mathrm{s} / \mathrm{he}$ has learned the skills and acquired the necessary knowledge and incorporates them very well. Their performance and effort would be better than expected of participants in general. They would be considered role models to other participants on this element.

The last two items are Responsivity items that reflect very specific problems that participants may face that facilitators believe could interfere with either their Performance or Effort in the program. They are scored differently than the preceding items. Item 18 captures a range of learning problems that make understanding and using the program material difficult.

-2 A score of -2 indicates that the issue is a serious problem interfering with progress

+2 Indicates that the participant has strengths in learning and learning strategies that enhance progress.

Item 19 assesses the extent to which the program material is alien to the participants possibly because the skills, scenarios, attitudes are not referenced in their culture or background and therefore they may not have an opportunity to apply the objectives of the program to their lives.

-2 indicates that the program material is completely novel to the participant and unlikely to have any application to the offender's context in the community.

+2 indicates a full understanding of the program material and how it can be integrated into the participant's life in the community. 


\section{Measure scoring method:}

$\underline{\text { Scale and Total Score: }}$

Add together the $-2,-1,0,+1,+2$ scores for items on each scale score and the total score

Total scale score for Effort: items 1, 2, 3, 4

Total scale score for Performance: items 5, 9, 10, 11, 12, 13, 14, 15, 16

Total for Responsivity: items 6, 7, 8, 17

Total Program Score for the measure: add all the items in Effort and Performance divide by the number of items scored for the overall score which would be between -2 and +2 .

\section{Interpretation:}

- An overall score of $\mathbf{- 2}$ to $\mathbf{- 1}$ for the program indicates poor Effort, and Performance (skill and knowledge). If the offender completes the program his/her report would read "attended all sessions". They may need more maintenance to assist them to develop and augment their skills.

- An overall score of $\mathbf{- 1}$ to less than 0 indicates some Effort demonstrated, some Skill and Knowledge development, but pointing to an overall report comment of "attended all sessions" They may need more maintenance to assist them to develop and augment their skills.

- An overall score $\mathbf{0}$ to $+\mathbf{1}$ indicates satisfactory to good level of Effort, Skill and Knowledge development and pointing to a successful completion of the program

- An overall score of $+\mathbf{1}$ to $+\mathbf{2}$ indicates good to excellent level of Effort and Performance to the program and points to a successful completion of all sessions of the program.

This measure would be used in conjunction with other program performance measures, your observations, and the observations of collaterals who observe the offender to guide report writing. The written final program report would integrate a description of the offenders' (1) effort, (2) performance, and (3) responsivity to the program based on specific changes described in the individual items; raw scores are not provided in reports.

Note: Responsivity items are removed from the calculation but, should be considered in the final report. 


\section{Appendix B: SIR-Proxy Items}

1) Current Offences

Incest - current sentence

Paedophilia - current sentence

Other sex offence (excluding sexual assault) - current sentence

Victims of sex offence(s) were 17 years old or younger

Homicide

Caused death

Drug cultivation

Drug trafficking

Drug importation

Violence (assault, robbery)

Arson/fire setting

Forcible confinement/kidnapping

Conspire to commit

Use of prohibited weapons

Discharge firearms

Break and enter with commission of another offence

2) Age at Admission

40 or over

20 or under

3) Previous Incarceration

Adult court or youth court involvements

Two to four convictions

One conviction

Five to nine convictions

Ten to fourteen convictions

4) Revocation or Forfeiture

Failures on conditional release

5) Act of Escape

Attempted escapes/UAL/escapes from secure custody

6) Age at First Adult Conviction

Youth court involvements 
7) Previous Convictions for Assault

Violence (assault, robbery)

8) Marital Status at Most Recent Admission

Currently single

9) Interval at Risk Since Last Offence

No previous youth/adult court convictions and no previous federal terms Less than 6 months since last incarceration

10) Current Total Aggregate Sentence

Aggregate sentence is 5 years and up to 6 years

Aggregate sentence is 6 years or more

11) Previous Convictions for Sexual Offences

Sexual offence

12) Previous Convictions for Break and Enter

One adult/youth court conviction

Two to four adult/youth court convictions

Five to nine adult/youth court convictions

Ten to fourteen adult/youth court convictions

Fifteen or more adult/youth court convictions

Break and enter with commission of another offence

13) Employment Status at Arrest

Was employed at time of arrest for current offence(s) 
Appendix C: Reliability Analyses of the Composite Offender Competency Index

Table A. Inter-item Correlations for Need for Change Subscale.

\begin{tabular}{lcc}
\hline \multicolumn{1}{c}{ Scale Item } & $\begin{array}{c}\text { Corrected Item-Total } \\
\text { Correlation }\end{array}$ & $\begin{array}{c}\text { Cronbach's Alpha if } \\
\text { Item Deleted }\end{array}$ \\
\hline Motivation & .422 & .444 \\
Negative attitude towards rehabilitation & .394 & .496 \\
Narrow and rigid thinking & .382 & .494 \\
\hline
\end{tabular}

Note. 3-item scale Cronbach's $\alpha=.58$.

Table B. Inter-item Correlations for Personal Accountability Subscale.

\begin{tabular}{lcc}
\hline \multicolumn{1}{c}{ Scale Item } & $\begin{array}{c}\text { Corrected Item-Total } \\
\text { Correlation }\end{array}$ & $\begin{array}{c}\text { Cronbach's Alpha if } \\
\text { Item Deleted }\end{array}$ \\
\hline Feels especially self-important & .299 & .677 \\
$\begin{array}{l}\text { Incapable of understanding the feelings } \\
\text { of others }\end{array}$ & .538 & .598 \\
Has disregard for others & .431 & .638 \\
Socially unaware & .394 & .650 \\
Hostile & .363 & .659 \\
Is not conscientious & .456 & .629 \\
\hline
\end{tabular}

Note. 6-item scale Cronbach's $\alpha=.68$. 
Table C. Inter-item Correlations for Cognitive Flexibility Subscale.

\begin{tabular}{lcc}
\hline \multicolumn{1}{c}{ Scale Item } & $\begin{array}{c}\text { Corrected Item-Total } \\
\text { Correlation }\end{array}$ & $\begin{array}{c}\text { Cronbach's Alpha if } \\
\text { Item Deleted }\end{array}$ \\
\hline $\begin{array}{l}\text { Has difficulties solving interpersonal } \\
\text { problems }\end{array}$ & .538 & .582 \\
Unable to recognize problem areas & .328 & .655 \\
Poor conflict resolution & .499 & .595 \\
Copes with stress poorly & .320 & .655 \\
Unable to generate choices & .472 & .603 \\
Unaware of consequences & .269 & .675 \\
\hline
\end{tabular}

Note. 6-item scale Cronbach's $\alpha=.67$.

Table D. Inter-item Correlations for Inhibitory Control Subscale.

$\begin{array}{ccc}\text { Scale Item } & \begin{array}{c}\text { Corrected Item-Total } \\ \text { Correlation }\end{array} & \begin{array}{c}\text { Cronbach's Alpha if } \\ \text { Item Deleted }\end{array}\end{array}$

\begin{tabular}{lll}
\hline Impulsive & .415 & .505 \\
Takes risks inappropriately & .304 & .562 \\
Thrill seeking & .366 & .530 \\
Has low frustration tolerance & .348 & .539 \\
Non-reflective & .319 & .556
\end{tabular}

Note. 5 -item scale Cronbach's $\alpha=.59$. 
Table E. Inter-item Correlations for Knowledge Acquisition Subscale.

\begin{tabular}{lcc}
\hline \multicolumn{1}{c}{ Scale Item } & $\begin{array}{c}\text { Corrected Item-Total } \\
\text { Correlation }\end{array}$ & $\begin{array}{c}\text { Cronbach's Alpha if } \\
\text { Item Deleted }\end{array}$ \\
\hline Finds learning difficult & .677 & .826 \\
Learning disabilities & .533 & .840 \\
Memory problems & .503 & .843 \\
Concentration problems & .544 & .840 \\
Problems with reading & .673 & .827 \\
$\begin{array}{l}\text { Problems with writing (employment } \\
\text { domain) }\end{array}$ & .702 & .824 \\
Problems with numeracy & .543 & .841 \\
$\begin{array}{l}\text { Difficulty comprehending instructions } \\
\text { Has problem writing (community }\end{array}$ & .554 & .839 \\
functioning domain) & .548 & .839 \\
$\begin{array}{l}\text { Unable to express verbally (community } \\
\text { functioning domain) }\end{array}$ & .235 & .858 \\
\hline
\end{tabular}

Note. 10-item scale Cronbach's $\alpha=.85$. 
Appendix D: Factor Analysis in Development Sample

Table A. Oblique Rotated (Promax) Pattern Matrix Extracted with Principal Axis

Factoring for Offender Competencies in Development Sample.

\begin{tabular}{|c|c|c|c|c|c|c|}
\hline & \multicolumn{6}{|c|}{ Factor } \\
\hline & 1 & 2 & 3 & 4 & 5 & 6 \\
\hline $\begin{array}{l}\text { Feels especially self- } \\
\text { important }\end{array}$ & .630 & -.046 & -.123 & -.025 & -.201 & .056 \\
\hline Motivation & .559 & -.014 & -.051 & .026 & .049 & -.041 \\
\hline Hostility problem & .551 & -.021 & .153 & .029 & -.136 & -.093 \\
\hline $\begin{array}{l}\text { Narrow and rigid } \\
\text { thinking }\end{array}$ & .528 & .125 & .083 & -.109 & -.016 & .061 \\
\hline $\begin{array}{l}\text { Poor attitude toward } \\
\text { rehabilitation }\end{array}$ & .517 & .038 & -.034 & -.014 & -.054 & .009 \\
\hline $\begin{array}{l}\text { Incapable of } \\
\text { understanding the } \\
\text { feelings of others }\end{array}$ & .470 & .045 & .013 & -.056 & .245 & -.054 \\
\hline $\begin{array}{l}\text { Low frustration } \\
\text { tolerance }\end{array}$ & .431 & -.107 & .342 & .160 & -.101 & -.091 \\
\hline Has disregard for others & .376 & .029 & .152 & -.097 & .041 & .170 \\
\hline Low conscientiousness & .349 & -.004 & -.076 & .036 & .282 & .149 \\
\hline Reading problem & -.024 & .820 & .004 & -.044 & -.027 & .030 \\
\hline Numeracy problem & -.005 & .585 & .056 & .048 & -.075 & .043 \\
\hline Poor writing & .042 & .563 & -.049 & .049 & -.007 & -.012 \\
\hline Comprehension problem & .066 & .389 & -.026 & .278 & -.009 & .009 \\
\hline Poor oral & .020 & .282 & -.030 & -.036 & .140 & -.047 \\
\hline Poor problem solving & -.005 & .028 & .710 & -.050 & .082 & -.072 \\
\hline Poor conflict resolution & .091 & .000 & .703 & -.007 & -.012 & -.087 \\
\hline Poor stress management & -.075 & -.009 & .625 & .001 & -.072 & .084 \\
\hline Impulsive & -.026 & -.060 & .409 & .093 & .047 & .293 \\
\hline Concentration problems & -.035 & -.023 & .046 & .753 & -.031 & .068 \\
\hline Memory problems & .008 & .045 & -.015 & .619 & -.013 & -.021 \\
\hline Learning disability & -.046 & .039 & -.027 & .595 & .103 & -.034 \\
\hline Learning difficulty & -.026 & .260 & -.002 & .559 & .019 & -.044 \\
\hline
\end{tabular}


Offender Competencies 128

\begin{tabular}{lcccccc}
\hline $\begin{array}{l}\text { Unaware of } \\
\text { consequences }\end{array}$ & -.215 & -.034 & -.015 & .022 & $\mathbf{. 7 0 8}$ & -.029 \\
$\begin{array}{l}\text { Unable to generate } \\
\text { choices }\end{array}$ & -.161 & .025 & $\mathbf{. 3 3 3}$ & -.031 & $\mathbf{. 4 7 6}$ & .029 \\
$\begin{array}{l}\text { Socially unaware } \\
\text { Non-reflective }\end{array}$ & .177 & .001 & -.055 & .090 & $\mathbf{. 4 1 3}$ & -.047 \\
$\begin{array}{l}\text { Unable to recognize } \\
\text { problem areas }\end{array}$ &. $\mathbf{3 1 7}$ & -.063 & -.104 & .064 & $\mathbf{. 4 0 5}$ & .066 \\
$\begin{array}{l}\text { Problematic risk taking } \\
\text { Thrill seeking }\end{array}$ & -.049 & .080 & .014 & -.085 & $\mathbf{. 3 7 6}$ & -.083 \\
\hline
\end{tabular}

Table B. Oblique Rotated (Promax) Structure Matrix Extracted with Principal Axis Factoring for Offender Competencies in Development Sample.

\begin{tabular}{|c|c|c|c|c|c|c|}
\hline & \multicolumn{6}{|c|}{ Factor } \\
\hline & 1 & 2 & 3 & 4 & 5 & 6 \\
\hline $\begin{array}{l}\text { Narrow and rigid } \\
\text { thinking }\end{array}$ & .588 & .155 & .362 & .103 & .333 & .311 \\
\hline $\begin{array}{l}\text { Incapable of } \\
\text { understanding the } \\
\text { feelings of others }\end{array}$ & .588 & .131 & .337 & .122 & .497 & .222 \\
\hline Motivation & .545 & .089 & .251 & .118 & .335 & .204 \\
\hline Low conscientiousness & .541 & .118 & .286 & .161 & .496 & .360 \\
\hline Has disregard for others & .538 & .070 & .396 & .068 & .348 & .388 \\
\hline $\begin{array}{l}\text { Low frustration } \\
\text { tolerance }\end{array}$ & .525 & .109 & .518 & .246 & .282 & .197 \\
\hline Hostility & .515 & .087 & .354 & .128 & .218 & .165 \\
\hline $\begin{array}{l}\text { Poor attitude toward } \\
\text { rehabilitation }\end{array}$ & .476 & .095 & .216 & .090 & .230 & .211 \\
\hline $\begin{array}{l}\text { Feels especially self- } \\
\text { important }\end{array}$ & .465 & -.022 & .118 & -.011 & .102 & .233 \\
\hline Reading problem & .098 & .785 & .138 & .476 & .113 & .037 \\
\hline Numeracy problem & .103 & .614 & .165 & .427 & .079 & .063 \\
\hline
\end{tabular}


Offender Competencies 129

\begin{tabular}{|c|c|c|c|c|c|c|}
\hline Poor writing & .106 & .590 & .091 & .401 & .109 & .012 \\
\hline Comprehension problem & .168 & .571 & .167 & .532 & .158 & .069 \\
\hline Poor oral & .101 & .281 & .070 & .168 & .170 & -.003 \\
\hline Poor conflict resolution & .409 & .143 & .714 & .212 & .317 & .182 \\
\hline Poor problem solving & .372 & .147 & .709 & .193 & .359 & .180 \\
\hline Poor stress management & .244 & .092 & .582 & .162 & .178 & .238 \\
\hline Impulsive & .350 & .095 & .529 & .213 & .301 & .437 \\
\hline Concentration problems & .145 & .461 & .260 & .744 & .162 & .135 \\
\hline Learning difficulty & .115 & .617 & .198 & .720 & .172 & .015 \\
\hline Memory problems & .112 & .438 & .173 & .639 & .134 & .038 \\
\hline Learning disability & .107 & .427 & .170 & .624 & .204 & .027 \\
\hline $\begin{array}{l}\text { Unaware of } \\
\text { consequences }\end{array}$ & .163 & .075 & .170 & .118 & .571 & .070 \\
\hline Non-reflective & .523 & .086 & .263 & .156 & .560 & .288 \\
\hline $\begin{array}{l}\text { Unable to generate } \\
\text { choices }\end{array}$ & .291 & .136 & .460 & .170 & .535 & .198 \\
\hline $\begin{array}{l}\text { Unable to recognize } \\
\text { problem areas }\end{array}$ & .446 & .138 & .277 & .103 & .504 & .138 \\
\hline Socially unaware & .378 & .152 & .226 & .201 & .497 & .136 \\
\hline Problematic risk taking & .233 & .064 & .207 & .063 & .127 & .623 \\
\hline Thrill-seeking & .339 & -.025 & .177 & .058 & .182 & .530 \\
\hline
\end{tabular}


Appendix E: Reliability Analyses of the Factor- Analysis Derived Offender Competency Index in the Development Sample

Table A. Inter-item Correlations for Personal Accountability and Need for Change Factor.

\begin{tabular}{lcc}
\hline \multicolumn{1}{c}{ Item } & $\begin{array}{c}\text { Corrected Item-Total } \\
\text { Correlation }\end{array}$ & $\begin{array}{c}\text { Cronbach's Alpha if } \\
\text { Item Deleted }\end{array}$ \\
\hline Motivation & .472 & .775 \\
Poor attitude toward rehabilitation & .412 & .781 \\
Feels especially self-important & .352 & .786 \\
Narrow and rigid thinking & .529 & .766 \\
Hostility problem & .450 & .777 \\
Has disregard for others & .482 & .772 \\
Incapable of understanding the & .534 & .766 \\
feelings of others & .448 & .777 \\
Low frustration tolerance & .466 & .775 \\
Non-reflective & .499 & .770 \\
Low conscientiousness & & \\
\hline
\end{tabular}

Note. 10 -item scale Cronbach's $\alpha=.79$. 
Table B. Inter-item Correlations for Literacy and Numeracy Factor

\begin{tabular}{lcc}
\hline \multicolumn{1}{c}{ Item } & $\begin{array}{c}\text { Corrected Item-Total } \\
\text { Correlation }\end{array}$ & $\begin{array}{c}\text { Cronbach's Alpha if } \\
\text { Item Deleted }\end{array}$ \\
\hline Reading problem & .638 & .578 \\
Numeracy problem & .506 & .675 \\
Poor writing & .469 & .684 \\
Comprehension problem & .459 & .691 \\
\hline
\end{tabular}

Note. 4-item scale Cronbach's $\alpha=.72$.

Table C. Inter-item Correlations for Cognitive Flexibility Factor.

\begin{tabular}{lcc}
\hline \multicolumn{1}{c}{ Item } & $\begin{array}{c}\text { Corrected Item-Total } \\
\text { Correlation }\end{array}$ & $\begin{array}{c}\text { Cronbach's Alpha if } \\
\text { Item Deleted }\end{array}$ \\
\hline Low frustration tolerance & .454 & .727 \\
Poor problem solving & .590 & .690 \\
Poor conflict resolution & .598 & .686 \\
Poor stress management & .456 & .725 \\
Impulsive & .482 & .718 \\
Unable to generate choices & .380 & .747 \\
\hline
\end{tabular}

Note. 6-item scale Cronbach's $\alpha=.75$. 
Table D. Inter-item Correlations for Knowledge Acquisition Ability Factor.

\begin{tabular}{lcc}
\hline \multicolumn{1}{c}{ Item } & $\begin{array}{c}\text { Corrected Item-Total } \\
\text { Correlation }\end{array}$ & $\begin{array}{c}\text { Cronbach's Alpha if } \\
\text { Item Deleted }\end{array}$ \\
\hline Concentration problems & .608 & .702 \\
Memory problems & .552 & .730 \\
Learning disability & .550 & .733 \\
Learning difficulty & .599 & .706 \\
\hline
\end{tabular}

Note. 4-item scale Cronbach's $\alpha=.77$.

Table E. Inter-item Correlations for Cognitive Awareness Factor.

\begin{tabular}{lcc}
\hline \multicolumn{1}{c}{ Item } & $\begin{array}{c}\text { Corrected Item-Total } \\
\text { Correlation }\end{array}$ & $\begin{array}{c}\text { Cronbach's Alpha if } \\
\text { Item Deleted }\end{array}$ \\
\hline Unaware of consequences & .452 & .583 \\
Unable to generate choices & .406 & .605 \\
Socially unaware & .395 & .611 \\
Non-reflective & .411 & .603 \\
Unable to recognize problem & .383 & .617 \\
areas & & \\
\hline
\end{tabular}

Note. 5-item scale Cronbach's $\alpha=.66$. 
Table F. Inter-item Correlations for Inhibitory Control Factor.

\begin{tabular}{lcc}
\hline \multicolumn{1}{c}{ Item } & $\begin{array}{c}\text { Corrected Item-Total } \\
\text { Correlation }\end{array}$ & $\begin{array}{c}\text { Cronbach's Alpha if } \\
\text { Item Deleted }\end{array}$ \\
\hline Impulsive & .310 & .507 \\
Problematic risk taking & .375 & .405 \\
Thrill seeking & .375 & .403 \\
\hline
\end{tabular}

Note. 3-item scale Cronbach's $\alpha=.54$. 
Appendix F: Factor Analysis in Cross-Validation Sample

Table A. Oblique Rotated (Promax) Structure Matrix Extracted with Principal Axis

Factoring for Offender Competencies in Cross-Validation Sample.

\begin{tabular}{|c|c|c|c|c|c|c|}
\hline & \multicolumn{6}{|c|}{ Factor } \\
\hline & 1 & 2 & 3 & 4 & 5 & 6 \\
\hline $\begin{array}{l}\text { Feels especially self- } \\
\text { important }\end{array}$ & .604 & -.115 & -.104 & .002 & -.136 & -.009 \\
\hline $\begin{array}{l}\text { Narrow and rigid } \\
\text { thinking }\end{array}$ & .583 & .079 & .064 & -.042 & -.068 & .057 \\
\hline $\begin{array}{l}\text { Poor attitude toward } \\
\text { rehabilitation }\end{array}$ & .580 & .041 & -.028 & .008 & -.139 & .004 \\
\hline $\begin{array}{l}\text { Incapable of } \\
\text { understanding the } \\
\text { feelings of others }\end{array}$ & .570 & .029 & -.011 & -.040 & .192 & -.062 \\
\hline Motivation & .541 & -.003 & .005 & .018 & -.012 & -.012 \\
\hline Hostility & .509 & -.071 & .144 & .061 & -.072 & -.084 \\
\hline Has disregard for others & .393 & .086 & .125 & -.082 & -.033 & .148 \\
\hline Low conscientiousness & .355 & .023 & -.044 & .002 & .218 & .181 \\
\hline Reading problem & -.023 & .926 & -.015 & -.139 & -.015 & .000 \\
\hline Numeracy problem & -.028 & .634 & .090 & .002 & -.091 & .090 \\
\hline Poor writing & .028 & .592 & -.037 & .035 & -.003 & -.041 \\
\hline Comprehension problem & .079 & .415 & -.035 & .258 & -.045 & -.023 \\
\hline Poor conflict resolution & .054 & .001 & .727 & -.033 & .024 & -.076 \\
\hline Poor problem solving & .025 & .041 & .699 & -.035 & .084 & -.118 \\
\hline Poor stress management & -.059 & -.007 & .602 & .008 & -.096 & .073 \\
\hline $\begin{array}{l}\text { Low frustration } \\
\text { tolerance }\end{array}$ & .331 & -.049 & .369 & .141 & -.048 & -.034 \\
\hline Impulsive & -.073 & -.052 & .367 & .094 & .039 & .346 \\
\hline Concentration problems & .005 & -.010 & .028 & .757 & -.073 & .069 \\
\hline Memory problems & .047 & .073 & .014 & .575 & -.042 & -.078 \\
\hline Learning disability & -.074 & .165 & -.047 & .538 & .133 & -.005 \\
\hline Learning difficulty & -.068 & .395 & -.016 & .452 & .080 & -.028 \\
\hline
\end{tabular}




\begin{tabular}{lcccccc}
\hline $\begin{array}{l}\text { Unaware of } \\
\text { consequences }\end{array}$ & -.164 & -.069 & -.036 & .001 &. $\mathbf{7 4 5}$ & -.057 \\
$\begin{array}{l}\text { Unable to generate } \\
\text { choices }\end{array}$ & -.145 & -.006 & .297 & -.046 & .487 & .041 \\
$\begin{array}{l}\text { Socially unaware } \\
\text { Non-reflective }\end{array}$ & .271 & .029 & -.082 & .036 &. .391 & -.065 \\
Unable to recognize & .284 & -.028 & -.066 & .016 & .341 & .171 \\
problem areas & .329 & .023 & -.009 & -.058 & .337 & -.066 \\
Problematic risk taking & -.025 & .069 & -.015 & -.042 & -.063 & $\mathbf{. 6 3 1}$ \\
Thrill-seeking & .142 & -.075 & -.068 & .032 & -.017 & $\mathbf{. 4 7 7}$ \\
\hline
\end{tabular}

Table B. Oblique Rotated (Promax) Structure Matrix Extracted with Principal Axis

Factoring for Offender Competencies in Cross-validation Sample.

\begin{tabular}{|c|c|c|c|c|c|c|}
\hline & \multicolumn{6}{|c|}{ Factor } \\
\hline & 1 & 2 & 3 & 4 & 5 & 6 \\
\hline $\begin{array}{l}\text { Incapable of } \\
\text { understanding the } \\
\text { feelings of others }\end{array}$ & .635 & .157 & .327 & .150 & .480 & .272 \\
\hline $\begin{array}{l}\text { Narrow and rigid } \\
\text { thinking }\end{array}$ & .613 & .151 & .355 & .137 & .304 & .357 \\
\hline Low conscientiousness & .549 & .151 & .301 & .169 & .453 & .406 \\
\hline Motivation & .534 & .102 & .277 & .129 & .289 & .263 \\
\hline Non-reflective & .524 & .128 & .285 & .167 & .514 & .385 \\
\hline Has disregard for others & .512 & .122 & .358 & .099 & .274 & .381 \\
\hline $\begin{array}{l}\text { Poor attitude toward } \\
\text { rehabilitation }\end{array}$ & .501 & .107 & .222 & .108 & .184 & .252 \\
\hline Hostility & .500 & .055 & .348 & .136 & .242 & .213 \\
\hline $\begin{array}{l}\text { Feels especially self- } \\
\text { important }\end{array}$ & .451 & -.061 & .128 & -.012 & .118 & .214 \\
\hline Reading problem & .097 & .830 & .066 & .417 & .187 & .003 \\
\hline Numeracy problem & .128 & .622 & .169 & .395 & .138 & .114 \\
\hline
\end{tabular}


Offender Competencies 136

\begin{tabular}{|c|c|c|c|c|c|c|}
\hline Poor writing & .101 & .610 & .060 & .389 & .166 & -.011 \\
\hline Comprehension problem & .155 & .569 & .116 & .504 & .177 & .040 \\
\hline Poor conflict resolution & .393 & .103 & .725 & .189 & .321 & .234 \\
\hline Poor problem solving & .368 & .148 & .697 & .211 & .353 & .185 \\
\hline Poor stress management & .233 & .054 & .562 & .145 & .139 & .249 \\
\hline $\begin{array}{l}\text { Low frustration } \\
\text { tolerance }\end{array}$ & .497 & .138 & .539 & .271 & .306 & .277 \\
\hline Impulsive & .322 & .074 & .498 & .205 & .259 & .469 \\
\hline Concentration problems & .175 & .443 & .245 & .746 & .192 & .150 \\
\hline Learning difficulty & .122 & .679 & .162 & 697 & .281 & .024 \\
\hline Learning disability & .117 & .513 & .149 & .650 & .285 & .046 \\
\hline Memory problems & .129 & .422 & .169 & .612 & .168 & .010 \\
\hline $\begin{array}{l}\text { Unaware of } \\
\text { consequences }\end{array}$ & .187 & .107 & .154 & .137 & .605 & .049 \\
\hline $\begin{array}{l}\text { Unable to generate } \\
\text { choices }\end{array}$ & .284 & .126 & .425 & .162 & .525 & .211 \\
\hline Socially unaware & .424 & .196 & .206 & .202 & .508 & .154 \\
\hline $\begin{array}{l}\text { Unable to recognize } \\
\text { problem areas }\end{array}$ & .467 & .138 & .258 & .121 & .485 & .184 \\
\hline Problematic risk taking & .256 & .046 & .188 & .045 & .098 & .593 \\
\hline Thrill-seeking & .333 & -.024 & .179 & .047 & .153 & .519 \\
\hline
\end{tabular}


Appendix G: Reliability Analyses of the Factor-Analysis Derived Offender Competency Index in the Cross-Validation Sample

Table A. Inter-item Correlations for Personal Accountability and Need for Change Factor.

\begin{tabular}{lcc}
\hline \multicolumn{1}{c}{ Item } & $\begin{array}{c}\text { Corrected Item-Total } \\
\text { Correlation }\end{array}$ & $\begin{array}{c}\text { Cronbach's Alpha if } \\
\text { Item Deleted }\end{array}$ \\
\hline Feels especially self-important & .361 & .780 \\
Motivation & .486 & .767 \\
Hostility problem & .436 & .772 \\
Narrow and rigid thinking & .534 & .759 \\
Poor attitude toward rehabilitation & .434 & .772 \\
Incapable of understanding the & .571 & .755 \\
feelings of others & .430 & .772 \\
Low frustration tolerance & .464 & .768 \\
Has disregard for others & .459 & .769 \\
Low conscientiousness & .406 & .776 \\
Unable to recognize problem & & \\
areas
\end{tabular}

Note. 10-item scale Cronbach's $\alpha=.79$. 
Table B. Inter-item Correlations for Literacy and numeracy Factor

\begin{tabular}{lcc}
\hline \multicolumn{1}{c}{ Item } & $\begin{array}{c}\text { Corrected Item-Total } \\
\text { Correlation }\end{array}$ & $\begin{array}{c}\text { Cronbach's Alpha if } \\
\text { Item Deleted }\end{array}$ \\
\hline Reading problem & .669 & .707 \\
Numeracy problem & .543 & .755 \\
Poor writing & .546 & .751 \\
Comprehension problem & .521 & .759 \\
Learning difficulty & .559 & .747 \\
\hline
\end{tabular}

Note. 5 -item scale Cronbach's $\alpha=.79$.

Table C. Inter-item Correlations for Cognitive Flexibility Factor.

\begin{tabular}{lcc}
\hline \multicolumn{1}{c}{ Item } & $\begin{array}{c}\text { Corrected Item-Total } \\
\text { Correlation }\end{array}$ & $\begin{array}{c}\text { Cronbach's Alpha if } \\
\text { Item Deleted }\end{array}$ \\
\hline Low frustration tolerance & .479 & .711 \\
Poor problem solving & .553 & .682 \\
Poor conflict resolution & .610 & .660 \\
Poor stress management & .462 & .716 \\
Impulsive & .440 & .723 \\
\hline
\end{tabular}

Note. 5-item scale Cronbach's $\alpha=.75$. 
Table D. Inter-item Correlations for Knowledge Acquisition Ability Factor.

\begin{tabular}{lcc}
\hline \multicolumn{1}{c}{ Item } & $\begin{array}{c}\text { Corrected Item-Total } \\
\text { Correlation }\end{array}$ & $\begin{array}{c}\text { Cronbach's Alpha if } \\
\text { Item Deleted }\end{array}$ \\
\hline Concentration problems & .612 & .712 \\
Memory problems & .528 & .754 \\
Learning disability & .591 & .724 \\
Learning difficulty & .612 & .711 \\
\hline
\end{tabular}

Note. 4-item scale Cronbach's $\alpha=.78$.

Table E. Inter-item Correlations for Cognitive Awareness Factor.

\begin{tabular}{lcc}
\hline \multicolumn{1}{c}{ Item } & $\begin{array}{c}\text { Corrected Item-Total } \\
\text { Correlation }\end{array}$ & $\begin{array}{c}\text { Cronbach's Alpha if } \\
\text { Item Deleted }\end{array}$ \\
\hline Unaware of consequences & .444 & .605 \\
Unable to generate choices & .422 & .615 \\
Socially unaware & .419 & .618 \\
Non-reflective & .414 & .619 \\
Unable to recognize problem & .406 & .623 \\
areas & & \\
\hline
\end{tabular}

Note. 5 -item scale Cronbach's $\alpha=.67$. 
Table F. Inter-item Correlations for Inhibitory Control Factor.

Item
Corrected Item-Total

Correlation
Cronbach's Alpha if Item Deleted

\begin{tabular}{lcc}
\hline Impulsive & .286 & .496 \\
Problematic risk taking & .358 & .380 \\
Thrill seeking & .360 & .376 \\
\hline
\end{tabular}

Note. 3-item scale Cronbach's $\alpha=.52$. 
Appendix H: Reliability Analyses of the Generic Program Performance Measure

Table A. Inter-item Correlations for GPPM Total Post-Score.

\begin{tabular}{|c|c|c|}
\hline Scale Item & $\begin{array}{c}\text { Corrected Item-Total } \\
\text { Correlation }\end{array}$ & $\begin{array}{c}\text { Cronbach's Alpha if } \\
\text { Item Deleted }\end{array}$ \\
\hline $\begin{array}{l}\text { GPPM } 1 \text { (Post): } \\
\text { Punctuality (Effort) }\end{array}$ & .41 & .96 \\
\hline $\begin{array}{l}\text { GPPM } 2 \text { (Post): } \\
\text { Participation (Effort) }\end{array}$ & .69 & .96 \\
\hline $\begin{array}{l}\text { GPPM } 3 \text { (Post): } \\
\text { Completes Work (Effort) }\end{array}$ & .71 & .96 \\
\hline $\begin{array}{l}\text { GPPM } 4 \text { (Post): } \\
\text { Attentive (Effort) }\end{array}$ & .78 & .96 \\
\hline $\begin{array}{l}\text { GPPM } 5 \text { (Post): } \\
\text { Applies Program Content } \\
\text { (Performance) }\end{array}$ & .83 & .95 \\
\hline $\begin{array}{l}\text { GPPM } 6 \text { (Post): } \\
\text { Interpersonal Relationship } \\
\text { (Responsivity) }\end{array}$ & .70 & .95 \\
\hline $\begin{array}{l}\text { GPPM } 7 \text { (Post): } \\
\text { Mutual Agreement (Responsivity) }\end{array}$ & .80 & .95 \\
\hline $\begin{array}{l}\text { GPPM } 8 \text { (Post): } \\
\text { Motivation to Change } \\
\text { (Responsivity) }\end{array}$ & .80 & .96 \\
\hline $\begin{array}{l}\text { GPPM } 9 \text { (Post): } \\
\text { Prosocial Goals (Performance) }\end{array}$ & .80 & .96 \\
\hline $\begin{array}{l}\text { GPPM } 10 \text { (Post): } \\
\text { Understands Consequences } \\
\text { (Performance) }\end{array}$ & .79 & .95 \\
\hline $\begin{array}{l}\text { GPPM } 11 \text { (Post): } \\
\text { Shows Concern for Consequences } \\
\text { (Performance) }\end{array}$ & .78 & .96 \\
\hline
\end{tabular}


GPPM 12 (Post):

Prosocial Attitudes (Performance)

GPPM 13 (Post):

Knows Self-Management Skills

(Performance)

GPPM 14 (Post):

Uses Self-Management Skills

(Performance)

GPPM 15 (Post):

.76

.95

Recognition of Factors

(Performance)

GPPM 16 (Post):

.79

.95

Develops Plan (Performance)

GPPM 17 (Post):

.69

.95

.96

81

.95

Ability to Learn (Responsivity)

Note. 17-item scale Cronbach's $\alpha=.96$.

Table B. Inter-item Correlations for GPPM Effort Subscale Post-Score.

\section{Scale Item}

\section{Corrected Item-Total}

Correlation

\section{Cronbach's Alpha if Item Deleted}

\begin{tabular}{lll}
\hline GPPM 1 (Post): & .47 & .85 \\
Punctuality (Effort) & & \\
GPPM 2 (Post): & .68 & .75 \\
Participation (Effort) & & \\
GPPM 3 (Post): & .69 & .75 \\
Completes Work (Effort) & & .72 \\
GPPM 4 (Post): & .75 & \\
Attentive (Effort) & & \\
\hline
\end{tabular}

Note. 4-item subscale Cronbach's $\alpha=.82$. 
Table C. Inter-item Correlations for GPPM Performance Subscale Post-Score.

\begin{tabular}{|c|c|c|}
\hline Scale Item & $\begin{array}{l}\text { Corrected Item-Total } \\
\text { Correlation }\end{array}$ & $\begin{array}{l}\text { Cronbach's Alpha if } \\
\text { Item Deleted }\end{array}$ \\
\hline $\begin{array}{l}\text { GPPM } 5 \text { (Post): } \\
\text { Applies Program Content } \\
\text { (Performance) }\end{array}$ & .79 & .94 \\
\hline $\begin{array}{l}\text { GPPM } 9 \text { (Post): } \\
\text { Prosocial Goals (Performance) }\end{array}$ & .81 & .94 \\
\hline $\begin{array}{l}\text { GPPM } 10 \text { (Post): } \\
\text { Understands Consequences } \\
\text { (Performance) }\end{array}$ & .81 & .94 \\
\hline $\begin{array}{l}\text { GPPM } 11 \text { (Post): } \\
\text { Shows Concern for Consequences } \\
\text { (Performance) }\end{array}$ & .81 & .94 \\
\hline $\begin{array}{l}\text { GPPM } 12 \text { (Post): } \\
\text { Prosocial Attitudes (Performance) }\end{array}$ & .77 & .94 \\
\hline $\begin{array}{l}\text { GPPM } 13 \text { (Post): } \\
\text { Knows Self-Management Skills } \\
\text { (Performance) }\end{array}$ & .79 & .94 \\
\hline $\begin{array}{l}\text { GPPM } 14 \text { (Post): } \\
\text { Uses Self-Management Skills } \\
\text { (Performance) }\end{array}$ & .82 & .94 \\
\hline $\begin{array}{l}\text { GPPM } 15 \text { (Post): } \\
\text { Recognition of Factors } \\
\text { (Performance) }\end{array}$ & .77 & .95 \\
\hline $\begin{array}{l}\text { GPPM } 16 \text { (Post): } \\
\text { Develops Plan (Performance) }\end{array}$ & .79 & .94 \\
\hline
\end{tabular}

Note. 9-item subscale Cronbach's $\alpha=.95$. 
Table D. Inter-item Correlations for GPPM Responsivity Subscale Post-Score.

\begin{tabular}{lcc}
\hline \multicolumn{1}{c}{ Scale Item } & $\begin{array}{c}\text { Corrected Item-Total } \\
\text { Correlation }\end{array}$ & $\begin{array}{c}\text { Cronbach's Alpha if } \\
\text { Item Deleted }\end{array}$ \\
\hline $\begin{array}{l}\text { GPPM 6 (Post): } \\
\text { Interpersonal Relationship } \\
\text { (Responsivity) }\end{array}$ & .69 & .80 \\
$\begin{array}{l}\text { GPPM 7 (Post): } \\
\text { Mutual Agreement (Responsivity) }\end{array}$ & .78 & .76 \\
$\begin{array}{l}\text { GPPM 8 (Post): } \\
\text { Motivation to Change }\end{array}$ & .71 & .79 \\
(Responsivity) & & \\
$\begin{array}{l}\text { GPPM 17 (Post): } \\
\text { Ability to Learn (Responsivity) }\end{array}$ & .57 & .86 \\
\hline
\end{tabular}

Note. 4-item subscale Cronbach's $\alpha=.85$. 